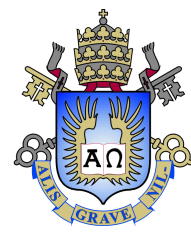

Isabelle Cunha Valim

\title{
Estratégias de modelagem e otimização aplicadas ao processo de deslignização do bagaço da cana-de-açúcar
}

Dissertação apresentada como requisito parcial para obtenção do grau de Mestre pelo Programa de Pós-graduação em Engenharia de Materiais e de Processos Químicos e Metalúrgicos do Departamento de Engenharia Química e de Materiais do Centro Técnico Científico da PUC-Rio.

Orientador : Prof. Brunno Ferreira dos Santos

Co-orientadora: Profa. Cecília Vilani 


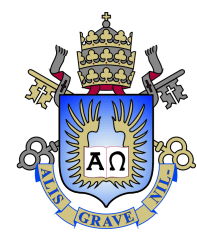

Isabelle Cunha Valim

\begin{abstract}
Estratégias de modelagem e otimização aplicadas ao processo de deslignização do bagaço da cana-de-açúcar
\end{abstract}

Dissertação apresentada como requisito parcial para obtenção do grau de Mestre pelo Programa de Pós-graduação em Engenharia de Materiais e de Processos Químicos e Metalúrgicos do Departamento de Engenharia Química e de Materiais do Centro Técnico Científico da PUC-Rio. Aprovada pela Comissão Examinadora abaixo assinada.

Prof. Brunno Ferreira dos Santos

Orientador

Departamento de Engenharia Química e de Materiais - PUC-Rio

Profa. Cecília Vilani

Co-orientadora

Departamento de Engenharia Química e de Materiais - PUC-Rio

Prof. Florian Alain Yannick Pradelle

Departamento de Engenharia Mecânica - PUC-Rio

Prof. Rafael Ramos de Andrade

Universidade Federal de São Paulo - UNIFESP

Prof. Márcio da Silveira de Carvalho

Coordenador Setorial do Centro Técnico Científico - PUC-Rio 
Todos os direitos reservados. É proibida a reprodução total ou parcial do trabalho sem autorização da universidade, do autor e do orientador.

\section{Isabelle Cunha Valim}

Graduou-se em Engenharia Química pela Pontifícia Universidade Católica do Rio de Janeiro (Rio de Janeiro, Brasil).

Ficha Catalográfica

Valim, Isabelle Cunha

Estratégias de modelagem e otimização aplicadas ao processo de deslignização do bagaço da cana-de-açúcar / Isabelle Cunha Valim; orientador: Brunno Ferreira dos Santos; co-orientadora: Cecília Vilani. - 2018.

115 f: il. color. ; $30 \mathrm{~cm}$

Dissertação (mestrado) - Pontifícia Universidade Católica do Rio de Janeiro, Departamento de Engenharia Química e de Materiais.

Inclui bibliografia

1. Engenharia de Materiais - Teses. 2. Engenharia Química - Teses. 3. Bagaço de cana-de-açúcar;. 4. Extração de lignina;. 5. Otimização;. 6. Planejamento experimental;. 7. Inteligência artificial.. I. Santos, Brunno Ferreira dos. II. Vilani, Cecília. III. Pontifícia Universidade Católica do Rio de Janeiro. Departamento de Engenharia Química e de Materiais. IV. Título. 


\section{Agradecimentos}

Ao meu marido Sheriton Valim, com quem amo compartilhar a vida. Obrigada por todo o incentivo e ajuda.

À minha família, especialmente minha mãe Vania Cunha e meu irmão Fillipe Cunha por cada sorriso de orgulho perante minhas conquistas. Também sou grata ao meu pai José Luiz que, com certeza, está vibrando lá do céu.

Aos professores Brunno Santos e Cecília Vilani. Resumi-los a orientadores é muito pouco para mim. Obrigada por todo apoio e amizade. Obrigada por me fazerem descobrir um novo amor na profissão.

À minha "minion" Anna Vieira pela disponibilidade e disposição em trabalhar pelo sucesso desse trabalho.

À professora Ana Rosa Martins pela ajuda e disponibilidade dos equipamentos para os primeiros experimentos.

Aos meus amigos João Marcos, Mayara Santos, Rafael Fuly e Talita Lisa pela compreensão nos meus momentos de ausência.

Aos meus amigos da PUC-Rio Amanda Balassiano, Ana Dourado, Julia Cardoso, Mayra Tavares, Rafael Basílio e Renata Nofal. Em particular, aqueles que pertencem ao meu grupo de pesquisa Artur Serpa, Caroline Dias, Felipe Zanone e Juliana Fidalgo por toda ajuda no trabalho realizado.

Ao técnico Henrique Meira por toda assistência prestada durante a etapa do processo realizada na PUC-Rio.

Ao Departamento de Física da PUC-Rio pela disponibilidade do equipamento para realização de análises.

Ao Instituto de Química Verde SENAI pela parceria nesse trabalho.

Ao CNPq e à PUC-Rio, pelos auxílios concedidos, sem os quais este trabalho não poderia ter sido realizado. 


\section{Resumo}

Valim, Isabelle Cunha; Santos, Brunno Ferreira dos; Vilani, Cecília. Estratégias de modelagem e otimização aplicadas ao processo de deslignização do bagaço da cana-de-açúcar. Rio de Janeiro, 2018. 115p. Dissertação de Mestrado - Departamento de Engenharia Química e de Materiais, Pontifícia Universidade Católica do Rio de Janeiro.

O bagaço da cana-de-açúcar é uma biomassa vegetal que possui muito potencial de uso devido aos seus três elementos estruturais: celulose, hemicelulose e lignina. Para servir como matéria prima na produção de insumos, o bagaço da cana-de-açúcar precisa passar por um processo de pré-tratamento. Nesse estudo, duas metodologias para o processo de pré-tratamento do bagaço da cana-de-açúcar foram utilizadas: a deslignização via peróxido de hidrogênio $\left(\mathrm{H}_{2} \mathrm{O}_{2}\right)$ e via dióxido de carbono supercrítico $\left(\mathrm{ScCO}_{2}\right)$. Para o estudo utilizando $\mathrm{H}_{2} \mathrm{O}_{2}$, foram desenvolvidos modelos a partir de planejamento experimental, Algoritmos Genéticos (GA, do inglês Genetic Algorithms), Redes Neurais Artificiais (RNA) e Neuro-Fuzzy (ANFIS). As variáveis independentes foram temperatura $\left(25-60^{\circ} \mathrm{C}\right)$, concentração de $\mathrm{H}_{2} \mathrm{O}_{2}(2-15 \%$ $\mathrm{m} / \mathrm{v})$ e $\mathrm{pH}(10-13)$, tendo como resposta os teores de lignina residual e oxidada no processo, através de análises de FT-IR e análise pelo método de Klason. Para o estudo utilizando $\mathrm{ScCO}_{2}$ foram construídos modelos a partir de RNA e ANFIS. As variáveis estudadas no processo foram: temperatura $\left(35-100^{\circ} \mathrm{C}\right)$, pressão $(75-300$ bar $)$ e teor de etanol na solução de co-solvente $(0-100 \%)$. De modo geral, para os dois processos, os modelos desenvolvidos consideram as variáveis independentes como sendo neurônios na camada de entrada e as variáveis dependentes como sendo neurônios na camada de saída. Todos os modelos neurais e ANFIS desenvolvidos neste trabalho foram avaliados pelo coeficiente de correlação $\left(\mathrm{R}^{2}\right)$ e índices de erro (SSE, MSE e RMSE), além do número de parâmetros. Os resultados mostraram que, dentre estas estratégias estudadas, os modelos neurais se mostraram mais satisfatórios para predição das respostas do pré-tratamento com $\mathrm{H}_{2} \mathrm{O}_{2}$, já que se encaixa nos índices de performance estipulados. $\mathrm{O}$ mesmo ocorreu no modelo neural para predição do teor de lignina residual no pré-tratamento com $\mathrm{ScCO}_{2}$. Para cada modelo polinomial e neural desenvolvido, foi realizada a investigação das superfícies de respostas e das curvas de contorno. Com esse recurso, foi possível a identificação dos melhores pontos operacionais para os processos, visando a minimização dos teores de lignina residual e oxidada na biomassa. 


\section{Palavras-chave}

Bagaço de cana-de-açúcar; Extração de lignina; Otimização;

Planejamento experimental; Inteligência artificial. 


\section{Abstract}

Valim, Isabelle Cunha; Santos, Brunno Ferreira dos (Advisor); Vilani, Cecília (Co-Advisor). Modeling and optimization strategies in sugarcane bagasse delignification process. Rio de Janeiro, 2018. 115p. Dissertação de Mestrado - Departamento de Engenharia Química e de Materiais, Pontifícia Universidade Católica do Rio de Janeiro.

Sugarcane bagasse is a plant biomass that has a great potential for use due to its three structural elements: cellulose, hemicellulose and lignin. To serve as raw material in the production of other products, sugarcane bagasse needs to undergo a pre-treatment process. In this study, two methodologies for the sugarcane bagasse pretreatment process were used: delignification via hydrogen peroxide $\left(\mathrm{H}_{2} \mathrm{O}_{2}\right)$ and via supercritical carbon dioxide $\left(\mathrm{ScCO}_{2}\right)$. The models for study the process with $\mathrm{H}_{2} \mathrm{O}_{2}$ were developed from experimental planning, Genetic Algorithms (GA), Artificial Neural Networks (ANN) and Neuro-Fuzzy (ANFIS). The independent variables were: temperature (25$\left.60{ }^{\circ} \mathrm{C}\right), \mathrm{H}_{2} \mathrm{O}_{2}$ concentration $(2-15 \% \mathrm{~m} / \mathrm{v})$ and $\mathrm{pH}(10-13)$. The residual and oxidized lignin contents in the process were evaluated from FT-IR and Klason method analysis. The models for study the process with $\mathrm{ScCO}_{2}$ were developed from RNA and ANFIS. The variables studied in the process were: temperature $\left(35-100^{\circ} \mathrm{C}\right)$, pressure $(75-300$ bar) and ethanol content in the aqueous solution of co-solvent (0-100\%). In general, for the two processes, the developed models consider the independent variables to be neurons in the input layer and the dependent variables to be neurons in the output layer. All the neural and ANFIS models developed in this study were evaluated by the correlation coefficient $\left(\mathrm{R}^{2}\right)$ and error indexes (SSE, MSE and RMSE), as well as the number of parameters. From the stipulated indices of performance, among the results obtained by the different strategies, the neural models were the most satisfactory for the prediction of pretreatment responses with $\mathrm{H}_{2} \mathrm{O}_{2}$. The same occurred in the neural model for prediction of the residual lignin content in the pre-treatment with $\mathrm{ScCO}_{2}$. Response surfaces and the contour curves were investigated for each polynomial and neural model developed. With this resource, it was possible to identify the best operational points for the processes, pointing at minimizing the residual and oxidized lignin contents in the biomass.

\section{Keywords}

Sugarcane bagasse; Lignin extraction; Optimization; Experimental design; Artificial intelligence. 


\section{Sumário}

1 Introdução 18

2 Objetivos $\quad 20$

2.1 Objetivos gerais 20

2.2 Objetivos Específicos 20

3 Revisão Bibliográfica $\quad 22$

3.1 Cana-de-açúcar 22

3.2 Biomassa Lignocelulósica 23

3.2.1 Celulose 24

$\begin{array}{ll}3.2 .2 \text { Hemicelulose } & 25\end{array}$

$\begin{array}{ll}3.2 .3 & \text { Lignina } \\ 3.3 & 26\end{array}$

3.3 Pré-tratamento 26

3.3.1 Pré-tratamento Químico 28

3.3.2 Pré-tratamento Físico 32

3.4 Modelagem e Otimização 34

3.4.1 Planejamento Experimental 34

3.4.2 Algoritmos Genéticos 36

3.4.2.1 Crossover 37

3.4.2.2 Mutação 38

$\begin{array}{ll}\text { 3.4.2.3 Critério de Parada } & 39\end{array}$

3.4.3 Redes Neurais Artificiais 39

3.4.3.1 Arquitetura de Redes Neurais Artificiais 41

3.4.3.2 Número de neurônios em cada camada 43

3.4.3.3 Treinamento das Redes Neurais Artificiais 43

3.4.3.4 Algoritmo Backpropagation 44

3.4.3.5 Funções de Ativação 45

3.4.4 Sistema de Inferência Adaptativa Neuro-Difusa 48

3.4.4.1 Sistema de inferência 48

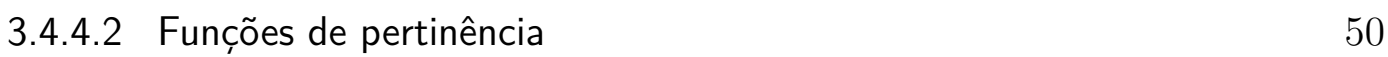

3.4.4.3 Métodos de grupamento $\quad 51$

$4 \quad$ Materiais e Métodos $\quad 53$

4.1 Tratamento primário do material lignocelulósico 53

4.2 Análise granulométrica do material lignocelulósico 53

4.3 Pré-tratamento com $\mathrm{H}_{2} \mathrm{O}_{2} \quad 54$

4.3.1 Planejamento experimental 54

4.3.2 Procedimento experimental $\quad 54$

4.4 Pré-tratamento com $\mathrm{ScCO}_{2} \quad 55$

4.4.1 Procedimento experimental $\quad 55$

4.5 Análises realizadas após a etapa de pré-tratamento da biomassa $\quad 57$

4.5.1 Determinação de lignina residual por Método Klason 57

4.5.2 Determinação de lignina oxidada a partir de análises de infravermelho. 58

4.6 Modelagem e Otimização $\quad 59$ 
4.6.1 Construção de modelos de predição pelo Método dos Mínimos Quadrados $\quad 59$

4.6.2 Construção de modelos de predição por Algoritmos Genéticos $\quad 59$

4.6.3 Construção de modelos de predição por Redes Neurais Artificiais 59

4.6.4 Construção de modelos de predição por Neuro-Fuzzy 62

4.6.5 Validação matemática dos modelos 62

4.6.6 Construção das superfícies de respostas e curvas de contorno 63

5 Resultados e Discussões $\quad \mathbf{6 4}$

5.1 Análise granulométrica do material lignocelulósico 64

5.2 Análise da composição de lignina no bagaço 65

5.3 Determinação de lignina residual por Método Klason 65

5.3.1 No processo de pré-tratamento com $\mathrm{H}_{2} \mathrm{O}_{2} \quad 65$

5.3.2 No processo de pré-tratamento com $\mathrm{ScCO}_{2} \quad 66$

5.4 Determinação de lignina oxidada por FT-IR 67

5.4.1 No processo de pré-tratamento com $\mathrm{H}_{2} \mathrm{O}_{2} \quad 67$

5.4.2 No processo de pré-tratamento com $\mathrm{ScCO}_{2} \quad 68$

$\begin{array}{lll}5.5 & \text { Contrução dos Modelos } & 69\end{array}$

5.5.1 No processo de pré-tratamento com $\mathrm{H}_{2} \mathrm{O}_{2} \quad 69$

5.5.1.1 Predição do teor de lignina residual por Mínimos Quadrados $\quad 69$

$\begin{array}{lll}\text { 5.5.1.2 Predição do teor de lignina residual por GA } & 75\end{array}$

5.5.1.3 Predição do teor de lignina residual por Redes Neurais Artificiais 79

5.5.1.4 Predição do teor de lignina residual por Neuro-Fuzzy 85

5.5.2 No processo de pré-tratamento com $\mathrm{ScCO}_{2}$

5.5.2.1 Predição do teor de lignina residual por Redes Neurais Artificiais 86

5.5.2.2 Predição do teor de lignina residual por Neuro-Fuzzy 90

6 Conclusão $\quad 92$

7 Sugestão para Trabalhos Futuros $\quad 94$

8 Referências bibliográficas $\quad 95$

9 Anexos $\quad 104$

9.1 Código para desenvolvimento dos modelos ANN 104

9.2 Código para desenvolvimento dos modelos GA 106

9.3 Código para geração das superfícies de respostas e curvas de contorno dos modelos polinomiais 108

9.4 Código para geração das superfícies de respostas e curvas de contorno dos modelos neurais 109

9.5 Manual para utilização da Toolbox para geração de modelos ANFIS 110 


\section{Lista de figuras}

Figura 3.1 Estrutura da biomassa lignocelulósica. 24

Figura 3.2 Estrutura da molécula de celulose. Fonte: Ferreira e Rocha, 2009. 24

Figura 3.3 Estrutura da molécula de hemicelulose. Fonte: Ferreira e Rocha, 2009.

Figura 3.4 Estrutura da molécula de lignina. Fonte: Ferreira e Rocha, 2009.

Figura 3.5 Efeito do pré-tratamento na biomassa. Fonte: Sari e Budiyono, 2014.

Figura 3.6 Representação espacial dos níveis de cada variável estudada no processo.

Figura 3.7 Mecanismo do operador genético crossover. Fonte: Eiben e Smith, 2007.

Figura 3.8 Mecanismo do operador genético mutação. Fonte: Eiben e Smith, 2007.

Figura 3.9 Representação matemática de um neurônio artificial. Fonte: Rego, 2017.

Figura 3.10 Rede Feedforward de uma única camada [1].

Figura 3.11 Rede Feedforward de múltiplas camadas [1].

Figura 3.12 Representação gráfica da função linear purelin e sua derivada.

Figura 3.13 Representação gráfica da função não linear logsig e sua derivada.

Figura 3.14 Representação gráfica da função não linear tansig e sua derivada.

Figura 3.15 Representação esquemática da atuação das funções de ativação tansig e purelin.

Figura 3.16 Estrutura geral da arquitetura ANFIS. Fonte: Akkaya, 2016.

Figura 3.17 Gráficos e equações das funções de pertinência.

Figura 4.1 Fluxograma do procedimento experimental do prétratamento do bagaço da cana-de-açúcar com $\mathrm{H}_{2} \mathrm{O}_{2}$.

Figura 4.2 Fluxograma do procedimento experimental do prétratamento do bagaço da cana-de-açúcar com $\mathrm{ScCO}_{2}$.

Figura 4.3 Imagem do conjunto de extração supercrítica Maqnagua utilizado neste trabalho.

Figura 5.1 Fração mássica e Fração mássica acumulada em função do diâmetro médio de partícula.

Figura 5.2 Diagrama de Pareto do modelo por Mínimos Quadrados para predição de lignina residual no processo de pré-tratamento com $\mathrm{H}_{2} \mathrm{O}_{2}$. 
Figura 5.3 Superfície de resposta e curva de contorno da interação entre as variáveis temperatura e concentração de peróxido para o modelo de predição por MMQ do teor de lignina residual após pré-tratamento com $\mathrm{H}_{2} \mathrm{O}_{2}$.

Figura 5.4 Superfície de resposta e curva de contorno da interação entre as variáveis temperatura e $\mathrm{pH}$ para o modelo de predição por MMQ do teor de lignina residual após pré-tratamento com $\mathrm{H}_{2} \mathrm{O}_{2}$.

Figura 5.5 Superfície de resposta e curva de contorno da interação entre as variáveis concentração de peróxido e pH para o modelo de predição por MMQ do teor de lignina residual após prétratamento com $\mathrm{H}_{2} \mathrm{O}_{2}$.

Figura 5.6 Comportamento dos dados preditos pelo modelo otimizado por GA com relação aos dados experimentais do processo de pré-tratamento com $\mathrm{H}_{2} \mathrm{O}_{2}$.

Figura 5.7 Superfície de resposta e curva de contorno da interação entre as variáveis temperatura e concentração de peróxido para o modelo de predição por GA do teor de lignina residual após pré-tratamento com $\mathrm{H}_{2} \mathrm{O}_{2}$.

Figura 5.8 Superfície de resposta e curva de contorno da interação entre as variáveis temperatura e $\mathrm{pH}$ para o modelo de predição por GA do teor de lignina residual após pré-tratamento com $\mathrm{H}_{2} \mathrm{O}_{2}$.

Figura 5.9 Superfície de resposta e curva de contorno da interação entre as variáveis concentração de $\mathrm{H}_{2} \mathrm{O}_{2}$ e pH para o modelo de predição por GA do teor de lignina residual após pré-tratamento com $\mathrm{H}_{2} \mathrm{O}_{2}$.

Figura 5.10 Janela do software Matlab R2018a indicando os parâmetros de simulação do modelo neural 3-4-1 (tansig-purelin / trainbr) para predição do teor de lignina residual após prétratamento com $\mathrm{H}_{2} \mathrm{O}_{2}$.

Figura 5.11 Gráficos da simulação do modelo neural 3-4-1 (tansigpurelin / trainbr) para predição do teor de lignina residual após pré-tratamento com $\mathrm{H}_{2} \mathrm{O}_{2}$.

Figura 5.12 Superfície de resposta e curva de contorno da interação entre as variáveis temperatura e concentração de peróxido para o modelo neural 3-4-1 (tansig-purelin / trainbr).

Figura 5.13 Superfície de resposta e curva de contorno da interação entre as variáveis temperatura e $\mathrm{pH}$ para o modelo neural 3-4-1 (tansig-purelin / trainbr).

Figura 5.14 Superfície de resposta e curva de contorno da interação entre as variáveis concentração de peróxido e $\mathrm{pH}$ para o modelo neural 3-4-1 (tansig-purelin / trainbr).

Figura 5.15 Topologia do modelo ANFIS desenvolvido para predição do teor de lignina residual no processo de pré-tratamento com $\mathrm{H}_{2} \mathrm{O}_{2}$. 
Figura 5.16 Gráficos da simulação do modelo neural com 1 camada intermediária 3-4-1 (tansig-purelin / traincgb) para predição do teor de lignina residual após pré-tratamento com $\mathrm{ScCO}_{2}$.

Figura 5.17 Superfície de resposta e curva de contorno da interação entre as variáveis temperatura e pressão para o modelo neural 3-4-1 (tansig-purelin / traincgb).

Figura 5.18 Superfície de resposta e curva de contorno da interação entre as variáveis temperatura e teor de etanol para o modelo neural 3-4-1 (tansig-purelin / traincgb).

Figura 5.19 Superfície de resposta e curva de contorno da interação entre as variáveis pressão e teor de etanol para o modelo neural 3-4-1 (tansig-purelin / traincgb).

Figura 5.20 Topologia do modelo ANFIS desenvolvido para predição do teor de lignina residual no processo de pré-tratamento com $\mathrm{ScCO}_{2}$. 


\section{Lista de tabelas}

Tabela 3.1 Composição média do bagaço da cana-de-açúcar. 23

Tabela 3.2 Métodos de pré-tratamento na biomassa. 28

Tabela 3.3 Valores de $\mathrm{pH}$ para diferentes tipo de pré-tratamento químico.

Tabela 4.1 Valores utilizados no planejamento experimental para o processo de deslignização do bagaço da cana-de-açúcar.

Tabela 4.2 Condições experimentais realizadas para estudo do processo de deslignização do bagaço da cana-de-açúcar usando $\mathrm{ScCO}_{2}$.

Tabela 5.1 Teores de lignina residual nas condições experimentais avaliadas para o processo de deslignização do bagaço com $\mathrm{H}_{2} \mathrm{O}_{2}$. $\quad 65$

Tabela 5.2 Teores de lignina residual nas condições experimentais avaliadas para o processo de deslignização do bagaço com $\mathrm{ScCO}_{2}$. 66

Tabela 5.3 Teores de lignina oxidada nas condições experimentais avaliadas para o processo de deslignização do bagaço com $\mathrm{H}_{2} \mathrm{O}_{2}$. $\quad 67$

Tabela 5.4 Teores de lignina oxidada em todas as condições experimentais avaliadas para o processo de deslignização do bagaço com $\mathrm{ScCO}_{2}$.

Tabela 5.5 Cálculo de efeito das variáveis sobre a predição do teor de lignina residual por MMQ no processo de pré-tratamento com $\mathrm{H}_{2} \mathrm{O}_{2}$.

Tabela 5.6 Comparação entre os teores médios de lignina residual obtidos experimentalmente e preditos pelo modelo por MMQ para o pré-tratamento com $\mathrm{H}_{2} \mathrm{O}_{2}$.

Tabela 5.7 ANOVA para o modelo de predição de lignina residual por MMQ no pré-tratamento com $\mathrm{H}_{2} \mathrm{O}_{2}$.

Tabela 5.8 ANOVA para o modelo de predição de lignina residual otimizado por GA no pré-tratamento com $\mathrm{H}_{2} \mathrm{O}_{2}$.

Tabela 5.9 Topologias testadas para o ajuste do modelo ANN com 1 camada intermediária para predição do teor de lignina residual no processo de pré-tratamento com $\mathrm{H}_{2} \mathrm{O}_{2}$.

Tabela 5.10 Tabela com os pesos e os bias que descrevem o modelo neural 3-4-1 (tansig-purelin / trainbr).

Tabela 5.11 Topologias testadas para o ajuste do modelo ANN com 2 camadas intermediárias para predição do teor de lignina residual no processo de pré-tratamento com $\mathrm{H}_{2} \mathrm{O}_{2}$.

Tabela 5.12 Topologias testadas para o ajuste do modelo ANN com 1 camada intermediária para predição do teor de lignina residual no processo de pré-tratamento com $\mathrm{ScCO}_{2}$.

Tabela 5.13 Tabela com os pesos e os bias que descrevem o modelo neural 3-4-1 (tansig-purelin / traincgb). 


\section{Lista de abreviaturas}

ANFIS - Adaptive Neuro-Fuzzy Inference System

ANOVA - Análise de Variância

ANN - Artificial Neural Network

DCCR - Delineamento Composto Central Rotacional

FT-IR - Fourier-Transform Infrared Spectroscopy

GA - Genetic Algorithms

$\mathrm{H}_{2} \mathrm{O}_{2}$ - Peróxido de Hidrogênio

MMQ - Método dos Mínimos Quadrados

MSE - Mean Squared Error

RMSE - Root Mean Squared Error

$\mathrm{ScCO}_{2}$ - Dióxido de Carbono Supercrítico

SSE - Sum Squared Error 


\section{Lista de variáveis}

$A_{i}, B_{i}$ - Valores difusos das variáveis $x$ e $y$ no ANFIS

$b_{i}-$ Bia associado ao neurônio $i$

$d X$ - Direção de busca da função

$d X_{\text {prev }}$ - Direção de busca anterior da função

$\frac{d_{p e r f}}{d X}$ - Derivada da performance com relação aos pesos e bias do neurônio X

$e-$ Erros associados

$e_{j}$ - Valor do erro calculado do neurônio $j$

$g X$ - Gradiente da função

$g X_{\text {prev }}$ - Valor do gradiente calculado na iteração anterior

$I$ - Matriz identidade

$j X$ - Matriz jacobiana da performance com relação aos pesos e bias do neurônio $\mathrm{X}$

$k$ - Número de variáveis de processo avaliadas no planejamento experimental

$M_{1}$ - Massa do cadinho filtrante de placa porosa seco vazio, em gramas

$M_{2}$ - Massa do cadinho filtrante de placa porosa com lignina, em gramas

$M_{\text {amostra }}$ - Massa da amostra de lignina seca, em gramas

$M_{10}$ - Massa das partículas retidas na peneira de 10 mesh, em gramas

$M_{12}$ - Massa das partículas retidas na peneira de 10 mesh, em gramas

$M_{32}$ - Massa das partículas retidas na peneira de 10 mesh, em gramas

$M_{35}$ - Massa das partículas retidas na peneira de 10 mesh, em gramas

$M_{48}$ - Massa das partículas retidas na peneira de 10 mesh, em gramas

$n_{C I 1}$ - Número de neurônios na $1^{\mathrm{O}}$ camada intermediária

$n_{C I 2}$ - Número de neurônios na $2^{\mathrm{o}}$ camada intermediária

$n_{E}$ - Número de neurônios na camada de entrada

$N_{p}$ - Número de parâmetros modificáveis na ANN

$n_{S}$ - Número de neurônios na camada de saída

$p_{i}, q_{i}, r_{i}$ - Parâmetros a serem ajustados no ANFIS

$s_{i}$ - Valor de entrada pela conexão $i$ do neurônio $j$

$x, y$ - Variáveis difusas de entrada no ANFIS

$x_{1}$ - Codificação da primeira variável a ser estudada nos processos

(temperatura)

$x_{2}$ - Codificação da segunda variável a ser estudada nos processos

(concentração de $\mathrm{H}_{2} \mathrm{O}_{2}$ ou pressão)

$x_{3}$ - Codificação da terceira variável a ser estudada nos processos ( $\mathrm{pH}$ ou teor

de etanol na solução aquosa de co-solvente)

$X_{\text {step }}$ - Valores de pesos e bias calculados na iteração anterior

$y_{i}$ - Resposta experimental do processo

$\hat{y}_{i}-$ Resposta predita pelos modelos

$\bar{y}$ - Resposta média dos modelos

$\alpha$ - Ponto axial do planejamento experimental desenvolvido 
$\alpha_{m o}-$ Termo momentum

$\beta_{i}$ - Parâmetros do modelo de regressão

$\gamma$ - Parâmetro escalar

$\Delta w_{i j}^{t+1}$ e $w_{i j}^{t}$ - Variações do peso do neurônio $j$ em relação à conexão $i$ nos instantes $t+1$ e $t$, respectivamente

$\eta$ - Taxa de aprendizado

$\theta$ - Valor limiar do neurônio na ANN

$\mu$ - Função de pertinência

$w_{n}$ - Peso atribuído à cada informação na ANN

$W_{i}$ - Grau de aplicabilidade de uma regra no ANFIS

$\overline{W_{i}}-$ Grau de aplicabilidade normalizado 
I think I found my place. Can't you feel it growing stronger? Little conquerors!

Walk, Foo Fighters. 


\section{Introdução}

Com a crescente demanda industrial e os sérios problemas ambientais enfrentados, como a alta emissão de $\mathrm{CO}_{2}$, buscar alternativas mais sustentáveis e economicamente viáveis tornou-se um grande desafio na sociedade atual.

Dentre as diversas linhas de atuação da química verde, destaca-se a produção de compostos químicos a partir de resíduos lignocelulósicos que, muitas vezes, são queimados pelas indústrias, a fim de gerar energia nas caldeiras. Um exemplo é a utilização do bagaço da cana-de-açúcar, resíduo gerado na produção de etanol, que oferece uma ampla e barata fonte de recursos renováveis, como a celulose e a hemicelulose presentes na biomassa.

A biomassa é composta por três elementos estruturais: celulose, hemicelulose e lignina. A celulose e a hemicelulose são os compostos de interesse nesse trabalho, já que são constituídas de xilose e glicose que podem ser hidrolisadas para açúcares redutores. Estes açúcares são encaminhados para posteriores processos de fermentação, de onde se é possível obter ácido lático ou etanol de segunda geração, por exemplo. A lignina, por ser a fração lignocelulósica que atua como proteção à estrutura da biomassa, deve ser extraída de forma a tornar disponível os compostos de interesse, aumentando o rendimento do processo, onde os açúcares presentes na biomassa servirão como matéria prima. No entanto, a lignina extraída não é descartada, podendo servir como produto de valor agregado em outros processos, após tratamento adequado.

No Brasil, o processo para extração de lignina da biomassa mais utilizado é o processo Kraft (hidróxido de sódio e sulfeto de sódio). No entanto, tratase de um método com muita geração de resíduos intermediários e com alta capacidade poluidora. Nesse cenário, surgem rotas sustentáveis alternativas para extração de lignina como, por exemplo, as que utilizam peróxido de hidrogênio $\left(\mathrm{H}_{2} \mathrm{O}_{2}\right)$ ou dióxido de carbono supercrítico $\left(\mathrm{ScCO}_{2}\right)$.

$\mathrm{O}$ tratamento alcalino com $\mathrm{H}_{2} \mathrm{O}_{2}$ no material lignocelulósico é vantajoso, já que pode ser realizado em condições de temperatura e pressão mais baixas. O peróxido de hidrogênio apresenta-se como um reagente de simples manuseamento, além de ser facilmente obtido em grande escala. Como se dissocia em oxigênio e água, representa baixo perigo ambiental, sem formação de resíduos.

Em relação ao fluido supercrítico, o dióxido de carbono $\left(\mathrm{CO}_{2}\right)$ é o mais 
utilizado por não ser tóxico, apresentar alta capacidade de difusão, ser naturalmente abundante, além de apresentar ponto crítico fácil de ser alcançado. Entretanto, por ser um solvente pouco polar, o $\mathrm{ScCO}_{2}$ quando utilizado sozinho apresenta algumas limitações que o impede de reagir com a lignina e de solubilizar os produtos polares gerados por essa macromolécula. Essa limitação pode ser minimizada com a adição de um co-solvente que proporcione melhora na capacidade solvente da mistura e aumente o rendimento da extração. $\mathrm{O}$ co-solvente utilizado neste trabalho foi álcool etílico hidratado $92,8^{\circ}$ INPM (etanol comercial).

Para saber as condições ideais dos parâmetros avaliados nos processos de deslignização do bagaço da cana-de-açúcar sugeridos neste trabalho, foram aplicadas diversas estratégias de modelagem matemática: modelagem estatística, a partir do uso de planejamento experimental e modelagens inteligentes, a partir do uso de GA, ANN e ANFIS.

A utilização de modelagem inteligente vem sendo amplamente estudada devido à simplicidade em descrever os processos, sem que seja preciso conhecimento profundo dos fenômenos envolvidos. Trata-se de uma estratégia que permite o estudo preciso de sistemas bastante complexos como, por exemplo, fermentações. Na literatura, não são relatados trabalhos utilizando modelagem inteligente para estudo dos processos de pré-tratamento do bagaço da cana-de-açúcar com $\mathrm{H}_{2} \mathrm{O}_{2}$ e $\mathrm{ScCO}_{2}$.

O planejamento de experimentos é uma estratégia que permite a obtenção do maior número possível de informações sobre o processo, realizando-se um número mínimo de experimentos. Para isso, os experimentos realizados devem ser minimamente controlados, a fim de se obter medidas precisas para as respostas do processo. A partir daí, é possível construir um modelo polinomial que descreva o processo. O Método dos Mínimos Quadrados (MMQ) é comumente utilizado para cálculo dos parâmetros do modelo obtido a partir do planejamento experimental. No entanto, GA pode ser utilizado na busca dos parâmetros otimizados do modelo polinomial desenvolvido. ANN e ANFIS, por sua vez, possuem alto desempenho na aprendizagem de mapeamentos não lineares, além da capacidade de reconhecimento e associação de padrões e se apresentam como alternativas à modelagem clássica, por apresentarem boa capacidade de predição.

Com os modelos definidos, é possível construir superfícies de respostas e curvas de contorno, onde é realizada a identificação das melhores condições operacionais para os processos de pré-tratamento do bagaço da cana-de-açúcar aqui estudados. 


\section{2}

\section{Objetivos}

\section{1}

\section{Objetivos gerais}

O objetivo desse trabalho é estudar as rotas sustentáveis dos processos de pré-tratamento do bagaço da cana-de-açúcar, com a utilização de $\mathrm{H}_{2} \mathrm{O}_{2}$ e $\mathrm{ScCO}_{2}$, visando a minimização dos teores de lignina residual e oxidada.

Para o processo de pré-tratamento via $\mathrm{H}_{2} \mathrm{O}_{2}$, as variáveis estudadas são temperatura $\left({ }^{\circ} \mathrm{C}\right)$, concentração de $\mathrm{H}_{2} \mathrm{O}_{2}(\% \mathrm{~m} / \mathrm{v})$ e $\mathrm{pH}$, ao passo que, no processo de pré-tratamento via $\mathrm{ScCO}_{2}$, as variáveis estudadas são temperatura $\left({ }^{\circ} \mathrm{C}\right)$, pressão (bar) e teor de etanol utilizado na solução aquosa de co-solvente $(\%)$.

\section{2}

\section{Objetivos Específicos}

1. Adaptar e aplicar a metodologia de pré-tratamento do bagaço da canade-açúcar.

2. Desenvolver os experimentos com base em planejamento experimental para o processo de pré-tratamento com $\mathrm{H}_{2} \mathrm{O}_{2}$.

3. Para o processo de pré-tratamento com $\mathrm{H}_{2} \mathrm{O}_{2}$, estudar e avaliar as variáveis temperatura $\left({ }^{\circ} \mathrm{C}\right)$, concentração de $\mathrm{H}_{2} \mathrm{O}_{2}(\% \mathrm{~m} / \mathrm{v})$ e $\mathrm{pH}$.

4. Para o processo de pré-tratamento $\mathrm{com} \mathrm{ScCO}_{2}$, estudar e avaliar as variáveis temperatura $\left({ }^{\circ} \mathrm{C}\right)$, pressão (bar) e teor de etanol na solução aquosa de co-solvente $(\%)$.

5. Quantificar o teor de lignina residual na biomassa.

6. Estimar o teor de lignina oxidada no processo.

7. Desenvolver e validar os modelos polinomiais de predição das respostas do processo, obtidos a partir da avaliação dos resultados experimentais.

8. Desenvolver e validar os modelos inteligentes de predição das respostas do processo, obtidos a partir da avaliação dos resultados experimentais. 
9. Construir as superfícies de respostas para cada modelo desenvolvido, a fim de se obter um direcionamento para o valor ótimo de cada variável estudada no processo. 


\section{3 \\ Revisão Bibliográfica}

A seguir, alguns aspectos pertinentes ao trabalho serão abordados para maior esclarecimento.

\section{1}

\section{Cana-de-açúcar}

A cana-de-açúcar, um vegetal do tipo gramínea pertencente ao gênero Saccharum, é um dos principais produtos agrícolas do Brasil, utilizada, principalmente, na produção de açúcar e etanol. Inicialmente cultivada na Indonésia e Nova Guiné, foi introduzida no Brasil na época das colonizações e, atualmente, é cultivada em regiões tropicais e subtropicais, como África e América do Sul [2].

Segundo relatório da Companhia Nacional de Abastecimento (CONAB) [3], o Brasil é o maior exportador mundial de açúcar, com estimativa de 23,60 milhões de toneladas na safra de 2018/2019. No atual cenário do país, devido ao aumento da demanda pelo uso de etanol, o percentual de cana-de-açúcar destinado à sua produção é de 64,77\% no acumulado da safra de 2018/2019, totalizando aproximadamente 4,81 bilhões de litros de etanol produzidos até junho de 2018. Tais dados mostram a importância da cana-de-açúcar na economia brasileira.

Entretanto, há uma grande geração de resíduos após a utilização da cana-de-açúcar como matéria prima. As próprias usinas produtoras de etanol costumam usar o bagaço da cana-de-açúcar como fonte energética, se tornando autossuficientes quanto à utilização de energia e obtenção de vapor. Contudo, impulsionado por questões ambientais, a queima desse material não é a melhor alternativa, já que emite uma grande quantidade de contaminantes na atmosfera [4].

O bagaço de cana-de-açúcar, no entanto, pode ter destino diferente, alternativo à queima para produção de energia. Seus componentes possuem alto potencial, podendo ser encaminhados à inúmeros processos industriais que utilizam a fibra como matéria prima na produção de papel e celulose, móveis e medula destinada à alimentação animal, por exemplo. Além disso, as frações de celulose e hemicelulose podem ser transformadas, via hidrólise, em açúcares 
fermentáveis que são utilizados como matéria prima para produção de ácido lático, etanol de segunda geração ou diversos outros produtos de maior valor agregado.

\section{2}

\section{Biomassa Lignocelulósica}

A biomassa lignocelulósica é composta por celulose, hemicelulose e lignina, além de outros componentes em frações menores, chamados de extrativos. A proporção de cada constituinte varia de acordo com a biomassa. A Tabela 3.1 apresenta a composição média do bagaço da cana-de-açúcar, de acordo com [5].

Tabela 3.1: Composição média do bagaço da cana-de-açúcar.

\begin{tabular}{ll}
\hline Componente & Composição \\
\hline Celulose & $38 \%-50 \%$ \\
Hemicelulose & $25 \%-27 \%$ \\
Lignina & $20 \%-30 \%$ \\
Extrativos & $5 \%-20 \%$ \\
\hline
\end{tabular}

A estrutura da biomassa é lamelar. As cadeias de celulose são compactadas através das ligações de hidrogênio. A lignina reveste a celulose e atua como um fixador das cadeias de celulose e hemicelulose, sendo esta última responsável pela ligação entre celulose e lignina [6]. A Figura 3.1 mostra a estrutura da biomassa lignocelulósica descrita. 


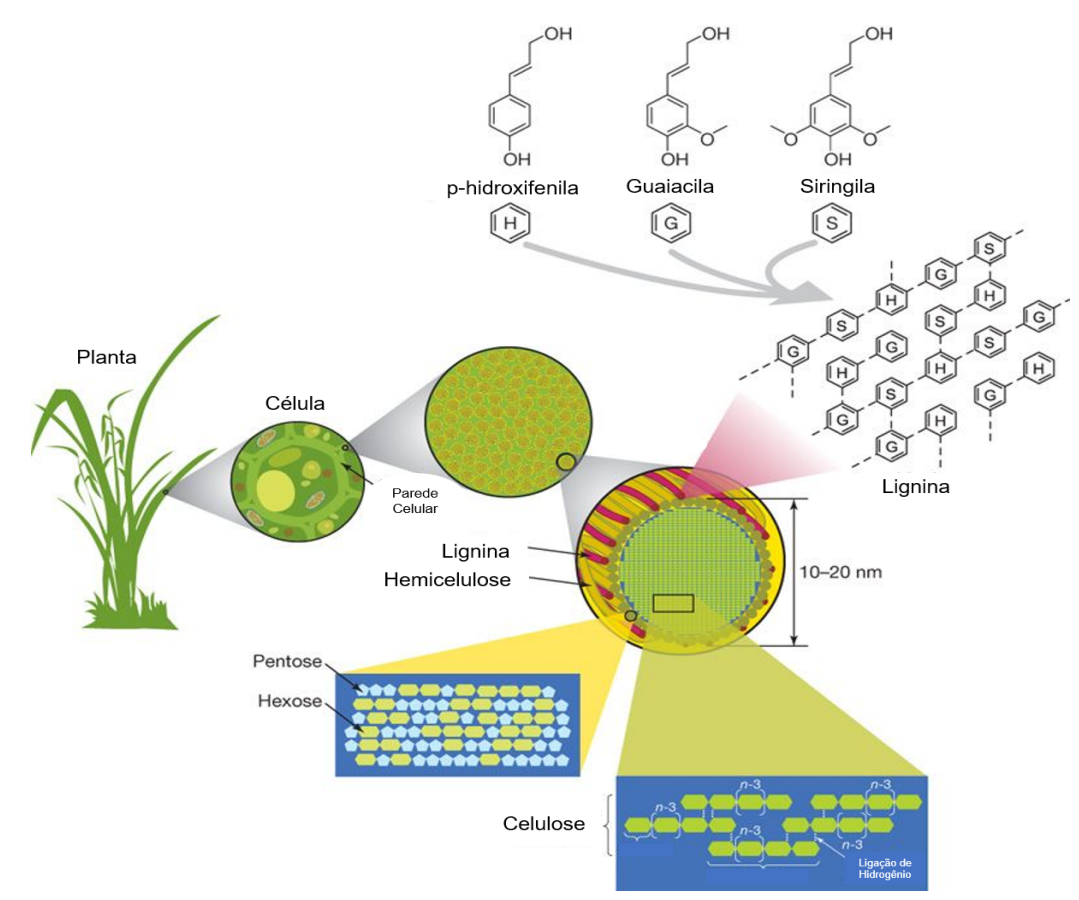

Figura 3.1: Estrutura da biomassa lignocelulósica [7].

\subsection{1}

\section{Celulose}

A celulose é o principal constituinte da biomassa lignocelulósica. É composta, exclusivamente, por monômeros de D-glicose unidos por ligações glicosídicas $\beta, 1-4$, que conferem a ela um forte agrupamento cristalino e compacto, sendo assim o principal componente hidratado de carbono da célula da parede da biomassa [8].

Essas unidades de glicose ligam-se de forma linear, formando longas cadeias poliméricas com parte amorfo e parte cristalina. A celulose é um polímero natural, caracterizado como homopolissacarídeo linear com a celobiose como unidade repetitiva. Sua fórmula geral é $\left(\mathrm{C}_{6} \mathrm{H}_{10} \mathrm{O}_{5}\right)_{n}$ [6]. A Figura 3.2 apresenta a estrutura da molécula de celulose.

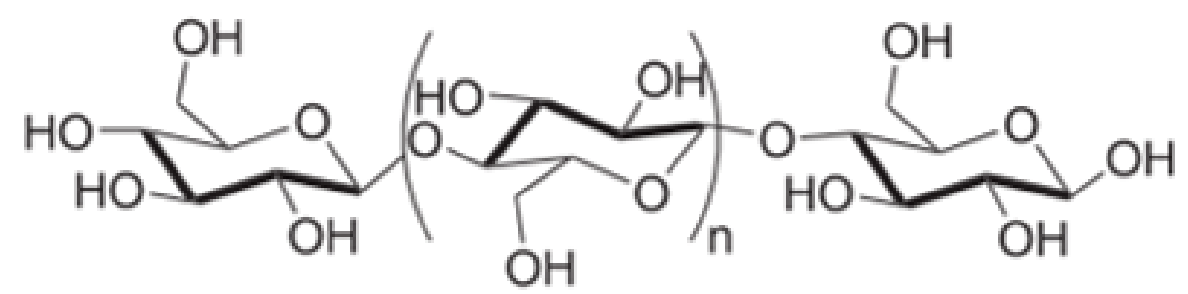

Figura 3.2: Estrutura da molécula de celulose [9]. 
Após a extração, a celulose é empregada principalmente na indústria de produção de papel e celulose. Os éteres de celulose possuem vasta aplicação industrial, que varia de auxiliares na polimerização em grande escala, aditivos para adesivos de papeis de parede e tintas, aos espessantes de viscosidade em cosméticos, gêneros alimentícios e farmacêuticos [10].

Outro destino para a molécula extraída é a produção de etanol celulósico, na qual se obtém a glicose a ser fermentada a partir de um processo de hidrólise da celulose. Essa hidrólise pode ser enzimática, pela ação de um coquetel enzimático que age em sinergia com a matéria prima, ou química, quando submetida a uma solução ácida de ácido sulfúrico ou clorídrico. Geralmente, essa celulose é extraída da cana-de-açúcar [11].

A utilização da celulose como matéria prima em outros processos apresenta grande vantagem com relação à utilização de combustíveis fósseis, já que é uma fonte renovável que pode ser encontrada em grande quantidade na natureza [12].

\subsection{2}

\section{Hemicelulose}

A hemicelulose está presente em todas as camadas da parede celular dos vegetais, apesar de ser encontrada em maior concentração nas camadas primária e secundária, onde se associa à celulose e à lignina [6].

Assim como a celulose, também é um carboidrato. Entretanto, é um polissacarídeo ramificado com baixo grau de polimerização sendo constituído por uma mistura de polímeros de pentoses, como a D-xilose e a L-arabinose e, em menor quantidade, polímeros de hexoses como D-glicose, D-galactose, Dmanose e ácidos glucorônicos. A hemicelulose varia na estrutura e composição, dependendo da fonte natural [9].

Essas características conferem à substância, em comparação com a celulose, maior facilidade de ser hidrolisada para seus monossacarídeos constituintes [13].

A Figura 3.3 apresenta a estrutura da molécula de hemicelulose.

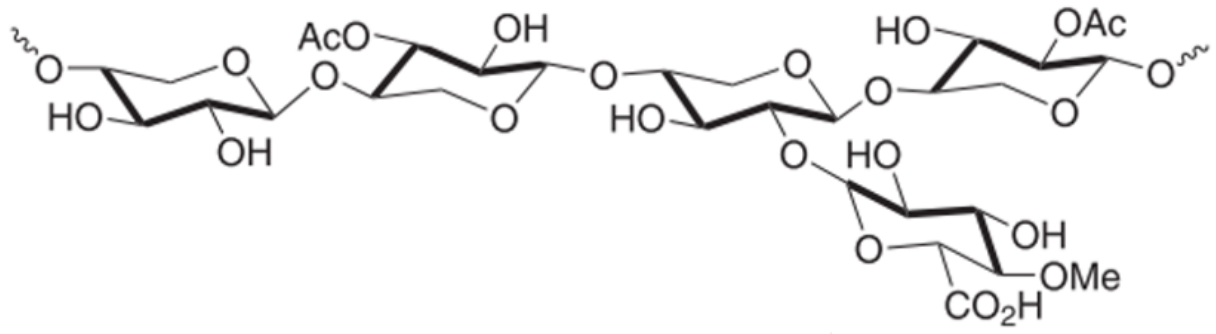

Figura 3.3: Estrutura da molécula de hemicelulose [9]. 


\subsection{3}

\section{Lignina}

A lignina se apresenta como uma substância de extrema importância para os vegetais. É responsável pelo transporte de água, nutrientes e metabólitos, além de ser responsável pela resistência mecânica e agir como uma parede de proteção contra agentes externos [14].

Apresenta estrutura bastante heterogênea, constituída de uma rede de aneis aromáticos unidos, formando um arranjo amorfo com grandes quantidades de ligações cruzadas entre aneis aromáticos [12]. A Figura 3.4 apresenta a estrutura hipotética da molécula de lignina.

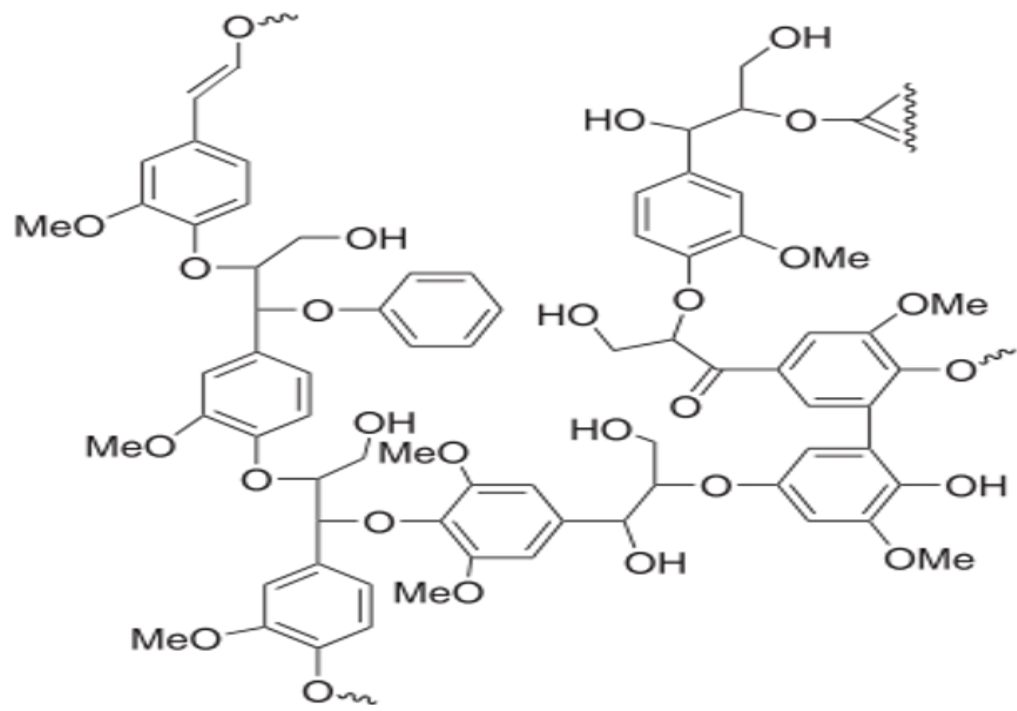

Figura 3.4: Estrutura da molécula de lignina [9].

Após transformações físico-químicas, a lignina gera diversos insumos de vasto interesse industrial como a vanila, ácido gálico, óleos, fenol e ácido acético [15]. Quando oxidada, a lignina possibilita a remoção de metais pesados em efluentes [16]. É utilizada, também, na fabricação de filmes, poliuretanos, fibras de carbono e fertilizantes [17].

\section{3}

\section{Pré-tratamento}

Para a conversão da biomassa em produtos de maior valor agregado, é necessário que a biomassa seja submetida a uma etapa de hidrólise dos carboidratos em açúcares fermentáveis e, subsequentemente, a uma etapa de fermentação. No entanto, a biomassa lignocelulósica possui grande resistência, fazendo com que o rendimento desse processo seja inferior a 20\%, segundo [18]. 
O pré-tratamento surge com o objetivo de reduzir o grau de cristalinidade da celulose, dissociar o complexo lignina-celulose, aumentar a área superficial da biomassa, preservar as pentoses maximizando os rendimentos em açúcares e evitar, ou minimizar, a formação dos compostos inibidores do processo em todas as etapas: separação dos materiais lignocelulósicos, hidrólise e, em alguns casos, a posterior fermentação [19].

O processo de separação dos materiais lignocelulósicos, ou deslignização, é realizado através do rompimento da parede celular da biomassa vegetal, permitindo remover, solubilizar ou despolimerizar a lignina [20]. Em outras palavras, o processo de deslignização consiste na extração da lignina presente no meio, com o objetivo de aumentar a digestibilidade do material e, por consequência, a disponibilidade de celulose para hidrólise em açúcares fermentáveis. No entanto, como a lignina está ligada à hemicelulose na estrutura da biomassa, é esperado que ocorra degradação parcial desse carboidrato. Dependendo das condições empregadas, pode-se observar, inclusive, degradação de celulose no processo de pré-tratamento [5].

A Figura 3.5 mostra um esquema do pré-tratamento realizado na biomassa.
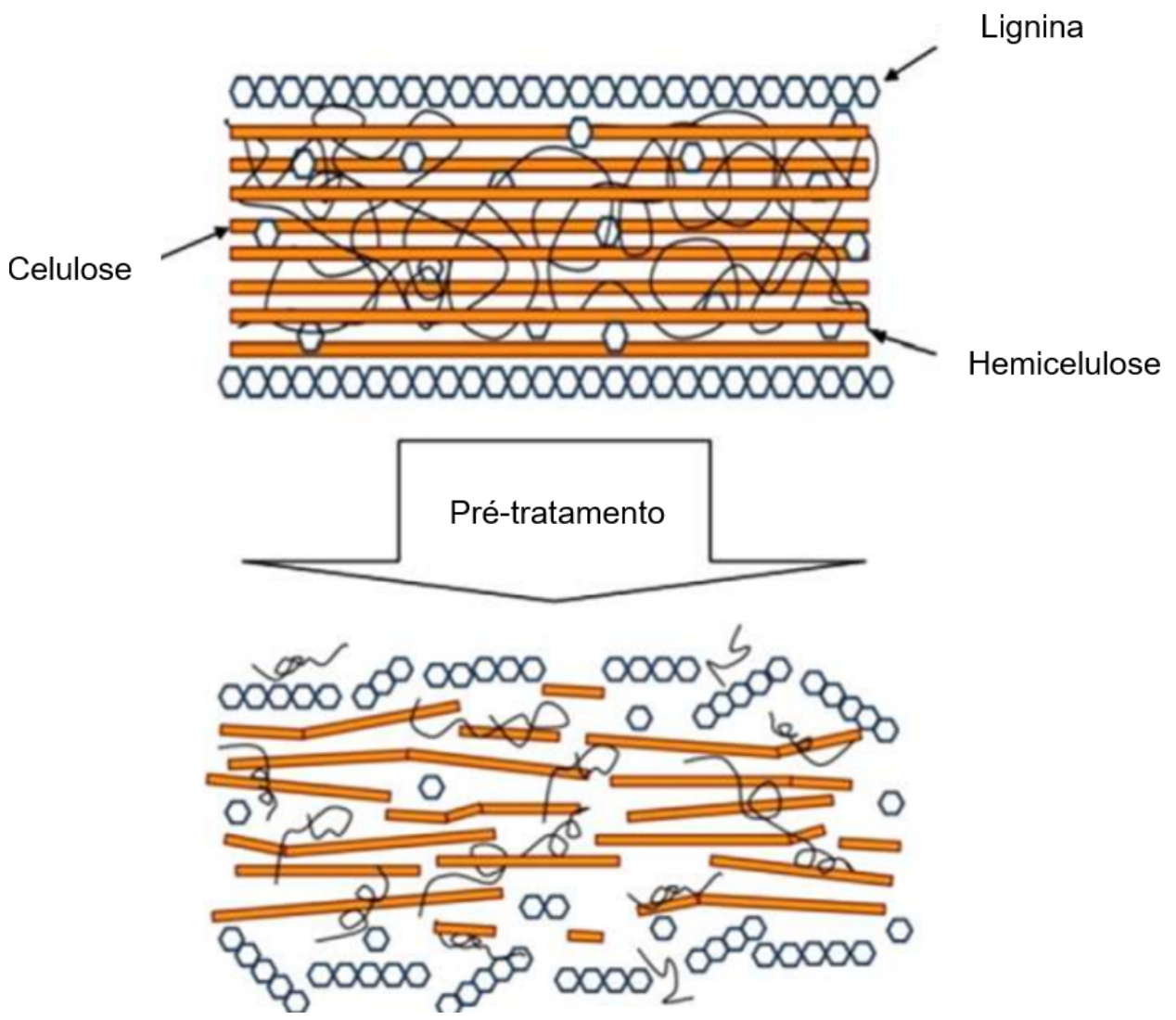

Figura 3.5: Efeito do pré-tratamento na biomassa [21].

Com relação ao custo, o processo de pré-tratamento é uma das etapas 
mais caras na conversão da biomassa lignocelulósica em produto de valor agregado. Sendo assim, estudos de modelagem e otimização para maximização do lucro apresentam grande potencial de pesquisa e desenvolvimento.

Existem diversos tipos de pré-tratamento que podem ser utilizados para remoção da lignina na biomassa aumentando, assim, a eficiência da hidrólise enzimática. A escolha do processo de pré-tratamento depende da finalidade ou proposta de utilização das frações lignocelulósicas [22] [23].

O pré-tratamento da biomassa pode ser dividido em quatro categorias: físico, químico, biológico e combinado. A Tabela 3.2 apresenta os diferentes métodos de pré-tratamento e as mudanças observadas na biomassa tratada.

Tabela 3.2: Métodos de pré-tratamento na biomassa.

\begin{tabular}{|c|c|c|c|}
\hline Métodos & $\begin{array}{c}\text { Operações que ocasionam mudança } \\
\text { na biomassa }\end{array}$ & Tipo de mudança observada & Referências \\
\hline Físico & $\begin{array}{l}\text { Moagem e trituração (bola, } \\
\text { energia vibratória, rolo duplo, } \\
\text { pressão); radiação; altas } \\
\text { temperaturas (pirólise, } \\
\text { explosão a vapor). }\end{array}$ & $\begin{array}{l}\text { Aumento da área superficial e } \\
\text { tamanho dos poros da partícula, } \\
\text { além da diminuição do grau de } \\
\text { polimerização. }\end{array}$ & $\begin{array}{l}{[24]} \\
{[25]} \\
{[26]}\end{array}$ \\
\hline Químico & $\begin{array}{l}\text { Bases; ácidos; gases; agentes } \\
\text { redutores e oxidantes; } \\
\text { solventes orgânicos. }\end{array}$ & $\begin{array}{l}\text { Deslignização, diminuição do } \\
\text { grau de polimerização e } \\
\text { cristalinidade da celulose } \\
\text { associada ao inchaço da } \\
\text { amostra, além do aumento da } \\
\text { porosidade. }\end{array}$ & $\begin{array}{l}{[27]} \\
{[28]} \\
{[29]}\end{array}$ \\
\hline Biológico & $\begin{array}{c}\text { Bolor branco (Pleurorus, } \\
\text { Pycnoporus, Ischnoderma, } \\
\text { Phlebia, etc) }\end{array}$ & $\begin{array}{c}\text { Deslignização e redução do grau } \\
\text { de polimerização da celulose } \\
\text { e hemicelulose. }\end{array}$ & $\begin{array}{l}{[30]} \\
{[31]}\end{array}$ \\
\hline Combinado & $\begin{array}{l}\text { Tratamento alcalino associado } \\
\text { com explosão a vapor; moagem } \\
\text { acompanhada com tratamento } \\
\text { alcalino ou tratamento ácido. }\end{array}$ & $\begin{array}{l}\text { Degradação da hemicelulose, } \\
\text { deslignização, aumento da área } \\
\text { superficial e aumento do } \\
\text { tamanho dos poros. }\end{array}$ & {$[32]$} \\
\hline
\end{tabular}

\subsection{1}

\section{Pré-tratamento Químico}

Os processos químicos são os mais utilizados comercialmente na indústria de papel e celulose. Podem ser classificados de acordo com o pH de operação do processo, como mostra a Tabela 3.3. 
Tabela 3.3: Valores de pH para diferentes tipo de pré-tratamento químico.

\begin{tabular}{cc}
\hline Processo & $\mathbf{p H}$ \\
\hline Ácido & $1,0-3,0$ \\
Bissulfito & 4,5 \\
Neutro & $6,0-8,0$ \\
Alcalino & $11,0-14,0$ \\
\hline
\end{tabular}

A utilização de diferentes produtos químicos para o pré-tratamento promove a realização de um grande número de pesquisas, sempre visando o aumento da eficiência e minimização dos custos do processo. Os diversos produtos utilizados podem ser ácidos, bases, gases, solventes orgânicos, álcoois, agentes oxidantes e redutores. Dentre esses produtos, as bases são os agentes de pré-tratamento mais usuais, uma vez que degradam menos a celulose, interessante para o processo de hidrólise e fermentação, além de formar menos inibidores com relação aos outros tipos de pré-tratamento. Além disso, é relatada na literatura, realização de hidrólise com a necessidade de menor carga enzimática em biomassas remanescentes do processo de pré-tratamento em meio alcalino [5].

Os tratamentos químicos que envolvem a utilização de agentes oxidantes também é de significativa relevância. A oxidação em meio alcalino é a metodologia mais comumente utilizada e a adição do agente oxidante favorece a remoção da lignina no meio [33]. Acredita-se que o $\mathrm{H}_{2} \mathrm{O}_{2}$ liberado pelos microrganismos atua no processo, indicando a importância de atuação dessa substância no pré-tratamento [12].

$\mathrm{O} \mathrm{H}_{2} \mathrm{O}_{2}$ é um líquido incolor, completamente miscível em água e altamente reativo, com alto poder de oxidação. Embora não seja um catalisador, atua como tal já que, com a adição de um agente externo, o peróxido dissocia-se em diferentes radicais que agem de maneira similar [?].

EM [34] foi proposto um mecanismo para explicar a dissociação do $\mathrm{H}_{2} \mathrm{O}_{2}$ e o motivo dele ser tão reativo quando em contato com a biomassa. Segundo o estudo, durante sua atuação, o $\mathrm{H}_{2} \mathrm{O}_{2}$ sofre dissociação em $\mathrm{pH}$ alcalino, formando o ânion hidroperóxido $\left(\mathrm{HOO}^{-}\right)$, que se apresenta como principal espécie reativa. Porém, em meio alcalino (com pH próximo a 11,5), o peróxido é instável e se decompõe em radicais hidroxila $(\mathrm{OH}-)$ e superóxido $\left(\mathrm{O}_{2}{ }^{-}\right)$. Estes radicais são os responsáveis pela oxidação da estrutura da lignina, devido ao ataque aos grupos hidrofílicos, como carboxilas, realizando quebras de ligações e levando à dissolução da lignina e da hemicelulose. O mecanismo é descrito a seguir de maneira mais completa. 
A um pH alcalino, o $\mathrm{H}_{2} \mathrm{O}_{2}$ dissocia-se na forma de hidroperóxido $\left(\mathrm{HOO}^{-}\right)$, conforme mostra a Equação 3-1.

$$
\mathrm{H}_{2} \mathrm{O}_{2} \leftrightarrow \mathrm{HOO}^{-}+\mathrm{H}^{+}
$$

Com o pH em 11,5, o hidroperóxido pode reagir com o peróxido de hidrogênio não dissociado para a formação de radicais hidroxila (OH-) e superóxido $\left(\mathrm{O}_{2}^{-}\right)$, como mostra a Equação 3-2.

$$
\mathrm{H}_{2} \mathrm{O}_{2}+\mathrm{HOO}^{-} \leftrightarrow . \mathrm{OH}+\mathrm{O}_{2}^{-}+\mathrm{H}_{2} \mathrm{O}
$$

$\mathrm{Na}$ ausência de outros reagentes, os radicais hidroxila e superóxido reagem entre si para a formação de $\mathrm{O}_{2}$ e água, conforme a Equação 3-3.

$$
\mathrm{OH}+\mathrm{O}_{2}^{-}+\mathrm{H}^{+} \leftrightarrow \mathrm{H}_{2} \mathrm{O}_{2}+\mathrm{O}_{2}
$$

A reação global de decomposição do peróxido de hidrogênio é determinada pela Equação 3-4

$$
\mathrm{H}_{2} \mathrm{O}_{2}+\mathrm{HOO}^{-}+\mathrm{H}^{+} \leftrightarrow 2 \mathrm{H}_{2} \mathrm{O}+\mathrm{O}_{2}
$$

Por fim, a dissociação do peróxido de hidrogênio pode ser definida, simplesmente, pela formação de água e oxigênio, conforma a Equação 3-5.

$$
2 \mathrm{H}_{2} \mathrm{O}_{2} \leftrightarrow 2 \mathrm{H}_{2} \mathrm{O}+\mathrm{O}_{2}
$$

É importante observar que, ao final do mecanismo, o peróxido se dissocia em água e oxigênio. Como não há a formação de nenhum outro resíduo, podese considerar que não ocorre impacto ambiental com sua utilização no processo de pré-tratamento da biomassa.

Quando o $\mathrm{H}_{2} \mathrm{O}_{2}$ se decompõe em condições alcalinas na presença de um substrato que contém lignina, a formação de oxigênio é menor que a máxima, indicando que os intermediários das reações estão envolvidos na reação de oxidação da lignina. Considerando ainda o fato de que o pH ótimo para o processo de deslignização é, segundo [5], por volta de 11,5, fica evidente que os intermediários gerados na reação apresentada pela Equação 3-2 estão envolvidos, já que esta é dependente do pH.

Foram realizados experimentos de pré-tratamento em fava de milho, palha de trigo, switchgrass e miscanthus em [?], visando a obtenção de açúcares disponíveis para a etapa de hidrólise enzimática. As amostras foram moídas para passar em peneiras de $5 \mathrm{~mm}$. O pré-tratamento foi realizado com uma solução $10 \%$ de $\mathrm{H}_{2} \mathrm{O}_{2}$ a $\mathrm{pH} 11,5$ por $24 \mathrm{~h}$ à temperatura ambiente $\left(25^{\circ} \mathrm{C}\right)$ e rotação de $90 \mathrm{rpm}$. O material remanescente do processo foi filtrado e lavado com água destilada e a parte insolúvel, levada à estufa a $45^{\circ} \mathrm{C}$ por 
48h e, posteriormente, armazenada à temperatura ambiente para realização das análises.

Ao final do pré-tratamento, em todas as biomassas estudadas, observouse a redução do teor de lignina presente no meio. Para a fava de milho e palha de trigo, a quantidade de lignina era menos da metade da quantidade original. Para switchgrass e miscanthus, observou-se uma redução de cerca de 40\%. Como proposto, o peróxido de hidrogênio alcalino foi capaz de extrair a lignina do material lignocelulósico, permitindo maior acesso aos carboidratos na etapa posterior do processo.

No mesmo experimento, [?] comparou a eficiência do pré-tratamento utilizando $\mathrm{H}_{2} \mathrm{O}_{2}$ com o pré-tratamento utilizando apenas $\mathrm{NaOH}$. O procedimento de pré-tratamento com o agente oxidante apresentou menor quantidade de lignina residual na biomassa do que o processo sem o agente oxidante.

Em [35] foram realizados experimentos para avaliar o pré-tratamento utilizando $\mathrm{H}_{2} \mathrm{O}_{2}$. As biomassas utilizadas por ele foram palha de trigo, casca de semente, além de outros materiais lignocelulósicos triturados à $2 \mathrm{~mm}$ de diâmetro. A solução utilizada apresentava $1 \%$ de $\mathrm{H}_{2} \mathrm{O}_{2}$ com pH 11,5. $\mathrm{O}$ experimento teve duração de $16 \mathrm{~h}$ à temperatura ambiente $\left(25^{\circ} \mathrm{C}\right)$. Os resultados indicaram que cerca de $50 \%$ da lignina havia sido dissolvida.

Analisando os trabalhos [?] e [35] pode-se concluir que com o aumento da concentração de peróxido, não necessariamente ocorrerá aumento na extração da lignina presente no meio, mas sim a ocorrência de dissolução da hemicelulose junto à dissolução de lignina.

No trabalho de [36], a biomassa utilizada foi a palha de centeio, que passou por diversos processos de preparo antes de ser submetida ao prétratamento com $\mathrm{H}_{2} \mathrm{O}_{2}$. O experimento avaliou a influência da temperatura, que variou entre $20^{\circ} \mathrm{C}$ e $70^{\circ} \mathrm{C}$ na extração da lignina do material lignocelulósico. A concentração de $\mathrm{H}_{2} \mathrm{O}_{2}$ foi mantida em $2 \%$ por $12 \mathrm{~h}$. Observou-se que mais de $50 \%$ da lignina foi removida a $20^{\circ} \mathrm{C}$, enquanto quase $90 \%$ foi removida a $70^{\circ} \mathrm{C}$.

Já no trabalho de Rabelo, 2007 [5], as variáveis temperatura e concentração de $\mathrm{H}_{2} \mathrm{O}_{2}$ também foram avaliadas durante o pré-tratamento do bagaço da cana-de-açúcar. Além disso, observou-se que a variável tempo não se mostrava relevante no processo pois, cerca de 45 min após o início, não havia mais formação significante de oxigênio, mostrando que todo peróxido já havia sofrido decomposição. 


\subsection{2}

\section{Pré-tratamento Físico}

Os processos físicos têm por objetivo tornar a matriz lignocelulósica mais acessível às enzimas do complexo celulase. Por isso, esses processos estão relacionados com a redução do tamanho de partícula e a redução da cristalinidade e do grau de polimerização da celulose e, consequentemente, com o aumento da superfície de contato da biomassa [33] [37].

Os processos físicos são vantajosos por serem insensíveis às características físicas e químicas da biomassa utilizada, ou seja, podem ser aplicados à qualquer biomassa, independente das suas características estruturais e composição [37].

Em [22] foi investigado o processo de pré-tratamento por hidrotermólise. Esse método não requer descompressão rápida e não utiliza catalisadores químicos externos. A temperatura desse pré-tratamento varia entre $160^{\circ} \mathrm{C}$ e $240{ }^{\circ} \mathrm{C}$, com aplicação de alta pressão para manter a água no estado líquido e remover hemicelulose e parte da lignina. Neste trabalho, observou-se que o prétratamento por hidrotermólise foi capaz de remover até $80 \%$ da hemicelulose presente na palha do milho, além de se mostrar eficiente também para a palha de trigo e o bagaço da cana-de-açúcar.

Por sua vez, [38] estudou o processo de pré-tratamento por explosão a vapor, que consiste na utilização de altas temperaturas e pressões, seguindo de expansão abrupta do conteúdo do reator à pressão atmosférica. Durante o processo, a hemicelulose é parcialmente hidrolisada e recuperada na forma de um hidrolisado hidrosolúvel, resultando em um material lignocelulósico altamente acessível às etapas posteriores de hidrólise e fermentação.

Segundo [33], a explosão a vapor na presença de $\mathrm{CO}_{2}$ é uma alternativa para se aproximar das condições ideais para remover os componentes que dificultam a hidrólise enzimática da biomassa. Dessa forma, é possível trabalhar a temperaturas mais baixas, se comparada com outras metodologias de explosão a vapor, o que proporciona maiores rendimentos, menores custos, menor impacto ambiental e maior segurança para o operador [39]. Neste contexto, vem sendo estudadas metodologias de pré-tratamento com $\mathrm{CO}_{2}$ na forma supercrítica.

Fluido supercrítico pode ser definido como um solvente que se encontra em condições de temperatura e pressão acima do ponto crítico [40]. Nessas condições, os fluidos apresentam propriedades semelhantes às de líquidos (densidade) e gases (compressibilidade), o que lhes confere características peculiares, que podem ser utilizadas para produção de compostos de interesse industrial. 
O fluido supercrítico mais utilizado é o $\mathrm{CO}_{2}$ que, por sua vez, não é tóxico, não agride o meio ambiente, apresenta alta capacidade de difusão, é inerte, tem baixa viscosidade e é naturalmente abundante, além de ser gasoso em temperatura ambiente [41] e de apresentar ponto crítico fácil de ser alcançado.

Entretanto, por ser um solvente pouco polar, o $\mathrm{ScCO}_{2}$ quando utilizado sozinho, possui algumas limitações que o impede de reagir com a lignina e de solubilizar os produtos polares gerados por essa macromolécula. Essa limitação pode ser minimizada com a adição de um co-solvente que proporcione melhora na capacidade solvente da mistura e aumente o rendimento da extração [42].

O uso de co-solventes em extração com fluido supercrítico tem sido empregado com o intuito de melhorar a eficiência, aumentando a produtividade e modificando a seletividade do processo. Seu uso pode alterar algumas características da mistura, tais como polaridade e interações específicas com o soluto [43].

Em [44], a utilização de 1-butanol como co-solvente possibilitou rendimento de 94,5\% no processo de deslignização do bagaço da cana-de-açúcar. No entanto, esse resultado foi obtido com a utilização de $60 \%$ de 1-butanol em relação à fração líquida, o que levou à degradação parcial dos polissacarídeos da biomassa.

Segundo [45], as variáveis temperatura e pressão influenciam diretamente no processo de pré-tratamento com $\mathrm{ScCO}_{2}$. Com a alteração dessas variáveis, ocorre alteração na densidade do fluido, característica responsável pela capacidade solvente do $\mathrm{ScCO}_{2}$. Meireles, 2008 relata ainda que, em geral, o aumento da pressão à temperatura constante causa o aumento da densidade do fluido supercrítico, elevando o seu poder solvente. Já o efeito da temperatura à pressão constante, leva à diminuição na densidade do solvente supercrítico.

Em [46], foi avaliada a influência das variáveis temperatura e pressão, além da utilização de etanol como co-solvente para o processo de prétratamento em cavacos de madeira de Pinus taeda e bagaço de cana-de-açúcar. No estudo, foi desenvolvida uma estratégia de planejamento experimental fatorial com a temperatura variando entre $142^{\circ} \mathrm{C}$ e $198^{\circ} \mathrm{C}$ e pressão variando entre 14,7 MPa e 23,2 MPa. A proporção do etanol utilizado como co-solvente variou entre $50 \%$ e $100 \%$.

Neste trabalho, observou-se que o pré-tratamento das biomassas estudadas apresentou alta eficiência quanto à remoção de lignina. Segundo os autores, a pressão exerceu um pequeno efeito sobre a deslignização. Por outro lado, a temperatura é um parâmetro importante e de forte efeito no processo. Os melhores resultados foram obtidos no experimento realizado a $190^{\circ} \mathrm{C}$ e 16 MPa, apresentando teores de extração de $93,1 \%$ e $88,4 \%$ para o cavaco de 
madeira e o bagaço da cana-de-açúcar, respectivamente. Quanto ao teor de cosolvente, para ambas biomassas, o melhor resultado foi obtido com a utilização da proporção 1:1 na mistura etanol-água. No caso do bagaço da cana-de-açúcar, observou-se que maior proporção de etanol pode aumentar o rendimento do pré-tratamento, mantendo o teor de extração de lignina acima de $80 \%$.

\section{4}

\section{Modelagem e Otimização}

Com a demanda do desenvolvimento de processos mais eficientes, com menores custos e impactos ambientais, torna-se necessária a utilização de ferramentas computacionais para se alcançar soluções ótimas. Visando a aplicação de métodos de otimização, é relevante que se construa um modelo matemático que descreva, de forma adequada, o processo a ser estudado.

Métodos clássicos de otimização, em geral, utilizam o gradiente da função objetivo para verificação do resultado, implicando que a função objetivo deva ser contínua em todos os pontos. Outro problema observado ocorre quando a função objetivo é multimodal, apresentando diversos pontos críticos no domínio estudado. Quando isso ocorre, os pontos críticos encontrados, na maioria das vezes, não são os globais. Dessa forma, observa-se a limitação de se otimizar o problema apenas a uma solução local, dependendo do ponto inicial fornecido.

No contexto da deslignização do bagaço da cana-de-açúcar, é importante ressaltar a importância da construção de modelos matemáticos de predição que correlacionem análises qualitativas não destrutivas com valores quantificados de lignina após o pré-tratamento da biomassa, visto que as metodologias usualmente aplicadas para quantificação desses teores são demoradas. Na literatura não são encontrados muitos trabalhos sobre modelagem e otimização dos processos de pré-tratamento. Dessa forma, é de extrema importância a investigação sobre o comportamento das variáveis envolvidas nos processos para que os experimentos sejam melhor direcionados, a fim de se obter o maior rendimento com menor custo. Nesse trabalho, propõe-se a modelagem utilizando a estratégia de planejamento experimental, cujos parâmetros dos modelos são obtidos por MMQ, além da modelagem por sistemas inteligentes, através da utilização de GA, ANN e ANFIS.

\subsection{1}

\section{Planejamento Experimental}

O planejamento consciente dos experimentos auxilia no estudo de influência das variáveis sobre as respostas desejadas, além de ser indispensável na obtenção de resultados confiáveis e análises estatísticas consistentes. A par- 
tir da utilização do planejamento experimental, é possível extrair do sistema em estudo o máximo de informação útil, executando um número mínimo de experimentos.

Experimentos delineados em esquemas fatoriais são aqueles que envolvem combinações entre os níveis de dois ou mais fatores. Entende-se por fatores as variáveis preditoras ou independentes, que apresentam seus níveis fixados, segundo o interesse do pesquisador. O esquema fatorial é dito completo quando são realizadas todas as combinações possíveis entre os níveis de cada fator [47].

Dá-se o nome de Delineamento Composto Central Rotacional (DCCR) ao planejamento experimental desenvolvido levando-se em consideração pontos axiais definidos. De modo geral, num DCCR com dois níveis originais, tem-se $2^{k}$ pontos fatoriais $+2 . k$ pontos axiais + número de pontos centrais. Os pontos axiais utilizados, geralmente são pontos do tipo $\pm \alpha=\left(2^{k}\right)^{1 / 4}[47]$.

Para um processo com 3 fatores, a disposição espacial dos níveis pode ser representada como um cubo no $\mathrm{R}^{3}$, onde os eixos correspondem às variáveis avaliadas. Os vértices do cubo equivalem aos pontos fatoriais do delineamento, enquanto os pontos axiais estão situados na região exterior ao cubo. No interior, observa-se o ponto central. A Figura 3.6 ilustra a representação espacial descrita.

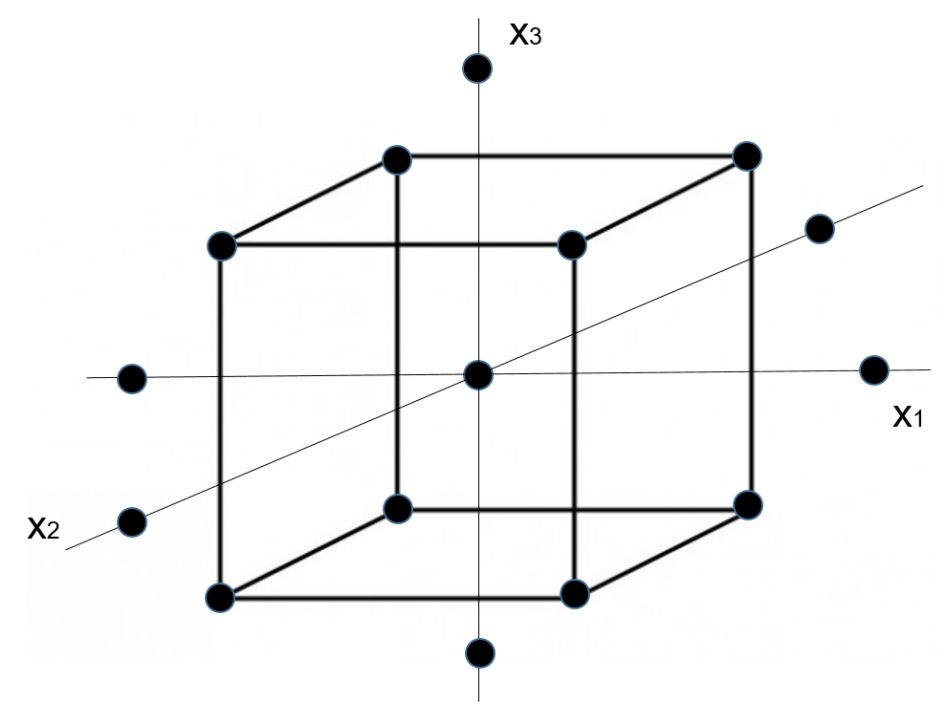

Figura 3.6: Representação espacial dos níveis de cada variável estudada no processo.

Para o planejamento fatorial completo com três variáveis independentes $\left(2^{3}\right)$, por exemplo, é necessária a realização de 17 ensaios, sendo 8 ensaios fatoriais, 6 ensaios em pontos axiais, que são essenciais para a construção de um modelo de $2^{\text {a }}$ ordem, além de 3 ensaios na condição central, indispensáveis para avaliar a qualidade de repetibilidade do processo. 
A partir dos resultados avaliados nos experimentos, é possível a construção de um modelo matemático empírico que, após validação estatística, pode ser usado na obtenção de superfícies de respostas, de onde se pode determinar as condições otimizadas para o processo.

EM [5] foi utilizado um planejamento fatorial completo $2^{3}$ para avaliar a influência do tempo reacional entre $6 \mathrm{~h}$ e $24 \mathrm{~h}$, da temperatura entre $20^{\circ} \mathrm{C}$ e $60^{\circ} \mathrm{C}$ e da concentração de $\mathrm{H}_{2} \mathrm{O}_{2}$ entre $1 \%$ e $5 \%$ no pré-tratamento do bagaço da cana-de-açúcar. Os resultados obtidos indicaram que o tempo de prétratamento não foi significativo a $90 \%$ de confiança. As superfícies de respostas obtidas apresentaram pontos de máximo nas extremidades, o que levou à realização de novos ensaios com o objetivo de se encontrar o ponto ótimo para as variáveis estudadas no processo. Nessa nova etapa, foi desenvolvido um planejamento fatorial $2^{2}+$ configuração estrela, tendo como fatores as variáveis temperatura entre $50^{\circ} \mathrm{C}$ e $70^{\circ} \mathrm{C}$ e concentração de $\mathrm{H}_{2} \mathrm{O}_{2}$ entre $4,17 \%$ e $9,83 \%$. O tempo de reação, já que não se mostrou significativo na etapa anterior, permaneceu fixo em $6 \mathrm{~h}$. Os resultados desse novo planejamento mostraram que, para a nova faixa estudada, a variável temperatura também não se mostrou significativa para 90\% de confiança. O modelo proposto determinou o valor ótimo para concentração de $\mathrm{H}_{2} \mathrm{O}_{2}$ em torno de $7 \%$. Como temperatura e tempo de reação foram avaliadas como variáveis não significativas, concluiu-se que o máximo rendimento do processo pode ser obtido a $25^{\circ} \mathrm{C}$ e $1 \mathrm{~h}$, por exemplo.

Além disso, [48] utilizou novamente planejamento fatorial para determinar a necessidade de redução do tamanho de partícula do bagaço da cana-deaçúcar, assim como para otimizar as condições de pré-tratamento e a carga das enzimas na hidrólise. A partir do planejamento, foi possível concluir que o pré-tratamento com $\mathrm{H}_{2} \mathrm{O}_{2}$ aumentou a digestibilidade enzimática da biomassa sem a necessidade de redução prévia do tamanho de partícula.

\section{4 .2}

\section{Algoritmos Genéticos}

Algoritmos Genéticos são técnicas heurísticas de otimização global que quase não necessitam de interferência humana. Baseiam-se na teoria de seleção natural, onde todos os indivíduos, dentro de um sistema, competem entre si. Operações de crossover e mutação são aplicadas aos indivíduos da população, de forma que os mais aptos sejam selecionados com mais frequência que os menos aptos, a fim de que as boas características passem a predominar na população de soluções [49].

Ao contrário dos métodos como gradiente que seguem a derivada da função para achar o ponto crítico, quase sempre local, os Algoritmos Genéticos 
não ficam estagnados nesse ponto, procurando indivíduos ainda melhores que levem à otimização para um ponto crítico global do problema.

Computacionalmente falando, a população é constituída por um conjunto de indivíduos aleatórios, formados a partir da concatenação dos valores das variáveis de interesse. A partir daí, utilizando a função objetivo pré-definida, avalia-se a adequação do indivíduo ao problema. O método de ranqueamento é utilizado para classificar os indivíduos com base em sua aptidão para que os melhores tenham maior chance de serem selecionados. Nesse ponto, operadores genéticos (crossover e mutação) são utilizados para gerar novos indivíduos, teoricamente mais aptos à solução. O algoritmo é encerrado quando se atinge o critério de parada pré-especificado [50].

Em [51], utilizou-se GA para estimação de parâmetros cinéticos do processo de fermentação em batelada da cana-de-açúcar para produção de etanol. Os experimentos foram realizados para temperaturas entre $28^{\circ} \mathrm{C} \mathrm{e} 40^{\circ} \mathrm{C}$. Como resultado, obteve-se correlação maior que $98 \%$ entre os dados preditos pelo modelo otimizado e os dados simulados. Além disso, observou-se que a utilização de GA impede que ocorra problema de definição de ponto inicial para a busca no espaço amostral, observado nos métodos de otimização clássica.

Em [52] foi utilizado GA a fim de otimizar o processo de fermentação para produção de etanol. Os parâmetros avaliados no trabalho foram temperatura (entre $30^{\circ} \mathrm{C}$ e $40^{\circ} \mathrm{C}$ ), $\mathrm{pH}$ (entre 5,1 e 6,5 ) e tempo de fermentação (entre $30 \mathrm{~h} \mathrm{e}$ $50 \mathrm{~h}$ ) do processo. Os experimentos foram realizados conforme o planejamento experimental desenvolvido e o modelo obtido foi utilizado como função de avaliação para o algoritmo. A técnica de otimização por Algoritmos Genéticos previu uma concentração máxima de cerca de $60 \mathrm{~g} / \mathrm{L}$ de etanol sob condição experimental de $31^{\circ} \mathrm{C}$, pH em 5,13 e 44h de fermentação.

\subsubsection{1}

\section{Crossover}

O crossover corresponde à troca de informações sobre os parâmetros que constituem dois indivíduos. A permutação das informações entre eles ocorre através do rompimento dos dois indivíduos em um mesmo local aleatório. Neste processo, são gerados dois descendentes compostos, em parte, pelas informações que constituíam cada um dos indivíduos originais [51]. Dessa forma, não é possível se obter um indivíduo com características novas, dado que sua formação é baseada, apenas, na mescla de informações previamente existentes.

Na execução do operador crossover, o algoritmo implementado no software Matlab seleciona aleatoriamente a informação a ser passada para os in- 
divíduos da próxima geração. Em problemas com restrições lineares, a implementação padrão da função de crossover cria o novo indivíduo como uma média ponderada das informações aleatoriamente selecionadas dos indivíduos antecessores [53].

A Figura 3.7 mostra o mecanismo de crossover a partir de dois indivíduos.

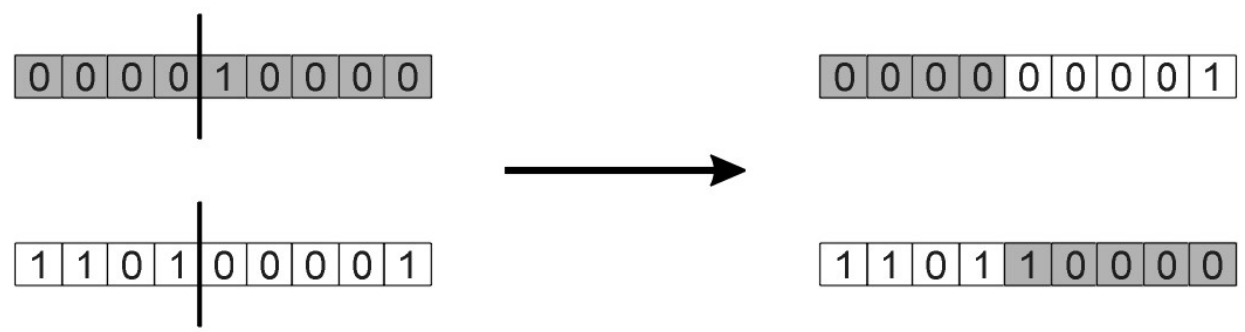

Figura 3.7: Mecanismo do operador genético crossover [54].

O uso desse operador genético influencia diretamente no resultado obtido pelo algoritmo. A utilização do crossover aumenta a variabilidade genética dos indivíduos, tendo como objetivo principal a produção de uma nova geração com maior qualidade, isto é, com indivíduos que se aproximem cada vez mais da solução ótima [49].

A probabilidade de que determinado indivíduo seja selecionado para o crossover é um dos parâmetros que pode ser alterado no algoritmo. Se este valor for de $100 \%$, nenhum indivíduo segue intacto para a próxima geração, o que pode afastar a otimização da solução ótima. Entretanto, se esse valor for de $0 \%$, a próxima geração será formada apenas por cópias dos indivíduos antecessores, o que desfavorece a variabilidade genética para descoberta da solução [55].

\subsubsection{2}

\section{Mutação}

A mutação ocorre através da troca de uma informação por outra em um mesmo indivíduo, fazendo com que ele apresente características inéditas. Esta mudança torna possível a busca pela solução ótima em regiões não exploradas pelos indivíduos da geração anterior [49].

$\mathrm{Na}$ execução do operador de mutação, o algoritmo implementado no software Matlab modifica aleatoriamente a informação a ser passada para o indivíduo da próxima geração [53].

A Figura 3.8 mostra o mecanismo de mutação em um indivíduo. 


\section{\begin{tabular}{l|l|l|l|l|l|l|l|l}
1 & 2 & 3 & 4 & 5 & 6 & 7 & 8 & 9
\end{tabular}$\longrightarrow$\begin{tabular}{ll|l|l|l|l|l|l|l|}
1 & 5 & 3 & 4 & 2 & 6 & 7 & 8 & 9 \\
\hline
\end{tabular}}

Figura 3.8: Mecanismo do operador genético mutação [54].

Assim como o operador crossover, a mutação é responsável na manutenção da variabilidade genética da população. Além disso, é fundamental para que as soluções obtidas não sejam pontos críticos locais, visto que é utilizada como ferramenta para ampliação do espaço de busca [49].

A probabilidade com que determinado indivíduo seja selecionado para a mutação também é um parâmetro que pode ser manipulado no algoritmo. Se este valor for de $100 \%$, os indivíduos serão tão afetados que o método se assemelharia a uma estratégia de busca aleatória. Por outro lado, se este valor for de $0 \%$, os indivíduos da próxima geração seriam constituídos exclusivamente por efeitos de crossover [55].

\subsubsection{3}

\section{Critério de Parada}

O término da execução do algoritmo não significa que a otimização foi completa e satisfatória. Os critérios de parada mais comumente utilizados pelo software Matlab são o número de gerações, valor esperado para o indivíduo mais apto, minimização da diferença dos valores dos indivíduos entre gerações e tempo máximo para execução da rotina computacional [53].

A minimização da diferença dos valores dos indivíduos entre as gerações indica que o método convergiu para uma solução satisfatória. No entanto, caso a interrupção da rotina seja ocasionada pela extrapolação do tempo de processamento ou do número de gerações pré-determinado, por exemplo, o resultado observado ao final tende a ser mais adequado que os valores utilizados como entrada, mas, não necessariamente, essa é a solução ótima do problema.

\subsection{3}

\section{Redes Neurais Artificiais}

A definição de um modelo altamente preciso para estudos quantitativos depende de condições como a distribuição de variáveis, o número de preditores e a complexidade das interações entre as variáveis. A escolha de um método estatístico que seja robusto e possa resolver essas relações complexas tornase um trabalho crucial. ANN é um método estatístico capaz de explorar as 
relações complexas existentes entre as variáveis de uma forma simples, criando um modelo de alta precisão [56].

São sistemas capazes de simular matematicamente sistemas neurais biológicos, compostos por unidades de processamentos simples (neurônios) dispostos em uma ou mais camadas. A partir das conexões estabelecidas entre esses neurônios e seus pesos associados, é calculada a resposta de saída [57].

Neurônios artificiais baseiam-se na estrutura de um neurônio biológico, que pode ser dividida em três partes: o dentrito, que recebe a informação do neurônio anterior; o corpo celular, que tem a função de processar a informação recebida e gerar respostas; e o axônio, responsável por transmitir as respostas geradas ao neurônio seguinte. O neurônio artificial, por sua vez, pode também ser dividido em três partes: a camada de entrada, que recebe as informações das variáveis de entrada; a camada intermediária, que processa a informação obtida na entrada; e a camada de saída, que corresponde à saída das informações [12].

Matematicamente falando, há $n$ terminais de entrada $\left(x_{1}, x_{2}, \ldots, x_{n}\right)$ e somente um terminal de saída $(y)$ no neurônio. No processamento das informações pelo neurônio, é levada em consideração a soma de todas as informações recebidas por ele. Cada informação possui um peso diferente $\left(w_{1}, w_{2}, \ldots, w_{n}\right)$, proporcional à variável que está sendo representada pelo neurônio. Esse peso é levado em consideração na soma das informações. Dessa forma, a informação pode ser representada como uma multiplicação entre a variável e seu peso correspondente $\left(x_{i} \cdot w_{i}\right)$.

Uma função de ativação é necessária para estimular o neurônio, que dispara ou não o sinal com a informação, dependendo da avaliação do seu valor com o limiar definido para o neurônio. A Equação 3-6 apresenta a avaliação realizada na decisão de ativação do neurônio no algoritmo.

$$
\sum_{i=1}^{n}\left(x_{i} \cdot w_{i}\right) \geq \theta
$$

$n$ : número de terminais de entrada do neurônio.

$x_{i} \cdot w_{i}$ : valor da informação de peso $w_{i}$ associado ao terminal de entrada $x_{i}$.

$\theta$ : valor limiar do neurônio.

Além dos pesos, as redes neurais apresentam um parâmetro independente chamado bia, elemento que serve para aumentar o grau de liberdade dos ajustes dos pesos. A presença dos bias evita o chamado trapping, o encalhamento em um mínimo local, e ajuda na convergência da rede [58]. 
Com o somatório calculado, a informação é direcionada para uma função de ativação responsável por ativar ou não a saída, dependendo do valor do somatório encontrado. Por fim, no terminal de saída, a resposta é passada para o neurônio seguinte, até que a informação percorra toda a rede neural, gerando a solução do problema.

A Figura 3.9 apresenta o esquema descrito de um neurônio artificial.

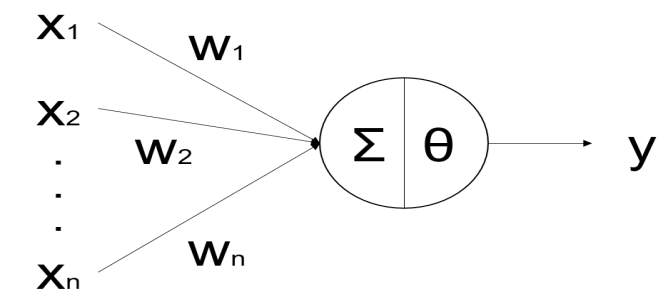

Figura 3.9: Representação matemática de um neurônio artificial [12].

A utilização de ANN na modelagem de bioprocessos vem sendo amplamente discutida. Por se tratar de sistemas com modelagens fenomenológicas complexas, o uso desse tipo de modelagem inteligente permite com que os resultados desejados sejam obtidos de forma simples, sem que seja preciso conhecer a fundo as reações envolvidas no processo.

Em [59], ANN foi utilizada para modelagem do pré-tratamento para liberação de polifenóis e açúcares de folhagem caída de pinheiro. Em [60], por sua vez, utilizou-se a modelagem com ANN para avaliar o desempenho de um biorreator anaeróbio para determinação do conteúdo de metano no rendimento de biogás, a partir da fração orgânica de resíduos sólidos urbanos.

No contexto do pré-tratamento do bagaço da cana-de-açúcar, [61] utilizou ANN na identificação das condições experimentais executadas, além da predição do teor de lignina oxidada na biomassa durante o processo.

\subsubsection{1}

\section{Arquitetura de Redes Neurais Artificiais}

A utilização de um único neurônio artificial para resolução de problemas não é recomendada, já que ele possui capacidade limitada. Nesse cenário, fazse necessária a associação de vários neurônios em uma rede para resolução de sistemas complexos.

A chamada rede Feedforward de uma única camada é a arquitetura existente mais simples. É composta por uma camada de entrada, uma camada intermediária e uma camada de saída. A camada de entrada corresponde às variáveis do processo. O nível intermediário faz a associação das informações 
de entrada, atribuindo a elas um peso fixo associado. A camada de saída possui as conexões e tem seus pesos ajustados linearmente. Esse tipo de rede é capaz de resolver problemas com várias variáveis, mas apresenta restrições de complexidade. A Figura 3.10 apresenta uma rede Feedforward de uma única camada.

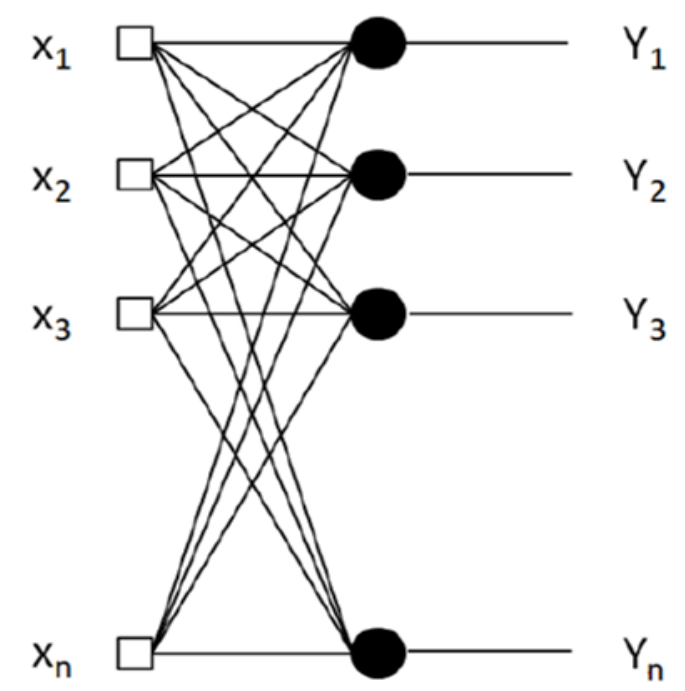

Figura 3.10: Rede Feedforward de uma única camada [1].

Por sua vez, a rede Feedforward de múltiplas camadas apresenta camadas intermediárias ocultas que proporcionam à rede neural maior capacidade para resolução de problemas complexos, como problemas que não são linearmente separáveis.

As camadas de entrada e saída apresentam a mesma funcionalidade apresentada na rede Feedforward de uma única camada. Já na camada intermediária, os pesos passam a ser parâmetros ajustáveis, proporcionando maior flexibilidade na solução do problema. A Figura 3.11 apresenta uma rede Feedforward de múltiplas camadas. 


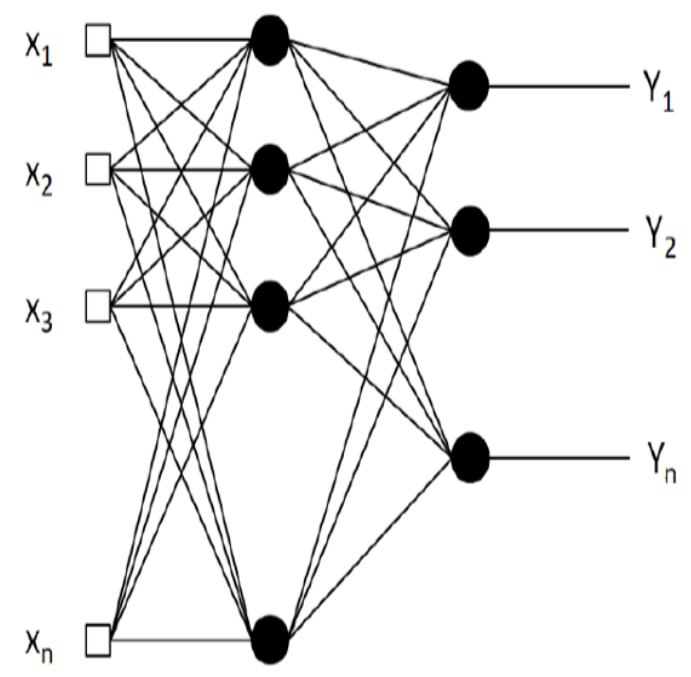

Figura 3.11: Rede Feedforward de múltiplas camadas [1].

\subsubsection{2}

\section{Número de neurônios em cada camada}

Decidida a arquitetura da rede, deve-se determinar a quantidade de neurônios presente em cada camada. A escolha ocorre heuristicamente, desde que sejam respeitadas algumas restrições. Em geral, esse parâmetro é variado de acordo com a complexidade do problema a ser modelado.

O número de neurônios na camada de entrada deve ser igual ao número de variáveis do processo que serão fornecidas à rede e o número de neurônios da camada de saída deve ser igual ao número de respostas que pretende se obter com o modelo neural desenvolvido.

O número de neurônios da camada intermediária é obtido por tentativa e erro. No entanto, uma escolha errada pode causar problemas de underfitting, quando a estrutura proposta se mostra insuficiente para resolução do problema ou overfitting, quando a rede é superdimensionada, o que leva à diminuição da capacidade de generalização e as respostas do problema se tornam tendenciosas.

\subsubsection{3}

\section{Treinamento das Redes Neurais Artificiais}

Existem vários algoritmos de treinamento disponíveis para redes neurais. A principal diferença entre eles é a maneira como os pesos são ajustados. Os algoritmos de treinamento são classificados em dois grandes grupos: treinamento supervisionado e treinamento não supervisionado. 
No treinamento não supervisionado, são fornecidos à rede apenas os dados de entrada e o aprendizado ocorre a partir da regularidade nos dados observados. Já no treinamento supervisionado, a rede neural é alimentada com os dados de entrada e os dados de saída esperados. A rede é estimulada e, levando em consideração os parâmetros de entrada, confere se os parâmetros de saída calculados correspondem aos dados de saída fornecidos. Esse ajuste é realizado a partir da minimização do erro entre a saída calculada pela rede durante o treinamento e a saída fornecida como dado de treinamento.

Um dos algoritmos de treinamento supervisionado mais utilizados é o de retropropagação, mais conhecido como Backpropagation [57].

\subsubsection{4}

\section{Algoritmo Backpropagation}

O algoritmo Backpropagation utiliza pares de dados de entrada e saída para ajustar os pesos e bias da rede, por meio da correção de índices de erro. O treinamento da rede neural por esse algoritmo ocorre em duas fases: fase forward e fase backward.

Na fase forward, a entrada dos dados de treinamento são feitos pela camada de entrada. A camada seguinte calcula seu sinal de saída, que irá servir como entrada para outra camada mais à frente. Ao final, as respostas calculadas na camada de saída são comparadas com os dados fornecidos à rede.

A fase backward se inicia pela camada de saída. O erro calculado nessa camada é retropropagado e, a partir daí, os neurônios da camada intermediária imediatamente anterior ajustam seus pesos, de forma a minimizar o erro.

A taxa de aprendizado da rede e o termo de momentum são dois parâmetros que influenciam o desempenho do processo de aprendizagem. A taxa de aprendizado $(\eta)$ é um termo constante que varia entre 0 e 1 . Segundo [12], uma taxa muito pequena implica em mudanças mais suaves nos valores de pesos e bias, porém aumenta o tempo necessário para o aprendizado. Além disso, pode causar problema de trapping. Por outro lado, uma taxa muito alta leva à mudanças mais bruscas e pode causar oscilação em torno do mínimo global. O termo de momentum $\left(\alpha_{m o}\right)$ é um termo que visa aumentar a taxa de aprendizado sem ocasionar a oscilação durante a aplicação do algoritmo de Backpropagation. Ele leva em consideração os efeitos das mudanças anteriores dos pesos na direção do movimento atual dos pesos [62].

A Equação 3-7 mostra como é calculada a variação do peso.

$$
\Delta w_{i j}^{t+1}=\eta s_{i} e_{j}+\alpha_{m o} w_{i j}^{t}
$$


$\Delta w_{i j}^{t+1}$ e $w_{i j}^{t}$ : variações do peso do neurônio $j$ em relação à conexão $i$ nos instantes $t+1$ e $t$, respectivamente.

$\eta$ : taxa de aprendizado.

$\alpha_{m o}$ : termo momentum.

$s_{i}$ : valor de entrada pela conexão $i$ do neurônio $j$.

$e_{j}$ : valor do erro calculado do neurônio $j$.

O treinamento pelo algoritmo Backpropagation pode, por muitas vezes, ser lento e apresentar baixo desempenho, principalmente se tratando da modelagem de problemas mais complexos.

No software Matlab, a implementação do algoritmo combina taxa de aprendizado adaptável com treinamento de momentum, sendo este um parâmetro de treinamento adicional. O Backpropagation calcula as derivadas da performance com relação aos pesos e bias. Desta forma, cada variável é ajustada de acordo com o gradiente de descida. A cada iteração, se o desempenho diminui com relação ao objetivo, a taxa de aprendizado é aumentada [63]. A Equação 3-8 apresenta o cálculo realizado pelo método.

$$
d X=\alpha_{m o} . d X_{p r e v}+\gamma \cdot \alpha_{m o} \cdot \frac{d_{p e r f}}{d X}
$$

$d X$ : direção de busca da função.

$\alpha_{m o}$ : termo momentum.

$d X_{\text {prev }}$ : direção de busca anterior da função.

$\gamma$ : parâmetro escalar.

$\frac{d_{p e r f}}{d X}$ : derivada da performance com relação aos pesos e bias do neurônio $\mathrm{X}$.

\subsubsection{5}

\section{Funções de Ativação}

Essas funções são utilizadas no processamento das informações em cada neurônio, gerando uma saída calculada de acordo com os pesos e bias do neurônio. Três tipos de equações matemáticas são mais comumente utilizadas como funções de ativação: função linear, função logística e função tangente hiperbólica. A ideal será determinada pela disposição e arquitetura da rede neural proposta [12].

A função linear é utilizada normalmente na camada de saída da rede. Esse tipo de função realiza uma transição linear entre dois estados. No software 
Matlab, essa função recebe o nome de purelin. A Equação 3-9 representa a função linear e a Equação 3-10 representa sua derivada. A Figura 3.12 mostra graficamente a função linear e sua derivada para valores genéricos de $p$ [64].

$$
\begin{gathered}
f(x)=p \cdot x \\
f^{\prime}(x)=p
\end{gathered}
$$
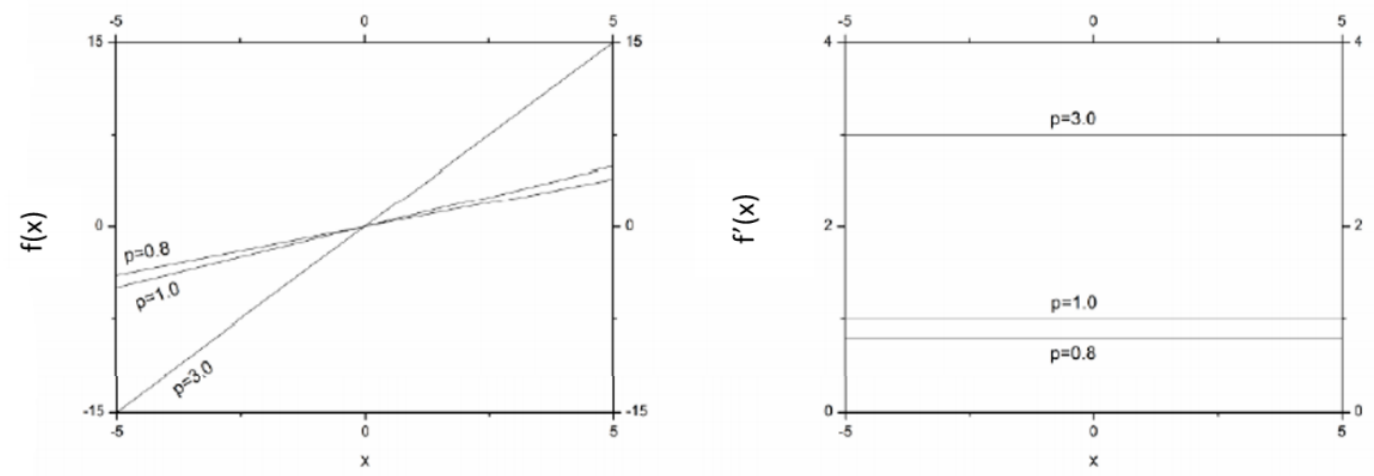

Figura 3.12: Representação gráfica da função linear purelin e sua derivada.

A função logística, por sua vez, é utilizada nas camadas intermediárias da rede neural e realiza uma transição não linear entre dois estados, sendo limitada por valores entre 0 e 1 . No software Matlab, essa função recebe o nome de logsig. A Equação 3-11 representa a função logística e a Equação 3-12 representa sua derivada. A Figura 3.13 mostra graficamente a função logística e sua derivada para valores genéricos de $p$ [64].

$$
\begin{gathered}
f(x)=\frac{1}{1+e^{-p \cdot x}} \\
f^{\prime}(x)=p \cdot f(x) \cdot(1-f(x))
\end{gathered}
$$
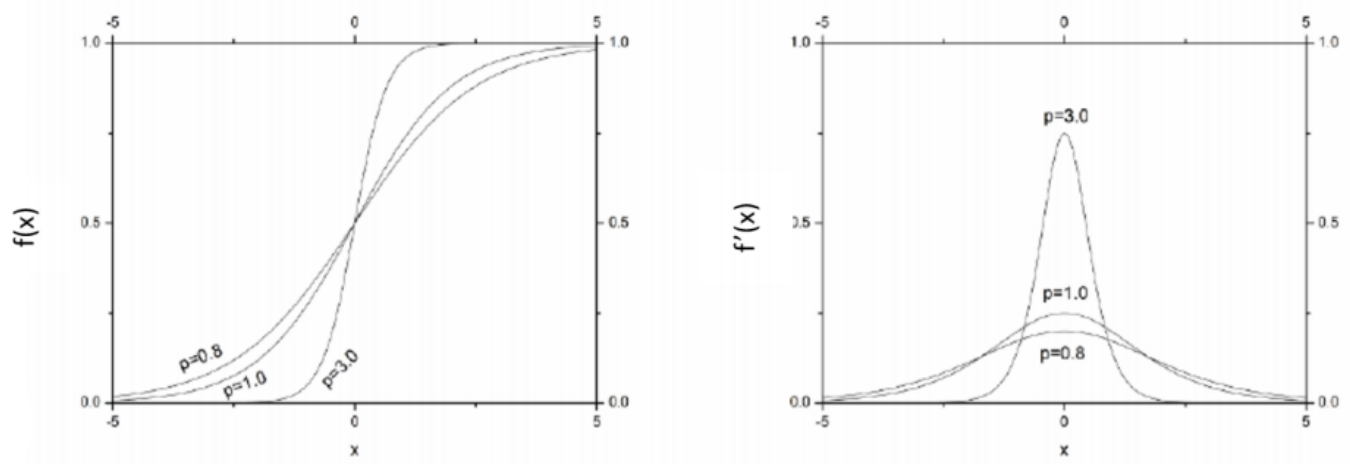

Figura 3.13: Representação gráfica da função não linear logsig e sua derivada. 
A função tangente hiperbólica também é utilizada nas camadas intermediárias da rede neural e, assim como a função logística, realiza uma transição não linear entre dois estados. No entanto, essa função é limitada por valores entre -1 e 1. No software Matlab, essa função recebe o nome de tansig. A Equação 3-13 representa a função tangente hiperbólica e a Equação 3-14 representa sua derivada. A Figura 3.14 mostra graficamente a função tangente hiperbólica e sua derivada para valores genéricos de $p$ [64].

$$
\begin{gathered}
f(x)=\tanh (p \cdot x) \\
f^{\prime}(x)=p \cdot\left(1-f(x)^{2}\right)
\end{gathered}
$$
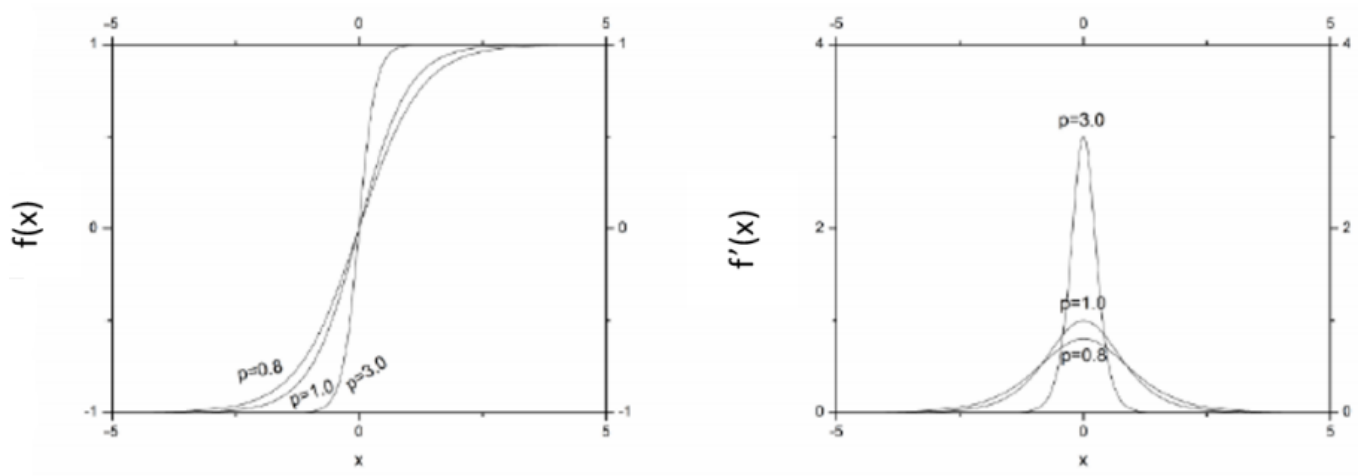

Figura 3.14: Representação gráfica da função não linear tansig e sua derivada.

A Figura 3.15 mostra um exemplo de utilização das funções de ativação tansig e purelin em uma rede neural [65].

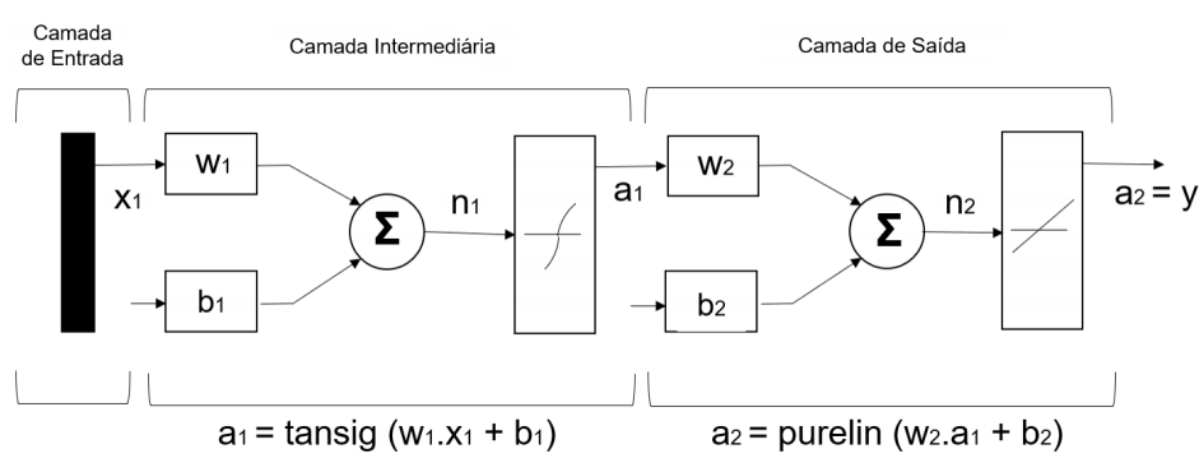

Figura 3.15: Representação esquemática da atuação das funções de ativação tansig e purelin. 


\subsection{4}

\section{Sistema de Inferência Adaptativa Neuro-Difusa}

Um sistema de inferência adaptativa neuro-difusa (Adaptative Neural Fuzzy Inference System - ANFIS), é um sistema híbrido que funciona como uma rede neural artificial, simulando um processo de inferência em sistemas difusos. De um ponto de vista estatístico, também é uma técnica de regressão não linear com a capacidade de aproximar qualquer função definida em um domínio compacto [66].

Esse tipo de modelagem permite unir ao processamento linguístico de um sistema de inferência a capacidade de adaptação e aprendizagem das redes neurais [67].

Em [68] foi utilizada modelagem ANFIS para predição do poder calorífico da biomassa. O conjunto de entrada para o modelo de previsão foi baseado em análises de carbono fixo, cinza e matéria volátil. Em [69], por sua vez, utilizouse modelagem ANFIS para estimar as frações lignocelulósicas de determinada biomassa utilizada em um processo de pirólise. Em [70], a modelagem ANFIS foi utilizada com o objetivo de se investigar a viabilidade de predição da qualidade do efluente de um sistema de reator de leito anaeróbio sequencial de fluxo ascendente.

Todos os casos relatados na literatura tratam de problemas que envolvem bastante não linearidade e complexidade. No entanto, para todos eles a modelagem ANFIS foi capaz de modelar o processo envolvido satisfatoriamente.

\subsubsection{1}

\section{Sistema de inferência}

O sistema de inferência está embutido na arquitetura ANFIS e pode ser de dois tipos: o modelo Takagi-Sugeno e o modelo Mamdani. No modelo Mamdani, as funções de pertinência das variáveis são conjuntos fuzzy. No entanto, para o sistema de inferência proposto em [71], as funções de pertinência das variáveis estão em função das variáveis de entrada. As regras apresentam, portanto, a forma geral apresentada na Equação 3-15.

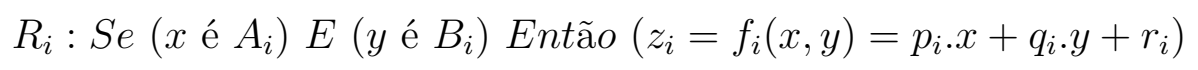

$x, y$ : variáveis difusas de entrada sobre os universos de domínio.

$A_{i}, B_{i}$ : valores difusos das variáveis $x$ e $y$ sobre os mesmos universos de domínio. 
$f_{i}(x, y)$ : função do tipo linear, onde $p_{i}, q_{i}$ e $r_{i}$ são os parâmetros a serem ajustados.

Em um sistema de inferência, o ANFIS recebe os valores das variáveis existentes no formato de conjuntos clássicos. Esses dados são transformados em variáveis linguísticas através de interações nas camadas intermediárias do modelo. Em [72] são apresentadas como as cinco camadas existentes no modelo são descritas. A Figura 3.16 mostra a estrutura geral de uma arquitetura ANFIS.

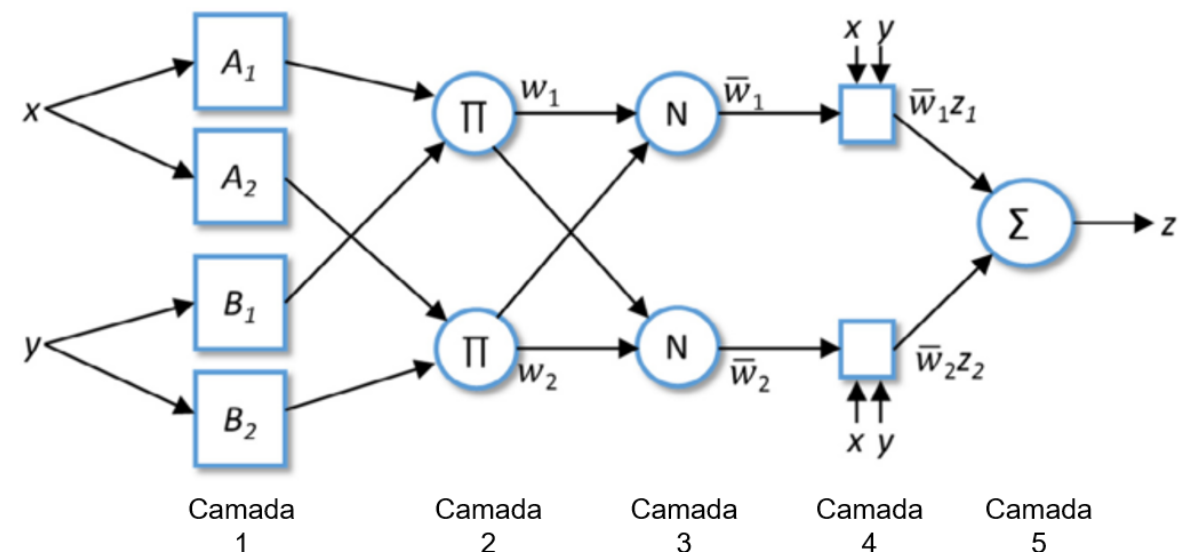

Figura 3.16: Estrutura geral da arquitetura ANFIS [68].

A primeira camada é do tipo adaptativa e a função é definida de acordo com a Equação 3-16, onde $x$ é a entrada do neurônio $i$. O valor difuso linguístico associado a essa função do neurônio é a chamada função de pertinência $(\mu)$.

$$
O_{i}^{1}=\mu A_{i}(x)
$$

A segunda camada é do tipo não adaptativa e, portanto, não possui parâmetros a serem ajustados. Neste ponto do algoritmo, uma função fixa de multiplicação dos sinais de entrada na camada é executada, resultando no grau de aplicabilidade $\left(W_{i}\right)$ de uma regra, como mostrado na Equação 3-17.

$$
W_{i}=\mu A_{i}(x) \cdot \mu B_{i}(y), i=1,2,3,4,5
$$

A terceira camada é não adaptativa. Nesta camada, a razão entre a aplicabilidade da regra e a soma da aplicabilidade de todo o sistema de regras é calculado para cada neurônio. As saídas dessa camada são chamadas de 
aplicabilidade normalizada. A Equação 3-18 mostra o cálculo realizado nesta etapa do algoritmo.

$$
\overline{W_{i}}=\frac{W_{i}}{W_{1}+W_{2}+W_{3}+W_{4}+W_{5}}, i=1,2,3,4,5
$$

A quarta camada é do tipo adaptativa com função de ativação, representada pela Equação 3-19, onde $W_{i}$ são as saídas da camada anterior e $p_{i} \cdot x, q_{i} \cdot y$ e $r_{i}$ são os parâmetros a serem justados, chamados de parâmetros consequentes.

$$
O_{i}^{4}=\overline{W_{i}} \cdot f_{i}=\overline{W_{i}}\left(p_{i} \cdot x+q_{i} \cdot y+r_{i}\right)
$$

A quinta e última camada também é do tipo não adaptativa e consiste em apenas um neurônio que calcula a saída final como a soma de todos os sinais de entrada da camada anterior, conforme mostra a Equação 3-20.

$$
O_{i}^{5}=\sum_{i} \overline{W_{i}} \cdot f_{i}=\frac{\sum_{i} W_{i} \cdot f_{i}}{\sum_{i} W_{i}}
$$

O modelo de inferência do tipo Takagi-Sugeno está sujeito a dois problemas quando a dimensão de dados de entrada é muito grande. O primeiro problema é a falha do raciocínio da rede e o segundo problema é o aumento exponencial do número de pertinências [73]. Para evitar essas situações, são aplicadas técnicas de agrupamento (clustering) aos dados.

\subsubsection{2}

\section{Funções de pertinência}

A função de pertinência especifica o grau de relevância $(\mu)$ com que a entrada $x$ satisfaz o valor linguístico, isto é, reflete o conhecimento que se tem em relação à intensidade com que o objeto pertence ao conjunto fuzzy.

Existem diversos tipos de funções de pertinência. As mais utilizadas são: trapezoidal (trapmf), triangular (trimf), gaussiana (gaussmf), gaussiana combinada (gauss2mf) e sigmoidal (sigmf). A Figura 3.17 apresenta cada função de pertinência matemática graficamente [74]. 


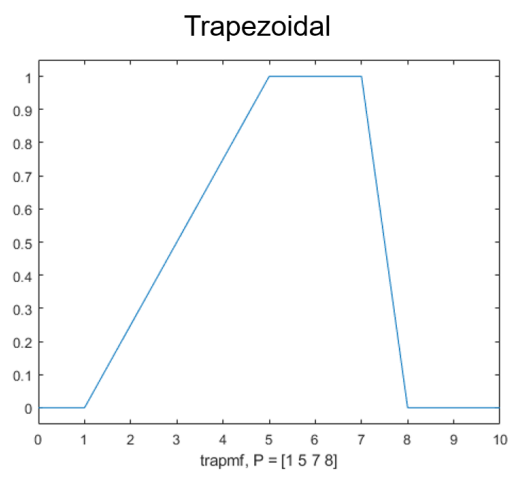

$f(x, a, b, c, d)=\max \left(\min \left(\frac{x-a}{b-a}, 1, \frac{d-x}{d-c}\right), o\right)$

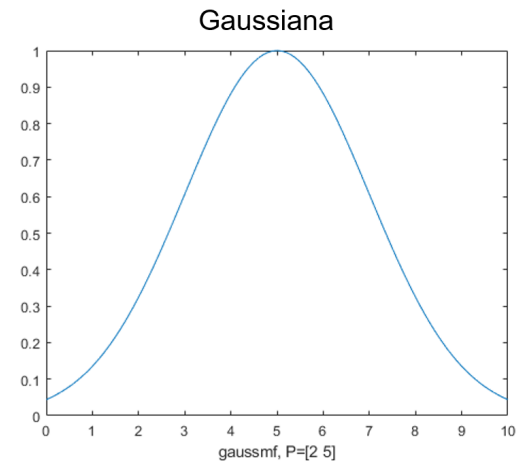

$f(x, \sigma, c)=e^{\frac{-(x-c)^{2}}{2 \sigma^{2}}}$

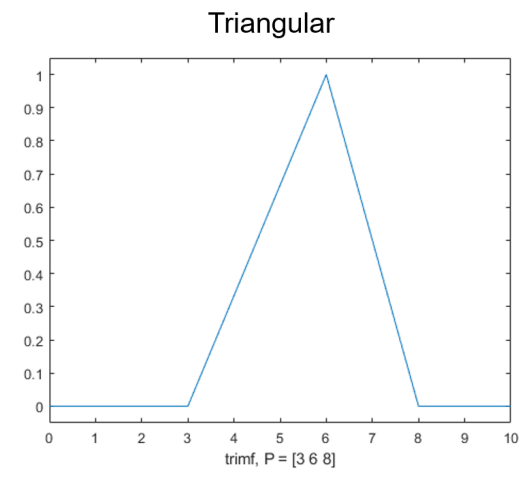

$f(x ; a, b, c)=\max \left(\min \left(\frac{x-a}{b-a}, \frac{c-x}{c-b}\right), o\right)$

Gaussiana Combinada

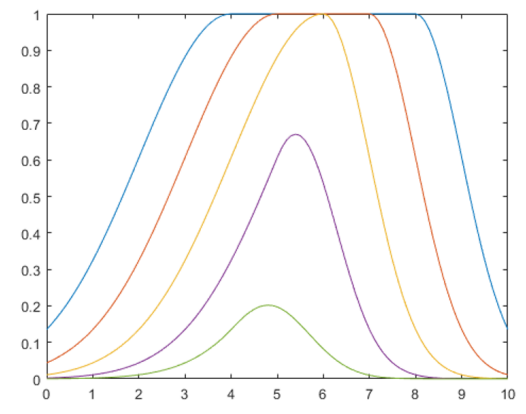

$f(x ; \sigma, c)=e^{\frac{-(x-c)^{2}}{2 \sigma^{2}}}$

Sigmoidal

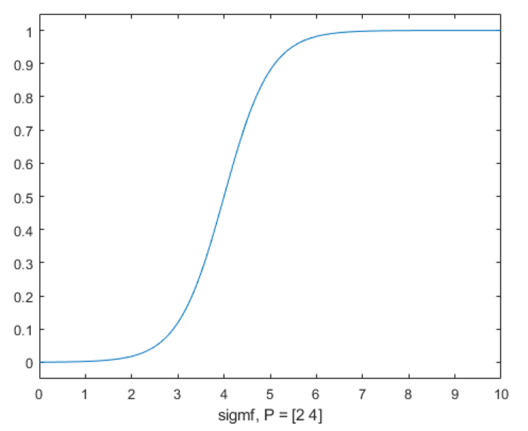

$f(x, a, c)=\frac{1}{1+e^{-a(x-c)}}$

Figura 3.17: Gráficos e equações das funções de pertinência.

\subsubsection{3}

\section{Métodos de grupamento}

Clustering é a classificação de objetos em diferentes grupos ou o particionamento de dados com algumas características em comum. O ANFIS apresenta diversas métodos para se estabelecer o grupamento dos dados. Os mais conhecidos são o Método do Particionamento de Grade (Grid Partitioning) e o Método de Grupamento Subtrativo (Subtractive Clustering).

No Método do Grid Partition, cada variável de entrada é associada a 
uma função de pertinência uniformemente distribuída. Uma regra é criada para cada combinação de função de pertinência e o parâmetro consequente de cada regra corresponde a uma função de saída diferente. Esse método se mostra eficiente quando o número de características para o grupamento dos dados é menor que seis. Acima desse valor, é necessária a utilização de um computador com maiores recursos de memória para execução da aplicação de forma satisfatória [75].

No Método de Subtractive Clustering, cada variável de entrada é associada a uma função de pertinência do tipo Gaussiana. Uma regra é aplicada para cada grupo de dados criado. Nesse caso, cada variável de saída é associada a uma função de pertinência do tipo linear [75].

Segundo [68], no Método de Subtractive Clustering é assumido que cada ponto de dados é um possível centro do grupo. Com base na concentração de pontos de dados vizinhos, calcula-se um grau de probabilidade de cada ponto de dados ser definido como centro do grupo. O ponto de dados com a maior probabilidade de ser o primeiro centro do grupo é determinado pelo algoritmo. Para se decidir o próximo grupo de dados e sua localização central, elimina-se todos os pontos de dados próximos ao primeiro centro determinado anteriormente. $\mathrm{O}$ algoritmo continua até que todos os dados estejam dentro dos raios pré-determinados para cada centro de grupo, ou seja, até que todos os dados de entrada fornecidos pertençam a um grupo.

O raio dos grupos é o valor usado como base de treinamento para os grupos. A determinação do seu valor é importante para que seja gerado, da melhor maneira possível, o número necessário de grupos para o sistema de inferência difusa. Outro parâmetro importante é o fator Squash. Esse fator é multiplicado pelo valor do raio para se determinar grupos vizinhos. Esse parâmetro influencia diretamente no número de regras difusas geradas inicialmente no sistema de inferência [73]. 


\section{4}

\section{Materiais e Métodos}

Neste capítulo, serão abordados aspectos pertinentes à preparação dos materiais, realização das etapas experimentais e modelagens desenvolvidas.

\section{1}

\section{Tratamento primário do material lignocelulósico}

A fonte lignocelulósica utilizada neste trabalho foi o bagaço da cana-deaçúcar, cedido pelo Instituto SENAI de Inovação em Química Verde.

O material foi lavado exaustivamente em água corrente. Em seguida, foi seco em estufa a $45^{\circ} \mathrm{C}$ por $48 \mathrm{~h}$.

A biomassa foi triturada com o auxílio de um triturador elétrico e armazenada em dessecador para posterior utilização.

\section{2}

\section{Análise granulométrica do material lignocelulósico}

Peneiras com valores de mesh na série Tyler de 10, 12, 32, 35 e 48 foram utilizadas para separação do material. As peneiras foram inicialmente pesadas e empilhadas, começando com a bandeja inferior, do maior valor de mesh para o menor valor de mesh.

Aproximadamente 33,0 g do bagaço da cana-de-açúcar foram adicionados na parte superior da série de peneiras presas em um agitador magnético. $\mathrm{O}$ sistema permaneceu sob agitação por 30 min. Após esse período, as peneiras foram novamente pesadas para determinação da massa retida em cada uma delas.

A fração mássica retida foi calculada pela divisão da massa de bagaço da cana-de-açúcar na peneira pela soma das massas de material em todas as peneiras. A equação 4-1 mostra como é o cálculo realizado para determinação da fração mássica retida na peneira de 10 mesh.

$$
\%_{10}=\frac{M_{10}}{M_{10}+M_{12}+M_{32}+M_{35}+M_{48}} \times 100
$$

$M_{10}$ : massa das partículas retidas na peneira de 10 mesh, em gramas. 
$M_{12}$ : massa das partículas retidas na peneira de 12 mesh, em gramas.

$M_{32}$ : massa das partículas retidas na peneira de 32 mesh, em gramas.

$M_{35}$ : massa das partículas retidas na peneira de 35 mesh, em gramas.

$M_{48}$ : massa das partículas retidas na peneira de 48 mesh, em gramas.

\section{3}

\section{Pré-tratamento com $\mathrm{H}_{2} \mathrm{O}_{2}$}

\subsection{1}

\section{Planejamento experimental}

Um DCCR com 3 variáveis independentes (temperatura, concentração de $\mathrm{H}_{2} \mathrm{O}_{2}$ e pH) foi usado para avaliar os parâmetros do processo de deslignização do bagaço da cana-de-açúcar. Ao total, foram realizados 17 ensaios: 8 ensaios fatoriais, 6 ensaios nos pontos axiais para permitir a construção de um modelo de $2^{\text {a }}$ ordem e 3 ensaios no ponto central, indispensáveis para avaliar a qualidade de repetibilidade do processo.

A Tabela 4.1 descreve os níveis em que cada variável foi estudada. As variáveis foram codificadas como $\mathrm{x}_{1}, \mathrm{x}_{2}$ e $\mathrm{x}_{3}$, respectivamente.

Tabela 4.1: Valores utilizados no planejamento experimental para o processo de deslignização do bagaço da cana-de-açúcar.

\begin{tabular}{ccccccc}
\hline Variáveis & Código & $\mathbf{- 1 , 6 8}$ & $\mathbf{- 1}$ & $\mathbf{0}$ & $\mathbf{+ 1}$ & $\mathbf{+ 1 , 6 8}$ \\
\hline Temperatura $\left({ }^{\circ} \mathrm{C}\right)$ & $\mathrm{x}_{1}$ & 25,0 & 32,1 & 42,5 & 52,9 & 60,0 \\
Concentração de $\mathrm{H}_{2} \mathrm{O}_{2}(\% \mathrm{~m} / \mathrm{v})$ & $\mathrm{x}_{2}$ & 2,0 & 4,6 & 8,5 & 12,4 & 15,0 \\
$\mathrm{pH}$ & $\mathrm{x}_{3}$ & 10,0 & 10,6 & 11,5 & 12,4 & 13,0 \\
\hline
\end{tabular}

\subsection{2}

\section{Procedimento experimental}

O processo experimental para extração de lignina do bagaço da cana-deaçúcar com $\mathrm{H}_{2} \mathrm{O}_{2}$ foi desenvolvido conforme [61], adaptado de [5]. Alíquotas de 2,0 g de bagaço de cana-de-açúcar foram colocadas em erlenmyers de 250 mL. Foi utilizado um béquer de $100 \mathrm{~mL}$ para o preparo da solução de prétratamento, onde foi adicionada a quantidade necessária de $\mathrm{H}_{2} \mathrm{O}_{2}$ para se obter a concentração necessária em cada experimento. Foi adicionada, também, uma solução de hidróxido de potássio (KOH) 5,0 mol.L $\mathrm{L}^{-1}$ até que o pH atingisse o valor desejado em cada condição experimental. Por fim, completou-se o volume com água destilada.

Um volume de $50 \mathrm{~mL}$ dessa solução alcalina de pré-tratamento foi despejado nos erlenmeyers contendo a biomassa. Os erlenmeyers foram colocados 
em um shaker na temperatura desejada para o teste sob agitação constante em $150 \mathrm{rpm}$ durante $1 \mathrm{~h}$. Todos os ensaios foram realizados em duplicata.

Ao final desta etapa, o material foi submetido a uma filtração à vácuo. A fração sólida foi lavada com $200 \mathrm{~mL}$ de água destilada e armazenada em tubos falcon, levados para a secagem em estufa a $45^{\circ} \mathrm{C}$. Após secos, foram levados para análise de Klason e FT-IR.

A fração líquida foi colocada, novamente, no erlenmeyer de $250 \mathrm{~mL}$. Após 24h, foi acidificada a pH 2,0 com uma solução de $\mathrm{H}_{2} \mathrm{SO}_{4} 1$ mol.L $\mathrm{L}^{-1}$. Após mais 24h, a solução foi centrifugada a $3.000 \mathrm{rpm}$ por $10 \mathrm{~min}$. A solução sobrenadante foi descartada e o precipitado foi levado à estufa para secagem.

A Figura 4.1 mostra o fluxograma do procedimento experimental descrito.

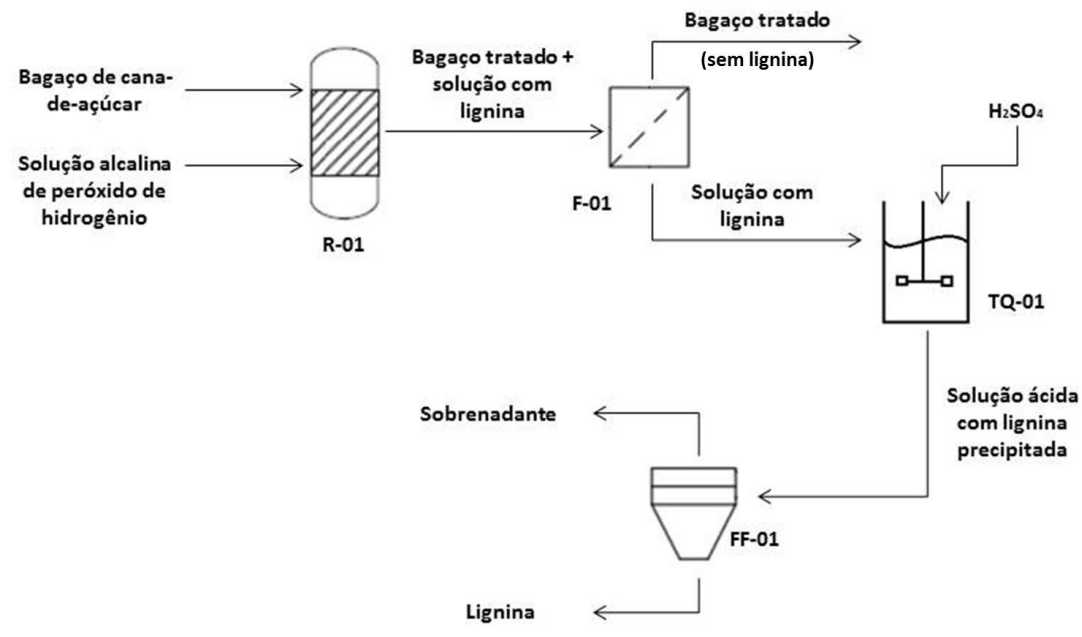

Figura 4.1: Fluxograma do procedimento experimental do pré-tratamento do bagaço da cana-de-açúcar com $\mathrm{H}_{2} \mathrm{O}_{2}$.

\section{4}

\section{Pré-tratamento com $\mathrm{ScCO}_{2}$}

\subsection{1}

\section{Procedimento experimental}

O processo experimental para extração de lignina do bagaço da cana-deaçúcar com $\mathrm{ScCO}_{2}$ foi desenvolvido conforme [44].

As reações foram processadas em um conjunto de extração supercrítica Maqnagua. Alíquotas de 46g de bagaço de cana-de-açúcar foram colocadas no equipamento, juntamente com $500 \mathrm{~mL}$ da solução aquosa de etanol comercial $92,8^{\circ}$ INPM. A reação no extrator ocorreu durante $1 \mathrm{~h}$, incluindo o tempo 
de estabilização da temperatura após a pressurização do $\mathrm{CO}_{2}$ em estado supercrítico no reator.

Após esse período, o extrato foi coletado e a biomassa foi lavada com 550 $\mathrm{mL}$ de uma solução de $\mathrm{NaOH} 1 \%(\mathrm{~m} / \mathrm{v})$ para remoção da lignina adsorvida nas fibras do material. A polpa obtida foi filtrada, lavada com água destilada e seca em estufa para análises posteriores.

A tabela 4.2 apresenta as condições de temperatura, pressão e teor de etanol na solução aquosa de co-solvente utilizadas em cada experimento.

Tabela 4.2: Condições experimentais realizadas para estudo do processo de deslignização do bagaço da cana-de-açúcar usando $\mathrm{ScCO}_{2}$.

\begin{tabular}{cccc}
\hline Ensaios & Temperatura $\left({ }^{\circ} \mathbf{C}\right)$ & Pressão (bar) & \% Etanol \\
\hline 1 & 74,0 & 190 & 50 \\
2 & 35,0 & 300 & 100 \\
3 & 91,0 & 75 & 100 \\
4 & 100,0 & 190 & 0 \\
5 & 84,0 & 180 & 50 \\
6 & 47,0 & 75 & 0 \\
7 & 105,0 & 75 & 0 \\
8 & 100,0 & 300 & 100 \\
9 & 47,0 & 75 & 100 \\
10 & 35,0 & 300 & 0 \\
11 & 77,0 & 190 & 50 \\
\hline
\end{tabular}

A Figura 4.2 mostra o fluxograma do procedimento experimental descrito e a Figura 4.3 mostra o equipamento de extração utilizado neste trabalho.

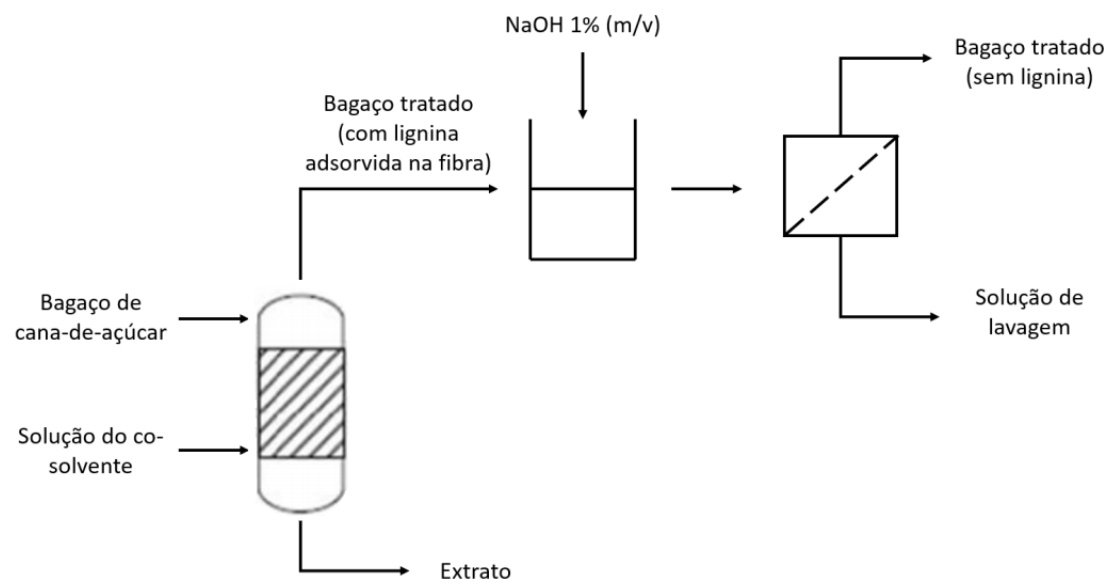

Figura 4.2: Fluxograma do procedimento experimental do pré-tratamento do bagaço da cana-de-açúcar com $\mathrm{ScCO}_{2}$. 


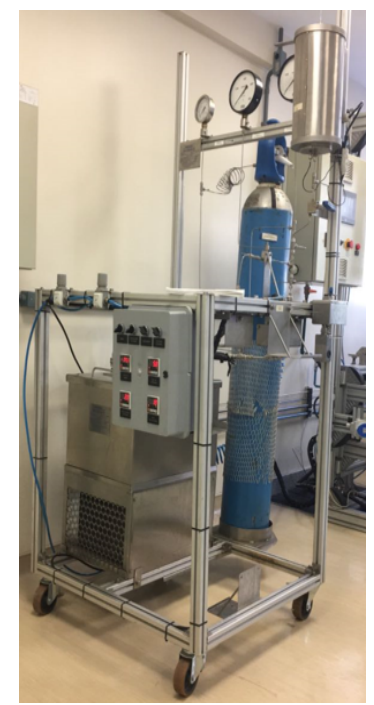

Figura 4.3: Imagem do conjunto de extração supercrítica Maqnagua utilizado neste trabalho.

\section{5}

\section{Análises realizadas após a etapa de pré-tratamento da biomassa}

\subsection{1}

\section{Determinação de lignina residual por Método Klason}

O método Klason para determinação de lignina residual seguiu o procedimento padrão NREL, segundo [76].

Cadinhos filtrantes com placa porosa foram lavados com água destilada e levados para secagem em estufa a $105^{\circ} \mathrm{C}$. A cada $1 \mathrm{~h}$, os cadinhos foram retirados da estufa e levados ao dessecador, até atingir temperatura ambiente. As massas dos cadinhos foram anotadas e o procedimento foi repetido até que se obtivesse massa constante.

Uma alíquota de 300,0 mg de cada amostra seca do bagaço foi colocada em tubos falcon devidamente identificados. Adicionou-se 3,0 mL de $\mathrm{H}_{2} \mathrm{SO}_{4}$ $72 \%(\mathrm{~m} / \mathrm{v})$ em cada tubo. A mistura foi agitada com auxílio de um vortex a cada 5 min até que a biomassa estivesse completamente solubilizada na solução ácida.

Depois de ocorrido o tempo da hidrólise, o conteúdo dos tubos falcon foi transferido para frascos de $500 \mathrm{~mL}$, com a adição de $84 \mathrm{~mL}$ de água destilada, fazendo com que a concentração ácida no meio fosse diluída para $4 \%$ (m/v). As amostras foram levadas para um autoclave, onde permaneceram a $121^{\circ} \mathrm{C}$ e 1,1 bar por 1h. Após a descompressão do autoclave, os frascos foram resfriados até a temperatura ambiente. 
O conteúdo do frasco passou por uma filtração à vácuo, utilizando-se os cadinhos filtrantes com placa porosa previamente pesados. Após essa etapa, os cadinhos foram levados, novamente, para secagem em estufa à $105^{\circ} \mathrm{C}$. A cada 1h, os cadinhos foram retirados da estufa e levados ao dessecador, até atingir temperatura ambiente. As massas dos cadinhos foram anotadas e o procedimento foi repetido até que se obtivesse massa constante.

O teor de lignina residual foi determinado pela diferença da massa do cadinho filtrante de placa porosa seco com a amostra e da massa do cadinho filtrante de placa porosa seco sem a amostra, como mostra a equação 4-2.

$$
\% \text { Lignina }_{\text {residual }}=\frac{M_{2}-M_{1}}{M_{\text {amostra }}}
$$

$M_{1}$ : massa do cadinho filtrante de placa porosa seco vazio, em gramas. $M_{2}$ : massa do cadinho filtrante de placa porosa com lignina, em gramas. $M_{\text {amostra }}$ : massa da amostra de lignina seca, em gramas.

\subsection{2}

\section{Determinação de lignina oxidada a partir de análises de infravermelho.}

A lignina oxidada no bagaço de cana-de-açúcar após o pré-tratamento pode ser estimada a partir de análises de FT-IR (Fourier Transform Infrared Spectroscopy).

Amostras da biomassa após o pré-tratamento foram analisadas em um espectrômetro Bruker. Todos os espectros foram realizados em uma faixa de comprimento de onda de $400 \mathrm{~cm}^{-1}$ a $4000 \mathrm{~cm}^{-1}$. A resolução espectral foi definida em $4 \mathrm{~cm}^{-1}$. As amostras não precisaram passar por nenhuma preparação anterior, sendo diretamente dispostas sobre o leitor óptico do aparelho. Os espectros foram obtidos em duplicata para cada amostra.

A razão entre a absorbância do comprimento de onda característico da ligação do tipo CO $\left(1030 \mathrm{~cm}^{-1}\right)$ e a absorbância do comprimento de onda característica de anéis aromáticos $\left(1420 \mathrm{~cm}^{-1}\right)$ foi calculada para cada amostra de biomassa antes e após o tratamento. Em sequência, foi calculada uma nova razão. Dividiu-se a razão calculada para o bagaço após o pré-tratamento pela razão calculada para o bagaço antes do pré-tratamento, conforme a equação 4-3. Este último valor fornece uma estimativa de quanta lignina foi oxidada na biomassa, conforme [61] e [77].

$$
\text { Lignina }_{\text {oxidada }}=\frac{(C O / \text { Aromático })_{\text {após o tratamento }}}{(C O / \text { Aromático })_{\text {antes do tratamento }}}
$$




\section{6}

\section{Modelagem e Otimização}

Todos os modelos foram desenvolvidos em um computador Windows 10 64 bits, com processador Intel Core i5-5200U CPU 2.2 GHz e memória 8 Gb.

\subsection{1}

\section{Construção de modelos de predição pelo Método dos Mínimos Quadrados}

A Equação 4-4 apresenta a estrutura dos modelos de predição para as respostas dos processos. O software Statistica 7.0 foi utilizado para cálculo dos coeficientes e validação estatística dos modelos.

$y=\beta_{0}+\beta_{1} x_{1}+\beta_{2} x_{2}+\beta_{3} x_{3}+\beta_{12} x_{1} x_{2}+\beta_{13} x_{1} x_{3}+\beta_{23} x_{2} x_{3}+\beta_{11} x_{1}{ }^{2}+\beta_{22} x_{2}{ }^{2}+\beta_{33} x_{3}{ }^{2}$

A variável de saída do modelo y corresponde à resposta do processo avaliada em cada modelo. $x_{1}, x_{2}$ e $x_{3}$ representam as variáveis codificadas para efeitos lineares. $x_{1} x_{2}, x_{1} x_{3}$ e $x_{2} x_{3}$ representam a interação entre as variáveis codificadas. Além disso, os demais termos representam os parâmetros do modelo de regressão, que foram estimados por MMQ.

\subsection{2}

\section{Construção de modelos de predição por Algoritmos Genéticos}

O polinômio apresentado na Equação 4-4 também corresponde aos modelos utilizados para a metodologia com GA. O software Matlab R2018a foi utilizado na busca dos parâmetros otimizados. Todos os parâmetros foram determinados através da minimização da função objetivo, fazendo com que as respostas preditas sejam as mais próximas possíveis dos valores obtidos experimentalmente, conforme visto na equação 4-5.

$$
F_{o b j}=\sum\left(\hat{y}_{i}-y_{i}\right)^{2}
$$

$y_{i}$ : valor observado experimentalmente

$\hat{y}_{i}$ : valor predito pelo modelo

\subsection{3}

\section{Construção de modelos de predição por Redes Neurais Artificiais}

Os modelos neurais para predição das respostas dos processos foram desenvolvidos com o software Matlab R2018a. Para a camada de entrada, foram 
utilizados 3 neurônios referentes às condições experimentais dos processos. Na camada de saída, foi utilizado apenas 1 neurônio, referente à variável que se desejava predizer em cada modelo.

A quantidade de neurônios na camada intermediária está relacionada com a capacidade de convergência da rede. O número de neurônios foi determinado de forma heurística dentro de uma faixa de segurança, o que impossibilitou a ocorrência de underfitting ou overfitting.

Uma boa estratégia é adotar o número mínimo de neurônios na camada intermediária como sendo maior ou igual à quantidade de neurônios utilizada na camada de entrada. O número máximo de neurônios é limitado pelo cálculo do número de parâmetros modificáveis da rede, que não deve ser maior que a quantidade de dados disponíveis para a etapa de treinamento.

Segundo [1], as equações 4-6 e 4-7 podem ser utilizadas para calcular o número de parâmetros modificáveis na rede neural com 1 e 2 camadas, respectivamente.

$$
\begin{gathered}
N_{p}=n_{C I 1} \times\left(n_{E}+n_{S}+1\right)+n_{S} \\
N_{p}=n_{C I 2} \times\left(n_{C I 1}+n_{S}+1\right)+n_{C I 1} \times\left(n_{E}+1\right)+n_{S}
\end{gathered}
$$

$N_{p}$ : Número de parâmetros modificáveis na rede.

$n_{C I 1}$ : Número de neurônios na $1^{\mathrm{O}}$ camada intermediária.

$n_{C I 2}$ : Número de neurônios na $2^{\mathrm{o}}$ camada intermediária.

$n_{E}$ : Número de neurônios na camada de entrada.

$n_{S}$ : Número de neurônios na camada de saída.

As funções de ativação testadas nas camadas intermediárias foram a função logística (logsig) e a função tangente hiperbólica (tansig). Na camada de saída, a função de ativação utilizada foi a função linear (purelin).

Os algoritmos de treinamento aplicados são derivações do algoritmo Backpropagation (traingdx). Dentre as variações mais populares, se destacam o algoritmo Levenberg-Marquardt Backpropagation (trainlm), Bayesian Regularization Backpropagation (trainbr), Conjugate Gradient With Powell-Beale Restarts Backpropagation (traincgb) e One-Step Secant Backpropagation (trainoss).

$\mathrm{Na}$ implementação do trainlm no software Matlab, é calculada uma matriz jacobiana do desempenho com relação aos pesos e bias. Cada variável é ajustada de acordo com o método de Levenberg-Marquardt, onde cada componente do gradiente é ponderada de acordo com a sua curvatura. Dessa 
forma, a convergência na direção de decrescimento do gradiente é acelerada [78]. A Equação 4-8 apresenta o cálculo realizado pelo método.

$$
d X=\frac{-\left(j X^{2}+I \gamma\right)}{j X . e}
$$

$d X$ : direção de busca da função.

$j X$ : matriz jacobiana da performance com relação aos pesos e bias do neurônio X.

$I$ : matriz identidade.

$\gamma$ : parâmetro escalar.

e: erros associados.

É importante observar que quando $\gamma$ é zero, a minimização ocorre de acordo com o método de Newton, utilizando a matriz hessiana na aproximação. Quando $\gamma$ é maior, o método se aproxima do método do gradiente descendente com passo pequeno. Como o método de Newton converge mais rápido, a implementação deste algoritmo tem por objetivo diminuir este parâmetro a cada iteração bem sucedida [79].

O algoritmo trainbr, por sua vez, realiza a regularização bayesiana dentro do algoritmo de Levenberg-Marquardt. Este artifício é utilizado para minimizar uma combinação linear de erros quadrados e pesos, além de modificar essa combinação para que, ao final do treinamento, a rede resultante apresente boa capacidade de generalização [80].

O algoritmo traincgb é implementado segundo o método de PowellBeale, onde a direção de busca é redefinida periodicamente para o negativo do gradiente. Esta redefinição ocorre quando o número de iterações é igual ao número de parâmetros avaliados na função [81]. Os pesos e bias para cada neurônio são ajustados de acordo com a Equação 4-9.

$$
X=X+\gamma \cdot d X
$$

$\gamma$ : parâmetro escalar.

$d X$ : direção de busca da função.

Neste algoritmo, a direção de busca $d X$ é calculada de acordo com a Equação 4-10.

$$
d X=-g X+d X_{\text {prev }} * X_{\text {prev }}
$$


$g X$ : gradiente da função.

$d X_{\text {prev }}$ : direção de busca anterior da função.

$X_{\text {step }}$ : valor dos pesos e bias na iteração anterior.

Por fim, a implementação do algoritmo de treinamento trainoss tem por finalidade preencher a lacuna entre os algoritmos de gradiente conjugado e quasi-Newton. Este algoritmo assume que a matriz hessiana na iteração anterior é a matriz identidade, não sendo necessário o cálculo de inversão de matrizes toda vez que a nova direção de busca for determinada. Por conta disso, este algoritmo requer menos esforço computacional se comparado aos algoritmos que utilizam métodos de gradiente conjugado [82]. Os pesos e bias para cada neurônio também são ajustados de acordo com a Equação 4-9. Entretanto, para este caso, $d X$ é calculado de acordo com a Equação 4-11.

$$
d X=-g X+\gamma_{1} \cdot X_{\text {step }}+\gamma_{2} \cdot g X_{\text {prev }}
$$

$$
\begin{aligned}
& g X: \text { gradiente da função. } \\
& \gamma_{1} \text { e } \gamma_{2} \text { : parâmetros escalares. } \\
& X_{\text {step }} \text { : valores de pesos e bias calculados na iteração anterior. } \\
& g X_{\text {prev }} \text { : valor do gradiente calculado na iteração anterior. }
\end{aligned}
$$

\subsection{4}

\section{Construção de modelos de predição por Neuro-Fuzzy}

Os modelos ANFIS foram desenvolvidos com a Fuzzy Logic Toolbox, aplicação acessada no software Matlab R2018a. Assim como nos modelos neurais, foram utilizados 3 neurônios na camada de entrada referente às condições experimentais dos processos. Na camada de saída, o único neurônio presente é referente à variável que se desejava predizer em cada modelo.

Os modelos ANFIS desenvolvidos foram baseados em subtractive clustering e utilizaram o algoritmo de treinamento híbrido.

\subsection{5}

\section{Validação matemática dos modelos}

Os modelos polinomiais desenvolvidos foram validados estatisticamente através da ANOVA. Por sua vez, os modelos neurais foram validados pelo coeficiente de correlação $\left(\mathrm{R}^{2}\right)$ e índices de erro como SSE (Sum Squared Error), MSE(Mean Squared Error) e RMSE (Root Mean Squared Error). 
As Equações 4-12, 4-13, 4-14 e 4-15 apresentam como são calculados o coeficiente de correlação e os índices de erro, onde $y_{i}$ é o valor observado experimentalmente, $\hat{y}_{i}$ é o valor predito pelo modelo e $\bar{y}$ é o valor médio.

$$
\begin{gathered}
R^{2}=1-\frac{\sum_{i=1}^{n}\left(\hat{y}_{i}-\bar{y}\right)^{2}}{\sum_{i=1}^{n}\left(\hat{y}_{i}-\bar{y}\right)^{2}+\sum_{i=1}^{n}\left(y_{i}-\hat{y}_{i}\right)^{2}} \\
S S E=\sum_{i=1}^{n}\left(y_{i}-\hat{y}_{i}\right)^{2} \\
M S E=\frac{1}{n} \cdot \sum_{i=1}^{n}\left(y_{i}-\hat{y}_{i}\right)^{2} \\
R M S E=\sqrt{\frac{1}{n} \cdot \sum_{i=1}^{n}\left(y_{i}-\hat{y}_{i}\right)^{2}}
\end{gathered}
$$

\subsection{6}

\section{Construção das superfícies de respostas e curvas de contorno}

Para construção das superfícies de respostas e curvas de contorno referentes aos modelos desenvolvidos a partir do processo de pré-tratamento com $\mathrm{H}_{2} \mathrm{O}_{2}$, uma variável por vez foi fixada em seu valor definido no ponto central do planejamento experimental desenvolvido, enquanto as outras variáveis foram variadas de acordo com o intervalo de estudo definido.

Já para o processo de pré-tratamento com $\mathrm{ScCO}_{2}$, uma variável por vez foi fixada no seu valor intermediário com relação aos outros valores utilizados no experimento, enquanto as outras variáveis também foram variadas de acordo com o intervalo investigado neste trabalho. 


\section{Resultados e Discussões}

A seguir, serão apresentados os resultados dos estudos realizados, além dos modelos desenvolvidos.

\section{1}

\section{Análise granulométrica do material lignocelulósico}

Após o tratamento primário de lavagem e secagem, o bagaço da cana-deaçúcar foi triturado. Uma amostra desse bagaço foi submetida a uma análise granulométrica.

O bagaço passou por uma série de peneiras de 10, 12, 32, 35 e 48 mesh. Dessa forma, foi possível calcular as frações mássicas retidas e acumuladas. A correspondência entre o valor de mesh e do tamanho em mm da partícula, é definida de acordo com [83].

A Figura 5.1 relaciona a fração mássica e a fração mássica acumulada em cada peneira com o tamanho médio da partícula.

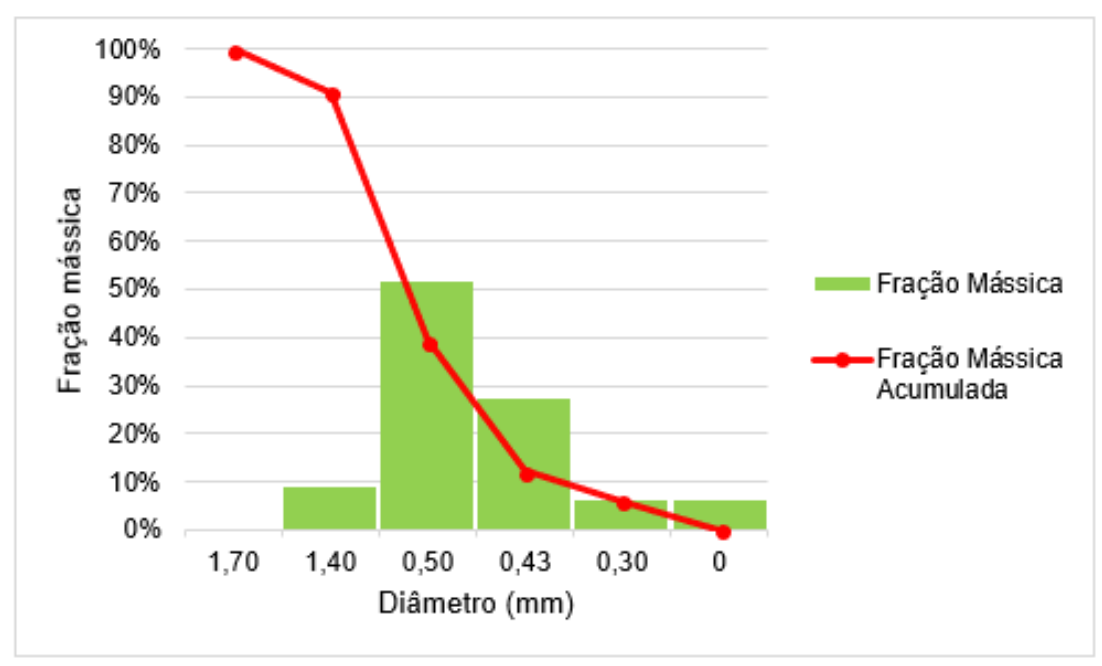

Figura 5.1: Fração mássica e Fração mássica acumulada em função do diâmetro médio de partícula.

A partir dos dados obtidos, é possível observar que há maior predominância de partículas com diâmetro médio de $0,5 \mathrm{~mm}$ na biomassa analisada, valor menor do que o observado nos experimentos reportados em [?] e em 
[48]. A fração mássica acumulada indica que 39,4\% da amostra analisada é composta por partículas de tamanho igual ou menor a esse. Sendo assim, a realização dos experimentos com esse tamanho de partícula pode proporcionar uma maior superfície de contato para o tratamento com $\mathrm{H}_{2} \mathrm{O}_{2}$ no bagaço da cana-de-açúcar.

\section{2}

\section{Análise da composição de lignina no bagaço}

Para fins de comparação, foi determinada a quantidade de lignina presente em uma amostra de bagaço de cana-de-açúcar que não foi submetida a nenhum pré-tratamento.

O valor médio encontrado para o teor de lignina residual foi de 20,45\% $\pm 0,17 \%$, o que está de acordo com os valores entre $20 \%$ e $30 \%$, reportados na literatura.

\section{3}

Determinação de lignina residual por Método Klason

\subsection{1}

\section{No processo de pré-tratamento com $\mathrm{H}_{2} \mathrm{O}_{2}$}

A quantificação da lignina residual foi medida através de um método gravimétrico, no qual o teor de lignina residual foi obtido pela razão entre a massa restante do processo de hidrólise ácida e a massa inicial utilizada na análise.

Os valores dos teores de lignina residual para todas as condições experimentais são mostradas na Tabela 5.1.

Tabela 5.1: Teores de lignina residual nas condições experimentais avaliadas para o processo de deslignização do bagaço com $\mathrm{H}_{2} \mathrm{O}_{2}$.

\begin{tabular}{|c|c|c|c|c|c|c|c|c|}
\hline $\begin{array}{c}\text { Temperatur } \\
\left({ }^{\circ} \mathrm{C}\right)\end{array}$ & $\begin{array}{c}\mathrm{FH}_{2} \mathrm{O}_{2} \\
(\mathrm{~m} / \mathrm{v})\end{array}$ & $\mathrm{pH}$ & $\begin{array}{l}\text { Lignina Residual } \\
\text { (1) }(\%)\end{array}$ & $\begin{array}{c}\text { Lignina Residual } \\
(2)(\%)\end{array}$ & $\begin{array}{c}\text { Lignina Residual } \\
(3)(\%)\end{array}$ & $\begin{array}{c}\text { Lignina Residual } \\
(4)(\%)\end{array}$ & $\begin{array}{l}\text { Lignina Residual } \\
\text { (Média)(\%) }\end{array}$ & $\begin{array}{c}\text { Desvio } \\
\text { Padrão (\%) }\end{array}$ \\
\hline \multicolumn{3}{|c|}{ Não tratado } & 20,57 & 20,33 & - & - & 20,45 & 0,17 \\
\hline 32,1 & 4,6 & 10,6 & 19,67 & 19,60 & 19,03 & 19,17 & 19,37 & 0,31 \\
\hline 52,9 & 4,6 & 10,6 & 20,30 & 21,30 & 21,60 & 22,03 & 21,31 & 0,74 \\
\hline 32,1 & 12,4 & 10,6 & 12,37 & 12,27 & 16,57 & 15,80 & 14,25 & 2,25 \\
\hline 52,9 & 12,4 & 10,6 & 9,83 & 10,37 & 5,47 & 11,07 & 9,18 & 2,53 \\
\hline 32,1 & 4,6 & 12,4 & 11,40 & 16,67 & 10,63 & 10,40 & 12,27 & 2,96 \\
\hline 52,9 & 4,6 & 12,4 & 6,80 & 6,27 & 7,83 & 8,27 & 7,29 & 0,92 \\
\hline 32,1 & 12,4 & 12,4 & 10,03 & 8,17 & 11,70 & 7,33 & 9,31 & 1,95 \\
\hline 52,9 & 12,4 & 12,4 & 7,70 & 7,67 & 7,40 & 7,37 & 7,53 & 0,17 \\
\hline 25,0 & 8,5 & 11,5 & 10,47 & 11,17 & 11,03 & 10,13 & 10,70 & 0,48 \\
\hline 60,0 & 8,5 & 11,5 & 7,37 & 7,10 & 5,70 & 4,37 & 6,13 & 1,39 \\
\hline 42,5 & 2,0 & 11,5 & 20,27 & 19,23 & 18,67 & 17,77 & 18,98 & 1,05 \\
\hline 42,5 & 15,0 & 11,5 & 7,83 & 7,47 & 8,00 & 5,57 & 7,22 & 1,12 \\
\hline 42,5 & 8,5 & 10,0 & 17,97 & 18,63 & 17,00 & 15,23 & 17,21 & 1,48 \\
\hline 42,5 & 8,5 & 13,0 & 8,37 & 6,53 & 9,03 & 8,43 & 8,09 & 1,08 \\
\hline 42,5 & 8,5 & 11,5 & 10,33 & 9,53 & 5,87 & 4,83 & 7,64 & 2,70 \\
\hline 42,5 & 8,5 & 11,5 & 11,23 & 10,73 & 10,77 & 10,07 & 10,70 & 0,48 \\
\hline 42,5 & 8,5 & 11,5 & 12,17 & 8,83 & 8,33 & 7,80 & 9,28 & 1,97 \\
\hline
\end{tabular}


No ensaio realizado à $52,9^{\circ} \mathrm{C}, 4,6 \%$ de $\mathrm{H}_{2} \mathrm{O}_{2} \mathrm{e} \mathrm{pH}$ de 10,6 , o valor médio apresentado para o teor de lignina residual é maior que o obtido para a amostra que não foi submetida a nenhum processo. No entanto, o valor aferido na análise se encontra dentro dos limites quando o desvio padrão é considerado. Dessa forma, considera-se que esta condição experimental foi a única que não se mostrou satisfatória para extração de lignina da biomassa.

Os valores apresentados na Tabela 5.1 mostram que, para uma mesma temperatura, quanto maior o valor de concentração de $\mathrm{H}_{2} \mathrm{O}_{2}$ ou maior o valor de $\mathrm{pH}$ no experimento, menor é o teor de lignina residual na biomassa. Contudo, a literatura relata que o aumento da concentração de $\mathrm{H}_{2} \mathrm{O}_{2}$ não necessariamente proporciona maior poder de extração de lignina ao processo. Frações de hemicelulose também podem estar sendo solubilizadas, o que não é interessante para o ponto de vista dos processos posteriores como hidrólise e fermentação [?] [35].

Em [84] e em [85] foi relatado que no pré-tratamento com $\mathrm{H}_{2} \mathrm{O}_{2}$ à temperatura de $30^{\circ} \mathrm{C}$ e concentração de $2 \%$ durante 8 h, foi alcançada remoção de cerca de 50\% e 60\% de lignina na biomassa, respectivamente. Entretanto, em concordância com [36], a utilização de maiores temperaturas, quando associada à valores mais elevados para concentração de $\mathrm{H}_{2} \mathrm{O}_{2}$ ou $\mathrm{pH}$, favorece a retirada de lignina da biomassa.

\subsection{2}

\section{No processo de pré-tratamento com $\mathrm{ScCO}_{2}$}

Analogamente ao conteúdo mostrado na seção 5.3.1, os teores de lignina residual obtidos para todas as condições experimentais do pré-tratamento com $\mathrm{ScCO}_{2}$ são apresentados na Tabela 5.2.

Tabela 5.2: Teores de lignina residual nas condições experimentais avaliadas para o processo de deslignização do bagaço com $\mathrm{ScCO}_{2}$.

\begin{tabular}{|c|c|c|c|c|c|c|}
\hline $\begin{array}{c}\text { Temperatura } \\
\left({ }^{\circ} \mathrm{C}\right)\end{array}$ & $\begin{array}{l}\text { Pressão } \\
\text { (bar) }\end{array}$ & $\begin{array}{c}\text { Teor de } \\
\text { etanol }(\%)\end{array}$ & $\begin{array}{c}\text { Lignina Residual } \\
\text { (1) }(\%)\end{array}$ & $\begin{array}{c}\text { Lignina ResidualLig } \\
(2)(\%)\end{array}$ & $\begin{array}{l}\text { ignina Residua } \\
\text { (Média)(\%) }\end{array}$ & $\begin{array}{c}\text { Desvio } \\
\text { Padrão }(\%)\end{array}$ \\
\hline & Nâo tratado & & 20,57 & 20,33 & 20,45 & 0,17 \\
\hline 74 & 190 & 50 & 19,03 & 18,23 & 18,63 & 0,57 \\
\hline 35 & 300 & 100 & 18,23 & 17,40 & 17,82 & 0,59 \\
\hline 91 & 75 & 100 & 16,20 & 14,93 & 15,57 & 0,90 \\
\hline 100 & 190 & 0 & 19,13 & 18,13 & 18,63 & 0,71 \\
\hline 84 & 180 & 50 & 14,80 & 15,13 & 14,97 & 0,24 \\
\hline 47 & 75 & 0 & 15,40 & 14,53 & 14,97 & 0,61 \\
\hline 105 & 75 & 0 & 18,73 & 21,90 & 20,32 & 2,24 \\
\hline 100 & 300 & 100 & 12,43 & 11,90 & 12,17 & 0,38 \\
\hline 47 & 75 & 100 & 17,70 & 17,80 & 17,75 & 0,07 \\
\hline 35 & 300 & 0 & 17,63 & 18,40 & 18,02 & 0,54 \\
\hline 77 & 190 & 50 & 18,97 & 18,93 & 18,95 & 0,02 \\
\hline
\end{tabular}


Em [86], é mencionado que os pré-tratamentos físicos apresentam menor eficiência no aumento da digestibilidade da biomassa, se comparados com os pré-tratamentos químicos. Os processos aqui estudados não foram avaliados na mesma escala e nas mesmas faixas de temperatura e, portanto, esse relato não pôde ser confirmado. No entanto, ao que tudo indica, os intervalos determinados para as variáveis estudadas não foram ideais para se atingir a minimização do teor de lignina residual no material. Neste trabalho, a condição experimental que apresenta menor teor de lignina residual é o ensaio realizado à $100^{\circ} \mathrm{C}, 300$ bar e $100 \%$ de etanol na solução co-solvente.

\section{4}

\section{Determinação de lignina oxidada por FT-IR}

A estimativa da quantidade de lignina oxidada foi feita através de análises de FT-IR, no qual o teor de lignina oxidada foi obtido pela razão entre comprimentos de onda característicos de estruturas presentes na lignina.

\subsection{1}

\section{No processo de pré-tratamento com $\mathrm{H}_{2} \mathrm{O}_{2}$}

Os valores dos teores de lignina oxidada para todas as condições experimentais do pré-tratamento com $\mathrm{H}_{2} \mathrm{O}_{2}$ são apresentadas na Tabela 5.3.

Tabela 5.3: Teores de lignina oxidada nas condições experimentais avaliadas para o processo de deslignização do bagaço com $\mathrm{H}_{2} \mathrm{O}_{2}$.

\begin{tabular}{|c|c|c|c|c|c|c|c|c|c|c|c|c|}
\hline \multirow[b]{2}{*}{$\begin{array}{c}\text { Temperatura } \\
\left({ }^{\circ} \mathrm{C}\right)\end{array}$} & \multirow[b]{2}{*}{$\begin{array}{c}\% \mathrm{H}_{2} \mathrm{O}_{2} \\
(\mathrm{~m} / \mathrm{v})\end{array}$} & \multirow[b]{2}{*}{$\mathrm{pH}$} & \multicolumn{2}{|c|}{ Amostra (1) } & \multicolumn{2}{|c|}{ Amostra (2) } & \multicolumn{2}{|c|}{ Amostra (3) } & \multicolumn{2}{|c|}{ Amostra (4) } & \multirow[b]{2}{*}{ Razão Média } & \multirow[b]{2}{*}{$\begin{array}{c}\text { Lignina } \\
\text { Oxidada (\% }\end{array}$} \\
\hline & & & $1420 \mathrm{~cm}^{-1}$ & $1030 \mathrm{~cm}^{-1}$ & $1420 \mathrm{~cm}^{-1}$ & $1030 \mathrm{~cm}^{-1}$ & $1420 \mathrm{~cm}^{-1}$ & $1030 \mathrm{~cm}^{-1}$ & $1420 \mathrm{~cm}^{-1}$ & $1030 \mathrm{~cm}^{-1}$ & & \\
\hline \multicolumn{3}{|c|}{ Não tratado } & 0,02937 & 0,1494 & \multicolumn{2}{|c|}{-} & \multicolumn{2}{|c|}{ - } & \multicolumn{2}{|c|}{ - } & 5,08682 & - \\
\hline 32,1 & 4,6 & 10,6 & 0,02194 & 0,11650 & 0,02229 & 0,11757 & 0,02265 & 0,11123 & 0,02260 & 0,11157 & 5,10801 & 100,42 \\
\hline 25 & 8,5 & 11,5 & 0,02022 & 0,10872 & 0,02065 & 0,11124 & 0,02061 & 0,11770 & 0,02105 & 0,11954 & 5,53836 & 108,88 \\
\hline 32,1 & 12,4 & 10,6 & 0,02568 & 0,13600 & 0,02611 & 0,13883 & 0,01324 & 0,08879 & 0,01356 & 0,09128 & 6,01271 & 118,20 \\
\hline 32,1 & 4,6 & 12,4 & 0,03537 & 0,21729 & 0,03603 & 0,22148 & 0,02207 & 0,11852 & 0,02264 & 0,12144 & 5,75615 & 113,16 \\
\hline 32,1 & 12,4 & 12,4 & 0,02457 & 0,12275 & 0,02492 & 0,12458 & 0,02254 & 0,10940 & 0,02289 & 0,11182 & 4,93346 & 96,99 \\
\hline 42,5 & 2 & 11,5 & 0,02016 & 0,10465 & 0,03921 & 0,20267 & 0,03952 & 0,20562 & 0,03421 & 0,16499 & 5,19066 & 102,04 \\
\hline 42,5 & 15 & 11,5 & 0,03421 & 0,16499 & 0,03440 & 0,16727 & 0,02573 & 0,14296 & 0,02614 & 0,14577 & 5,20451 & 102,31 \\
\hline 42,5 & 8,5 & 10 & 0,02792 & 0,12051 & 0,02867 & 0,12364 & 0,03350 & 0,15435 & 0,03394 & 0,15515 & 4,45189 & 87,52 \\
\hline 42,5 & 8,5 & 13 & 0,03149 & 0,17359 & 0,03214 & 0,17754 & 0,00995 & 0,05976 & 0,01032 & 0,06077 & 5,73277 & 112,70 \\
\hline 42,5 & 8,5 & 11,5 & 0,03203 & 0,18161 & 0,03263 & 0,18453 & 0,04543 & 0,23356 & 0,04596 & 0,23647 & 5,40286 & 106,21 \\
\hline 42,5 & 8,5 & 11,5 & 0,01428 & 0,08101 & 0,02574 & 0,12751 & 0,03277 & 0,17867 & 0,03355 & 0,18232 & 5,37831 & 105,73 \\
\hline 42,5 & 8,5 & 11,5 & 0,02537 & 0,14877 & 0,02591 & 0,15031 & 0,03900 & 0,18344 & 0,03900 & 0,18344 & 5,26811 & 103,56 \\
\hline 52,9 & 4,6 & 10,6 & 0,04046 & 0,19770 & 0,04122 & 0,20105 & 0,02223 & 0,10378 & 0,02229 & 0,10486 & 4,78415 & 94,05 \\
\hline 52,9 & 12,4 & 10,6 & 0,03620 & 0,19987 & 0,03677 & 0,20243 & 0,02840 & 0,16070 & 0,02909 & 0,16443 & 5,58437 & 109,78 \\
\hline 52,9 & 4,6 & 12,4 & 0,04872 & 0,27749 & 0,05054 & 0,28350 & 0,03184 & 0,18376 & 0,03240 & 0,18712 & 5,71292 & 112,31 \\
\hline 52,9 & 12,4 & 12,4 & 0,03986 & 0,21425 & 0,04054 & 0,21817 & 0,03629 & 0,17412 & 0,03691 & 0,17723 & 5,08909 & 100,04 \\
\hline 60 & 8,5 & 11,5 & 0,01371 & 0,09597 & 0,01420 & 0,09818 & 0,01371 & 0,09597 & 0,01420 & 0,09818 & 6,95704 & 136,77 \\
\hline
\end{tabular}

A razão entre as absorbâncias deveria ter sido maior na amostra de bagaço antes do pré-tratamento, o que não aconteceu com relação à todas as condições experimentais. No entanto, é adequado que o valor de absorbância no comprimento de onda de $1030 \mathrm{~cm}^{-1}$ seja maior que o valor de absorbância no comprimento de onda de $1420 \mathrm{~cm}^{-1}$, já que a quantidade de ligações do tipo CO existe em maior quantidade na estrutura da biomassa se comparada à quantidade das estruturas aromáticas, presentes somente à lignina [61]. 
Com a oxidação da biomassa, a tendência da absorbância no comprimento de onda de $1030 \mathrm{~cm}^{-1}$ é diminuir, já que a quantidade de ligações CO diminui. Neste trabalho, isso não foi observado para todas as condições experimentais analisadas.

Os resultados obtidos não são confiáveis por não apresentarem sentido físico quanto à oxidação da biomassa. Sendo assim, não é coerente que sejam desenvolvidos modelos de predição a partir deles. Acredita-se que a metodologia da análise de FT-IR sem o prévio preparo da amostra não foi a estratégia ideal a ser adotada. O bagaço da cana-de-açúcar estudado se apresentou difícil de ser triturado e, ao ser colocado sobre o leitor óptico do equipamento, pode não ter sido bem posicionado, ocasionando leituras equivocadas. Uma estratégia alternativa ao uso desse equipamento de leitura direta pode ser o uso do equipamento com análise de FT-IR através da confecção de pastilhas com KBr.

\section{4 .2}

\section{No processo de pré-tratamento com $\mathrm{ScCO}_{2}$}

Analogamente ao conteúdo mostrado na seção 5.4.1, os teores de lignina oxidada obtidos para todas as condições experimentais do pré-tratamento com $\mathrm{ScCO}_{2}$ estão apresentados na Tabela 5.4.

Tabela 5.4: Teores de lignina oxidada em todas as condições experimentais avaliadas para o processo de deslignização do bagaço com $\mathrm{ScCO}_{2}$.

\begin{tabular}{|c|c|c|c|c|c|c|c|c|}
\hline & & & \multicolumn{2}{|c|}{ Amostra (1) } & \multicolumn{2}{|c|}{ Amostra (2) } & \multirow[b]{2}{*}{ Razão Média } & \multirow[b]{2}{*}{$\begin{array}{c}\text { Lignina } \\
\text { Oxidada }(\%)\end{array}$} \\
\hline $\begin{array}{c}\text { Temperatura } \\
\left({ }^{\circ} \mathrm{C}\right)\end{array}$ & $\begin{array}{l}\text { Pressão } \\
\text { (bar) }\end{array}$ & $\begin{array}{c}\text { Teor de } \\
\text { etanol }(\%)\end{array}$ & $1420 \mathrm{~cm}^{-1}$ & $1030 \mathrm{~cm}^{-1}$ & $1420 \mathrm{~cm}^{-1}$ & $1030 \mathrm{~cm}^{-1}$ & & \\
\hline \multicolumn{3}{|c|}{ Não tratado } & 0,02937 & 0,1494 & \multicolumn{2}{|c|}{-} & 5,08682 & - \\
\hline 74 & 190 & 50 & 0,06343 & 0,25009 & 0,06154 & 0,25362 & 4,03200 & 79,26 \\
\hline 35 & 300 & 100 & 0,00904 & 0,05432 & 0,00963 & 0,05459 & 5,83880 & 114,78 \\
\hline 91 & 75 & 100 & 0,03133 & 0,10978 & 0,03227 & 0,11059 & 3,46551 & 68,13 \\
\hline 100 & 190 & 0 & 0,04274 & 0,17829 & 0,04327 & 0,17914 & 4,15578 & 81,70 \\
\hline 84 & 180 & 50 & 0,06570 & 0,15892 & 0,06623 & 0,16242 & 2,43562 & 47,88 \\
\hline 47 & 75 & 0 & 0,03438 & 0,10066 & 0,03496 & 0,10162 & 2,91731 & 57,35 \\
\hline 105 & 75 & 0 & 0,04102 & 0,15398 & 0,04222 & 0,15509 & 3,71358 & 73,00 \\
\hline 100 & 300 & 100 & 0,07778 & 0,25723 & 0,07548 & 0,25982 & 3,37469 & 66,34 \\
\hline 47 & 75 & 100 & 0,03399 & 0,11410 & 0,03487 & 0,11477 & 3,32412 & 65,35 \\
\hline 35 & 300 & 0 & 0,05001 & 0,16585 & 0,05144 & 0,16955 & 3,30620 & 65,00 \\
\hline 77 & 190 & 50 & 0,03780 & 0,18182 & 0,03885 & 0,18334 & 4,76461 & 93,67 \\
\hline
\end{tabular}

Assim como na avaliação dos resultados de lignina oxidada no processo de pré-tratamento com $\mathrm{H}_{2} \mathrm{O}_{2}$, é possível observar que as absorbâncias para o comprimento de onda $1030 \mathrm{~cm}^{-1}$ são maiores que as absorbâncias para o comprimento de onda de $1420 \mathrm{~cm}^{-1}$ em todos os ensaios. No entanto, esperava-se a diminuição dessas absorbâncias com relação aos valores obtidos na amostra de bagaço de cana-de-açúcar antes do pré-tratamento. Dessa forma, 
os resultados obtidos também não serão utilizados para o desenvolvimento de modelos de predição de lignina oxidada, pela mesma justificativa apresentada anteriormente.

\section{5}

\section{Contrução dos Modelos}

Os modelos foram desenvolvidos após realização das análises do método Klason, onde a variável a ser predita foi o teor de lignina residual na biomassa.

\subsection{1}

No processo de pré-tratamento com $\mathrm{H}_{2} \mathrm{O}_{2}$

\subsubsection{1}

\section{Predição do teor de lignina residual por Mínimos Quadrados}

O software Statistica 7.0 foi utilizado no cálculo dos coeficientes de regressão do modelo quadrático desenvolvido. A Equação 5-1 apresenta o modelo com $95 \%$ de confiança para predição de lignina residual obtido a partir do estudo das variáveis temperatura $\left(x_{1}\right)$, concentração de $\mathrm{H}_{2} \mathrm{O}_{2}\left(x_{2}\right)$ e $\mathrm{pH}$ $\left(x_{3}\right)$.

$$
\begin{array}{r}
y=330,3798+0,5794 x_{1}-8,0189 x_{2}-47,5571 x_{3}-0,0117 x_{1} x_{2}-0,0485 x_{1} x_{3} \\
+0,5170 x_{2} x_{3}-0,0005 x_{1}{ }^{2}+0,1072 x_{2}{ }^{2}+1,8134 x_{3}{ }^{2}
\end{array}
$$

O efeito das variáveis estudadas sobre a resposta de interesse é apresentado na Tabela 5.5, juntamente com a inferência sobre a média da população realizada a partir do teste $t$ de Student. 
Tabela 5.5: Cálculo de efeito das variáveis sobre a predição do teor de lignina residual por MMQ no processo de pré-tratamento com $\mathrm{H}_{2} \mathrm{O}_{2}$.

\begin{tabular}{ccccccc} 
& & & & & \multicolumn{2}{c}{ Estimativas por Intervalo (95\%) } \\
\cline { 6 - 7 } Fatores & Efeitos & Erro Padrão & $\mathbf{t}(\mathbf{7})$ & $\mathbf{p}$-valor & Limite Inferior & Limite Superior \\
\hline Média & 9,132 & 1,112 & 8,209 & $\mathbf{0 , 0 0 0 1}$ & 6,502 & 11,763 \\
$x_{1}$ & $-2,572$ & 1,045 & $-2,460$ & $\mathbf{0 , 0 4 3 5}$ & $-5,044$ & $-0,099$ \\
$x_{1}^{2}$ & $-0,116$ & 1,147 & $-0,101$ & 0,9225 & $-2,829$ & 2,597 \\
$x_{2}$ & $-5,839$ & 1,050 & $-5,563$ & $\mathbf{0 , 0 0 0 8}$ & $-8,321$ & $-3,357$ \\
$x_{2}^{2}$ & 3,262 & 1,166 & 2,798 & $\mathbf{0 , 0 2 6 6}$ & 0,505 & 6,019 \\
$x_{3}$ & $-6,329$ & 1,050 & $-6,030$ & $\mathbf{0 , 0 0 0 5}$ & $-8,811$ & $-3,847$ \\
$x_{3}^{2}$ & 2,938 & 1,166 & 2,520 & $\mathbf{0 , 0 3 9 8}$ & 0,181 & 5,695 \\
$x_{1} x_{2}$ & $-0,950$ & 1,366 & $-0,695$ & 0,5093 & $-4,181$ & 2,281 \\
$x_{1} x_{2}$ & $-0,908$ & 1,366 & $-0,665$ & 0,5275 & $-4,139$ & 2,322 \\
$x_{2} x_{3}$ & 3,629 & 1,366 & 2,656 & $\mathbf{0 , 0 3 2 6}$ & 0,398 & 6,860 \\
\hline
\end{tabular}

Como o modelo foi construído considerando-se $95 \%$ de confiança, seu nível de significância é $\alpha=0,05$. Dessa forma, se o $p$-valor de alguma variável se apresentar maior do que $\alpha$, essa variável é dita como não significativa para o modelo. Outra forma de se avaliar o grau de significância estatística das variáveis para o modelo é através do Diagrama de Pareto, apresentado na Figura 5.2. Por essa análise, observa-se que os termos de interação entre temperatura e concentração de $\mathrm{H}_{2} \mathrm{O}_{2}\left(x_{1} x_{2}\right)$ e entre temperatura e $\mathrm{pH}\left(x_{1} x_{3}\right)$, além do termo quadrático da temperatura $\left(x_{1}^{2}\right)$, não são significativos para predição do teor de lignina residual no processo. 


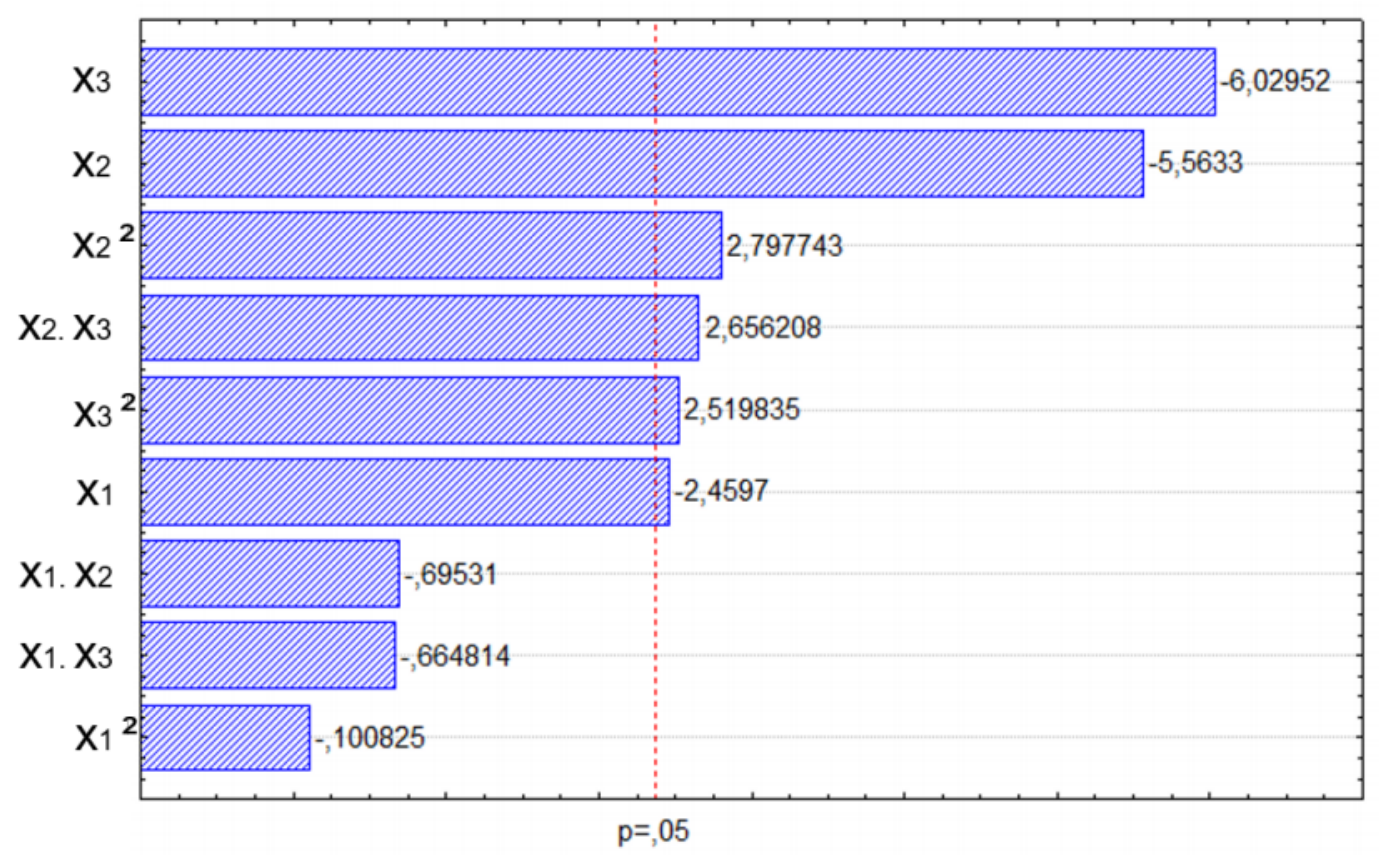

Figura 5.2: Diagrama de Pareto do modelo para predição de lignina residual no processo de pré-tratamento com $\mathrm{H}_{2} \mathrm{O}_{2}$.

Por não serem significativos para o modelo de predição desenvolvido, esses termos poderiam ser incorporados aos resíduos. No entanto, para que seja possível realizar a comparação deste modelo polinomial com o modelo polinomial obtido por GA, opta-se por avaliar o modelo em sua forma completa.

A Tabela 5.6 apresenta os teores médios de lignina residual no prétratamento com $\mathrm{H}_{2} \mathrm{O}_{2}$ obtidos experimentalmente e os valores preditos pelo modelo desenvolvido por MMQ. Vale ressaltar que os dados são próximos, o que indica a boa capacidade de predição do modelo.

A Tabela 5.7 apresenta a ANOVA construída para validação matemática. O Teste $F$ foi a ferramenta utilizada para verificar a adequabilidade do modelo de predição do teor de lignina residual no pré-tratamento com $\mathrm{H}_{2} \mathrm{O}_{2}$.

Considerando-se 9 graus de liberdade para os termos da regressão e 7 graus de liberdade para os resíduos, o valor de $F_{\text {tabelado }}$ para o nível de significância em $5 \%$ é de 3,68 . 
Tabela 5.6: Comparação entre os teores médios de lignina residual obtidos experimentalmente e preditos pelo modelo por MMQ para o pré-tratamento com

$$
\mathrm{H}_{2} \mathrm{O}_{2} \text {. }
$$

\begin{tabular}{|c|c|c|c|c|}
\hline $\begin{array}{c}\text { Temperatur } \\
\left({ }^{\circ} \mathrm{C}\right)\end{array}$ & $\begin{array}{c}\% \mathrm{H}_{2} \mathrm{O}_{2} \\
(\mathrm{~m} / \mathrm{v})\end{array}$ & $\mathrm{pH}$ & $\begin{array}{l}\text { Lignina Residual } \\
\text { Experimental(\%) }\end{array}$ & $\begin{array}{c}\text { Lignina Residual } \\
\text { Predita }(\%)\end{array}$ \\
\hline 32,1 & 4,6 & 10,6 & $19,37 \pm 0,31$ & 20,47 \\
\hline 52,9 & 4,6 & 10,6 & $21,31 \pm 0,74$ & 19,83 \\
\hline 32,1 & 12,4 & 10,6 & $14,25 \pm 2,25$ & 11,96 \\
\hline 52,9 & 12,4 & 10,6 & $9,18 \pm 2,53$ & 9,41 \\
\hline 32,1 & 4,6 & 12,4 & $12,27 \pm 2,96$ & 11,42 \\
\hline 52,9 & 4,6 & 12,4 & $7,29 \pm 0,92$ & 8,96 \\
\hline 32,1 & 12,4 & 12,4 & $9,31 \pm 1,95$ & 10,16 \\
\hline 52,9 & 12,4 & 12,4 & $7,53 \pm 0,17$ & 5,81 \\
\hline 25,0 & 8,5 & 11,5 & $10,70 \pm 0,48$ & 11,16 \\
\hline 60,0 & 8,5 & 11,5 & $6,13 \pm 1,39$ & 6,95 \\
\hline 42,5 & 2,0 & 11,5 & $18,98 \pm 1,05$ & 18,60 \\
\hline 42,5 & 15,0 & 11,5 & $7,22 \pm 1,12$ & 8,87 \\
\hline 42,5 & 8,5 & 10,0 & $17,21 \pm 1,48$ & 18,56 \\
\hline 42,5 & 8,5 & 13,0 & $8,09 \pm 1,08$ & 8,01 \\
\hline 42,5 & 8,5 & 11,5 & $7,64 \pm 2,70$ & 9,21 \\
\hline 42,5 & 8,5 & 11,5 & $10,70 \pm 0,48$ & 9,21 \\
\hline 42,5 & 8,5 & 11,5 & $9,28 \pm 1,97$ & 9,21 \\
\hline
\end{tabular}

Tabela 5.7: ANOVA para o modelo de predição de lignina residual por MMQ no pré-tratamento com $\mathrm{H}_{2} \mathrm{O}_{2}$.

\begin{tabular}{cccccc}
\hline \multirow{2}{*}{ Fontes de Variação } & $\begin{array}{c}\text { Soma dos } \\
\text { Quadrados }\end{array}$ & $\begin{array}{c}\text { Graus de } \\
\text { Liberdade }\end{array}$ & $\begin{array}{c}\text { Quadrados } \\
\text { Médios }\end{array}$ & $\mathbf{F}_{\text {calculado }}$ & F $_{\text {tabelado }}$ \\
\hline Regressão & 350,78 & 9 & 38,98 & & \\
Resíduos & 26,25 & 7 & 3,75 & 10,4 & 3,68 \\
Total & 377,03 & 16 & & & \\
\hline
\end{tabular}

Pela ANOVA, observa-se que o valor de $F_{\text {calculado }}$ igual a 10,4 é maior que o valor de $F_{\text {tabelado já determinado. Esse fato confirma que a regressão }}$ foi significativa e o modelo pode ser utilizado para análise preditiva. O $\mathrm{R}^{2}$ apresentado fornece uma medida da proporção da variação explicada pelo modelo em relação à variação total das respostas e, para esse caso, a porcentagem da variação explicada pelo modelo é de 93,04\%. 
As superfícies de respostas e curvas de contorno estão apresentadas nas Figuras 5.3, 5.4 e 5.5.
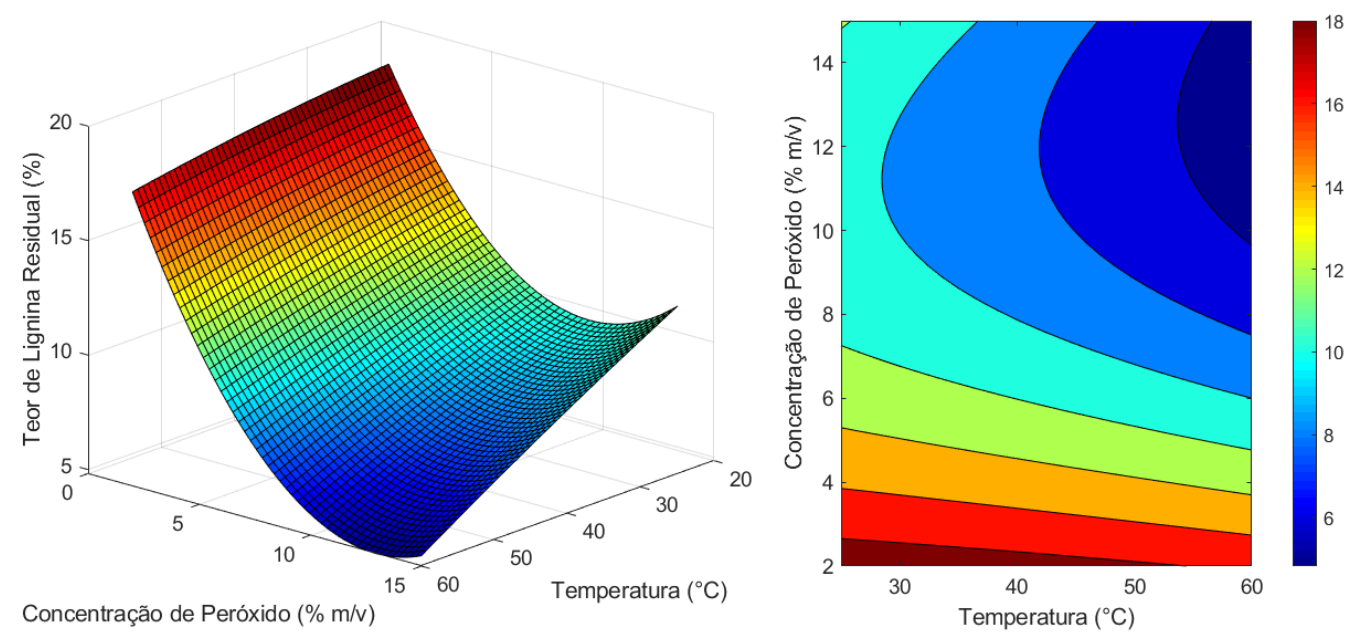

Figura 5.3: Superfície de resposta e curva de contorno da interação entre as variáveis temperatura e concentração de peróxido para o modelo de predição por MMQ do teor de lignina residual após pré-tratamento com $\mathrm{H}_{2} \mathrm{O}_{2}$.

Da Figura 5.3, é possível observar que a diminuição do valor da concentração de $\mathrm{H}_{2} \mathrm{O}_{2}$ no experimento leva ao maior teor de lignina residual na biomassa. Para valores mais altos de temperatura, a utilização de $8 \%$ de $\mathrm{H}_{2} \mathrm{O}_{2}$ começa a se mostrar satisfatória para a minimização do teor de lignina residual. A tendência de formação do vale que indica as condições ótimas para as variáveis estudadas no processo de pré-tratamento é observada para temperaturas acima de $30^{\circ} \mathrm{C}$ e concentração acima de $10 \%$.

Da mesma forma, a Figura 5.4 apresenta a interação entre as variáveis temperatura e $\mathrm{pH}$. 

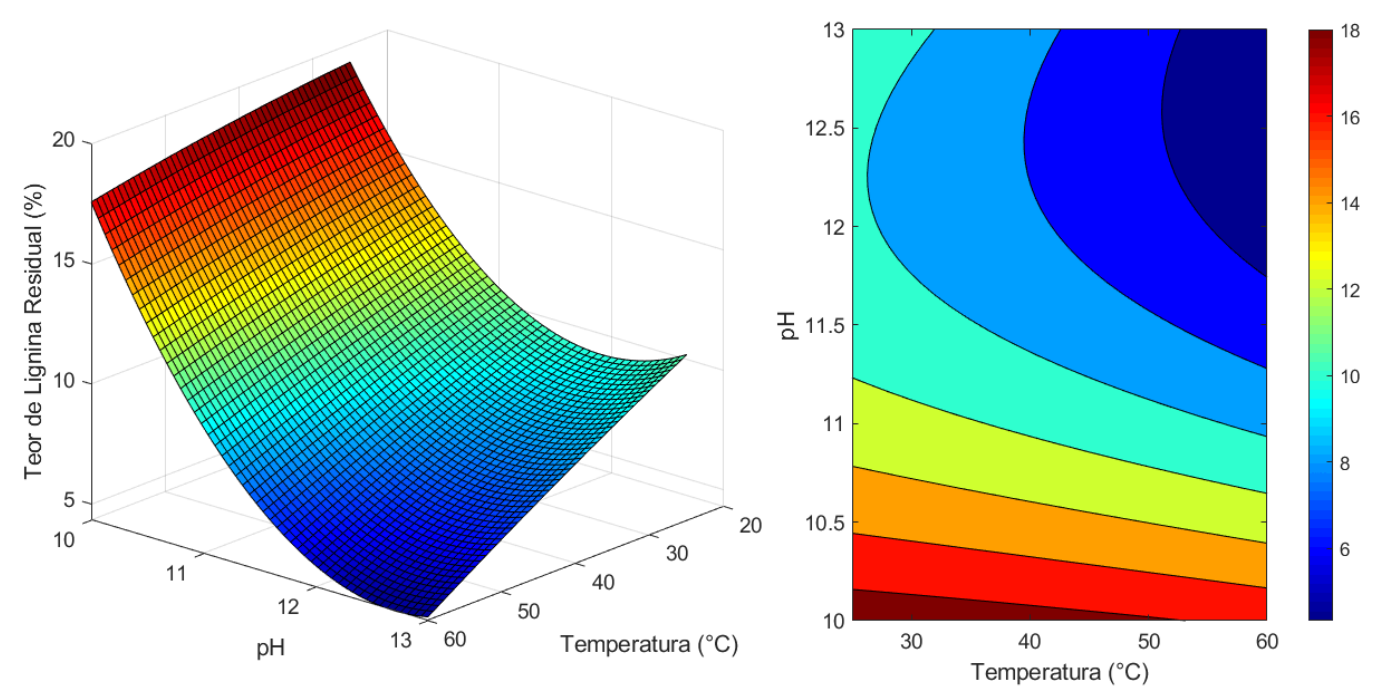

Figura 5.4: Superfície de resposta e curva de contorno da interação entre as variáveis temperatura e $\mathrm{pH}$ para o modelo de predição por MMQ do teor de lignina residual após pré-tratamento com $\mathrm{H}_{2} \mathrm{O}_{2}$.

De acordo com a superfície, a utilização dos menores valores de $\mathrm{pH}$ levam ao aumento do teor de lignina residual no processo, independente da temperatura utilizada. O ponto que indica a minimização da resposta do processo é observado a partir da temperatura de $35^{\circ} \mathrm{C}$ e pH a partir de 11,5 .

A Figura 5.5 mostra a interação entre as variáveis concentração de $\mathrm{H}_{2} \mathrm{O}_{2}$ e $\mathrm{pH}$.
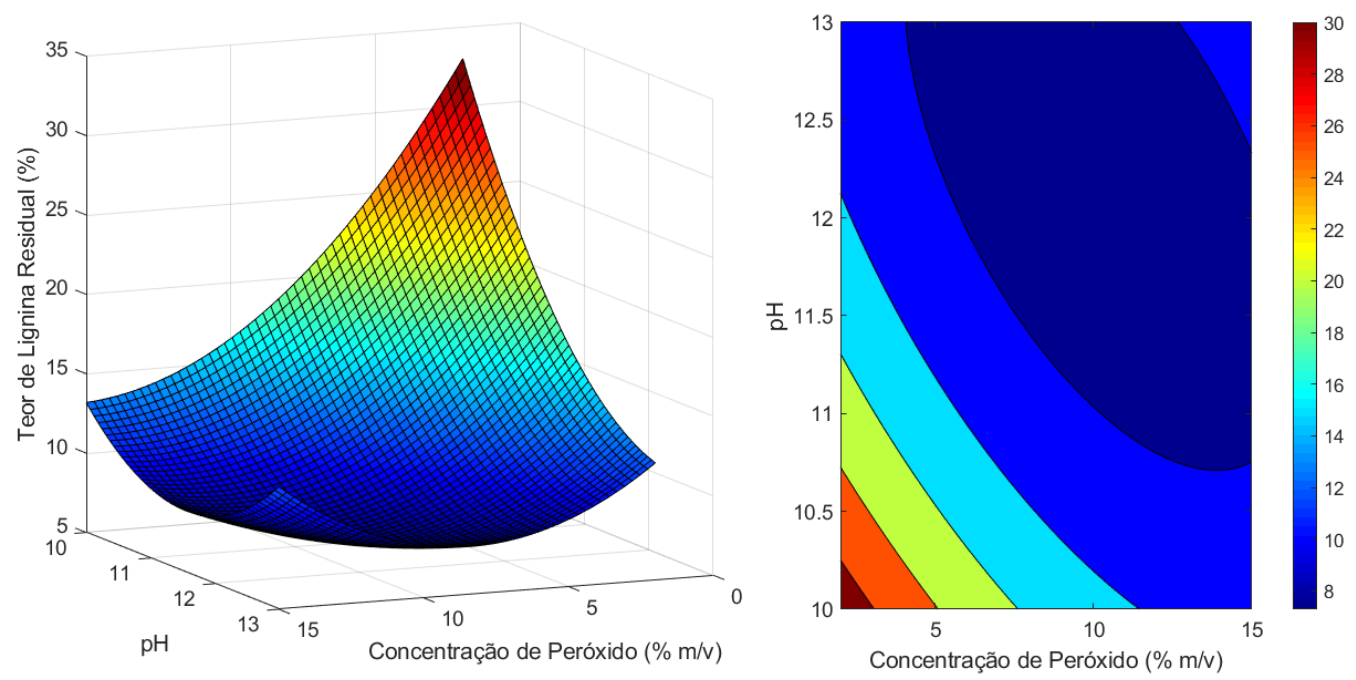

Figura 5.5: Superfície de resposta e curva de contorno da interação entre as variáveis concentração de peróxido e pH para o modelo de predição por MMQ do teor de lignina residual após pré-tratamento com $\mathrm{H}_{2} \mathrm{O}_{2}$. 
Neste caso, é possível observar a formação de um vale bem definido indicando que, para minimizar o teor de lignina residual, podem ser utilizados valores de $\mathrm{pH}$ entre 11 e 13, aproximadamente, dependendo do valor de concentração a ser empregado.

Segundo [5], o valor ótimo para a variável pH no processo de prétratamento do bagaço da cana-de-açúcar com $\mathrm{H}_{2} \mathrm{O}_{2}$ é de 11,5. Sendo assim, de acordo com a Figura 5.5 e tendo como base a informação da literatura, a utilização da concentração de $8 \%$ de $\mathrm{H}_{2} \mathrm{O}_{2}$ é suficiente para que o teor de lignina residual no processo seja minimizado.

Em [5], foi recomendada, para essa condição otimizada de pH, a utilização de $7 \%$ de $\mathrm{H}_{2} \mathrm{O}_{2}$ no processo, valor próximo ao encontrado neste trabalho.

Tendo sido definidos os valores ótimos das variáveis concentração e pH, analisou-se novamente a superfície apresentada na Figura 5.3. A partir da concentração de $\mathrm{H}_{2} \mathrm{O}_{2}$ pré-determinada, é possível observar que a temperatura mais adequada para a minimização do teor de lignina residual no processo é a de $60^{\circ} \mathrm{C}$.

\subsubsection{2}

\section{Predição do teor de lignina residual por GA}

Algoritmos Genéticos foram utilizados na busca dos valores otimizados dos parâmetros do modelo quadrático para predição do teor de lignina residual no processo de pré-tratamento com $\mathrm{H}_{2} \mathrm{O}_{2}$, apresentado na Equação 5-2.

$$
\begin{array}{r}
y=329,7001+0,782 x_{1}-7,8805 x_{2}-48,2977 x_{3}-0,0122 x_{1} x_{2}-0,0634 x_{1} x_{3} \\
+0,5062 x_{2} x_{3}-8,5002.10^{-4} x_{1}{ }^{2}+0,1077 x_{2}{ }^{2}+1,8771 x_{3}{ }^{2}
\end{array}
$$

Esse tipo de modelagem não exige que pontos iniciais de busca sejam fornecidos. Todavia, para melhor direcionamento ao ótimo do processo, os parâmetros estimados pelo modelo por MMQ foram utilizados como ponto de partida na busca dos parâmetros do modelo otimizado por GA. O algoritmo foi executado utilizando-se uma população de 7.500 indivíduos com 11.000 gerações. Os operadores de crossover e mutação foram utilizados em $80 \%$ e $25 \%$, respectivamente.

A Figura 5.6 apresenta o comportamento dos teores de lignina residual preditos pelo modelo com relação aos teores médios de lignina residual obtidos experimentalmente no processo de pré-tratamento com $\mathrm{H}_{2} \mathrm{O}_{2}$. É possível observar que o modelo é capaz de seguir a tendência dos valores experimentais, realizando uma bom ajuste dos dados. 


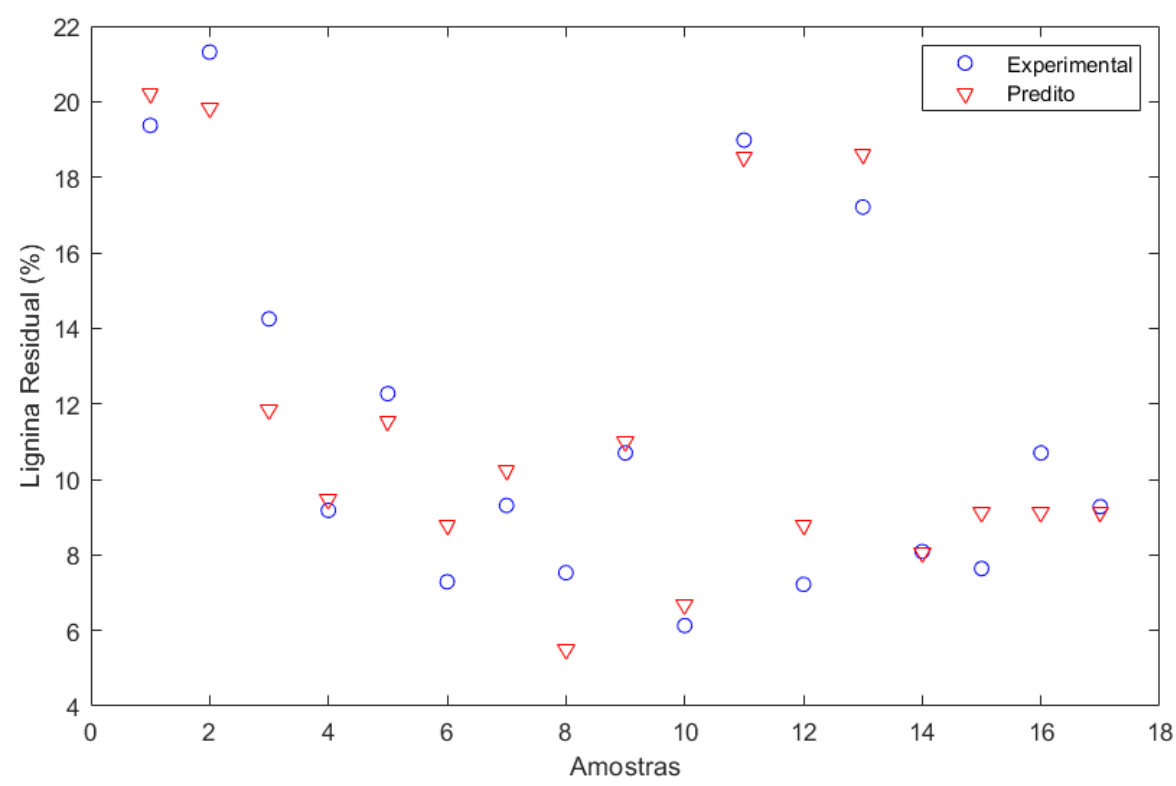

Figura 5.6: Comportamento dos dados preditos pelo modelo otimizado por GA com relação aos dados experimentais do processo de pré-tratamento com $\mathrm{H}_{2} \mathrm{O}_{2}$.

A Tabela 5.8 apresenta a ANOVA construída para validação do modelo. Tabela 5.8: ANOVA para o modelo de predição de lignina residual otimizado por GA no pré-tratamento com $\mathrm{H}_{2} \mathrm{O}_{2}$.

\begin{tabular}{cccccc}
\hline Fontes de Variação & $\begin{array}{c}\text { Soma dos } \\
\text { Quadrados }\end{array}$ & $\begin{array}{c}\text { Graus de } \\
\text { Liberdade }\end{array}$ & $\begin{array}{c}\text { Quadrados } \\
\text { Médios }\end{array}$ & $\mathbf{F}_{\text {calculado }}$ & $\mathbf{F}_{\text {tabelado }}$ \\
\hline Regressão & 354,00 & 9 & 39,33 & & \\
Resíduos & 26,37 & 7 & 3,77 & 10,4 & 3,68 \\
Total & 380,37 & 16 & & & $\mathbf{R}^{\mathbf{2}}$ \\
\hline
\end{tabular}

Assim como no modelo desenvolvido por MMQ, são considerados 9 graus de liberdade para a regressão e 7 graus de liberdade para os resíduos. Dessa forma, o valor de $F_{\text {tabelado }}$ para o nível de significância de $5 \%$ é de 3,68.

Pela ANOVA, observa-se que o valor de $F_{\text {calculado }}$ também é de 10,4. Esse

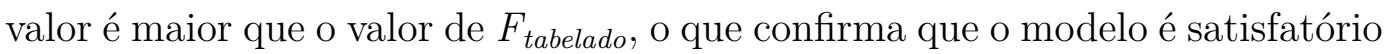
e pode ser utilizado para predição do teor de lignina residual. O $\mathrm{R}^{2}$ aponta que o modelo desenvolvido é capaz de explicar 93,07\% da variabilidade das variáveis envolvidas no processo.

As superfícies de respostas e curvas de contorno para o modelo de predição desenvolvido a partir de GA estão apresentadas nas Figuras 5.7, 5.8 e 5.9 . 

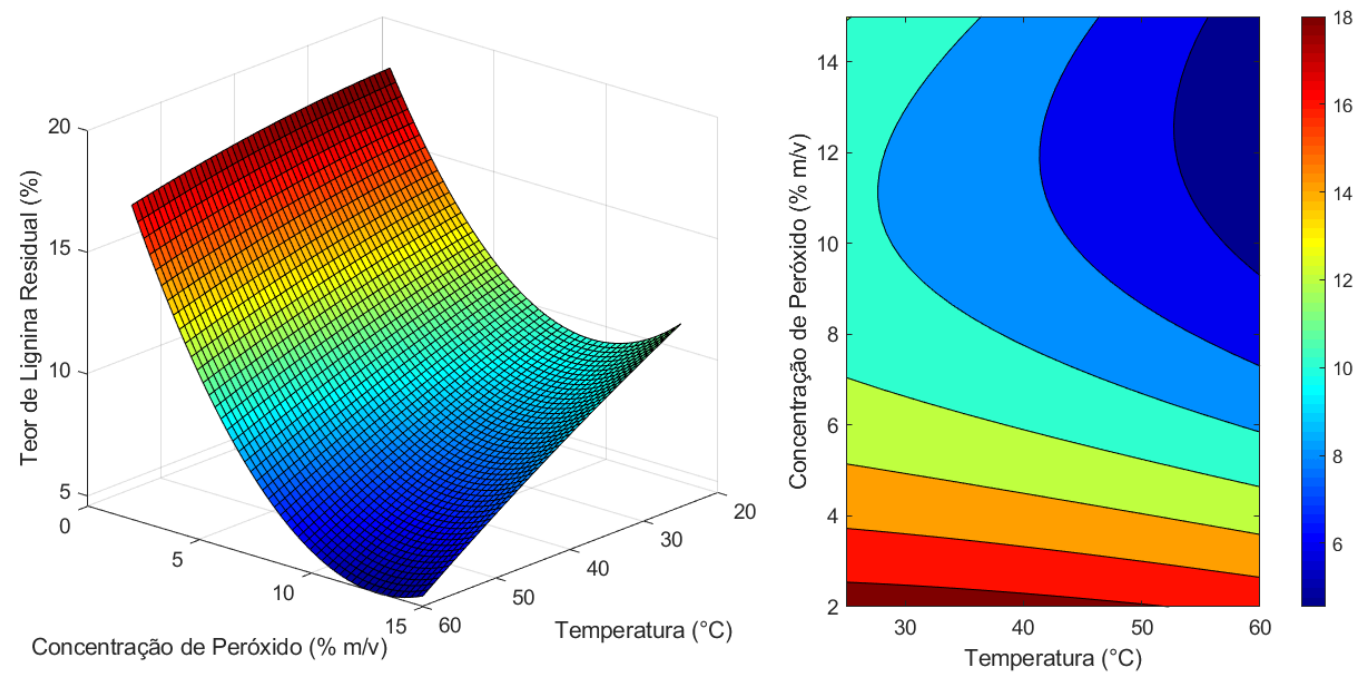

Figura 5.7: Superfície de resposta e curva de contorno da interação entre as variáveis temperatura e concentração de peróxido para o modelo de predição por GA do teor de lignina residual após pré-tratamento com $\mathrm{H}_{2} \mathrm{O}_{2}$.

A Figura 5.7 confirma o que foi discutido na Figura 5.3 referente à superfície de resposta da interação entre temperatura e concentração de peróxido para o modelo desenvolvido a partir de MMQ. A diminuição da concentração de $\mathrm{H}_{2} \mathrm{O}_{2}$, neste caso, também leva ao aumento do teor de lignina residual. Para temperaturas acima de $30^{\circ} \mathrm{C}$, a utilização de $10 \%$ de $\mathrm{H}_{2} \mathrm{O}_{2}$ faz com que o teor de lignina residual comece a diminuir, o que indica que houve maior eficácia no processo de pré-tratamento empregado.

A Figura 5.8 também confirma os resultados mostrados anteriormente. 

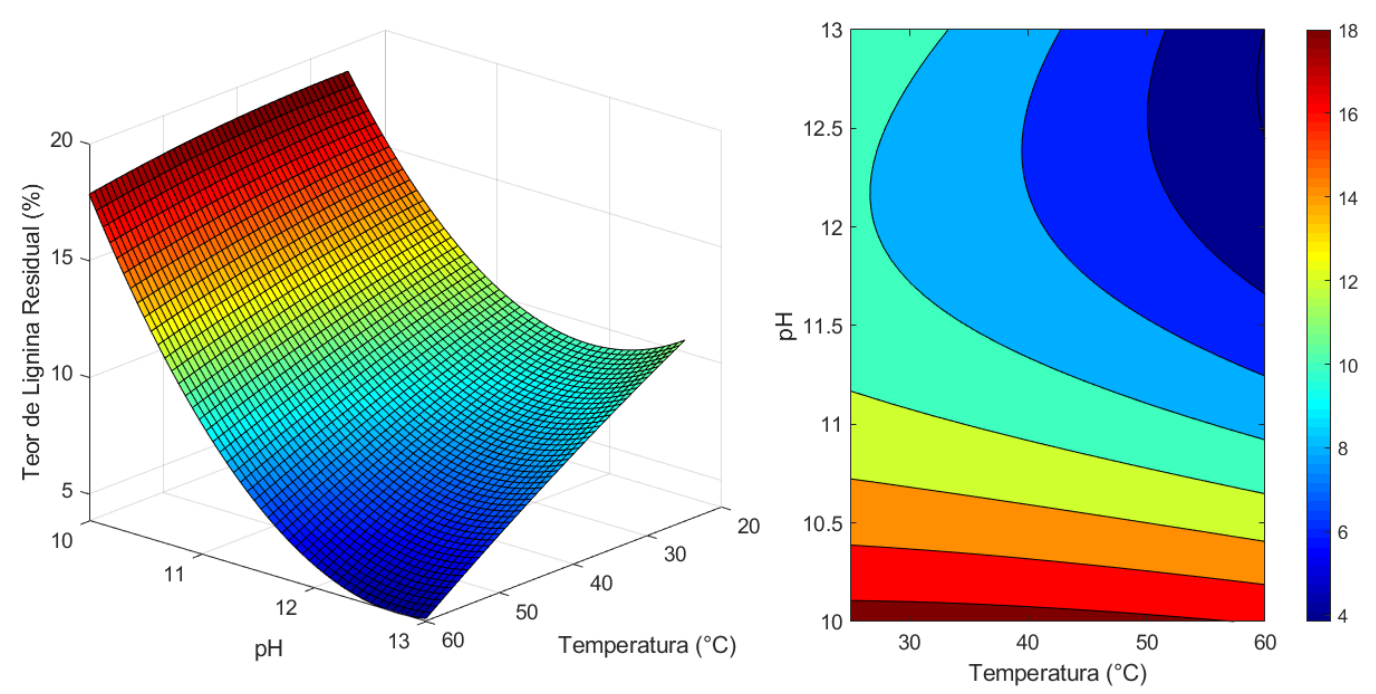

Figura 5.8: Superfície de resposta e curva de contorno da interação entre as variáveis temperatura e pH para o modelo de predição por GA do teor de lignina residual após pré-tratamento com $\mathrm{H}_{2} \mathrm{O}_{2}$.

Para o $\mathrm{pH}$ de 11,5 , pré-determinado na literatura como o ótimo para o processo, a utilização de $35^{\circ} \mathrm{C}$ leva à diminuição do teor de lignina residual nos experimentos.

A Figura 5.9 também apresenta um ponto de mínimo bem definido, onde é possível que se alcance o menor teor de lignina residual no processo de prétratamento. Para o pH de 11,5, acredita-se que a utilização de $8 \%$ de $\mathrm{H}_{2} \mathrm{O}_{2}$ seja suficiente para que se alcance o objetivo.
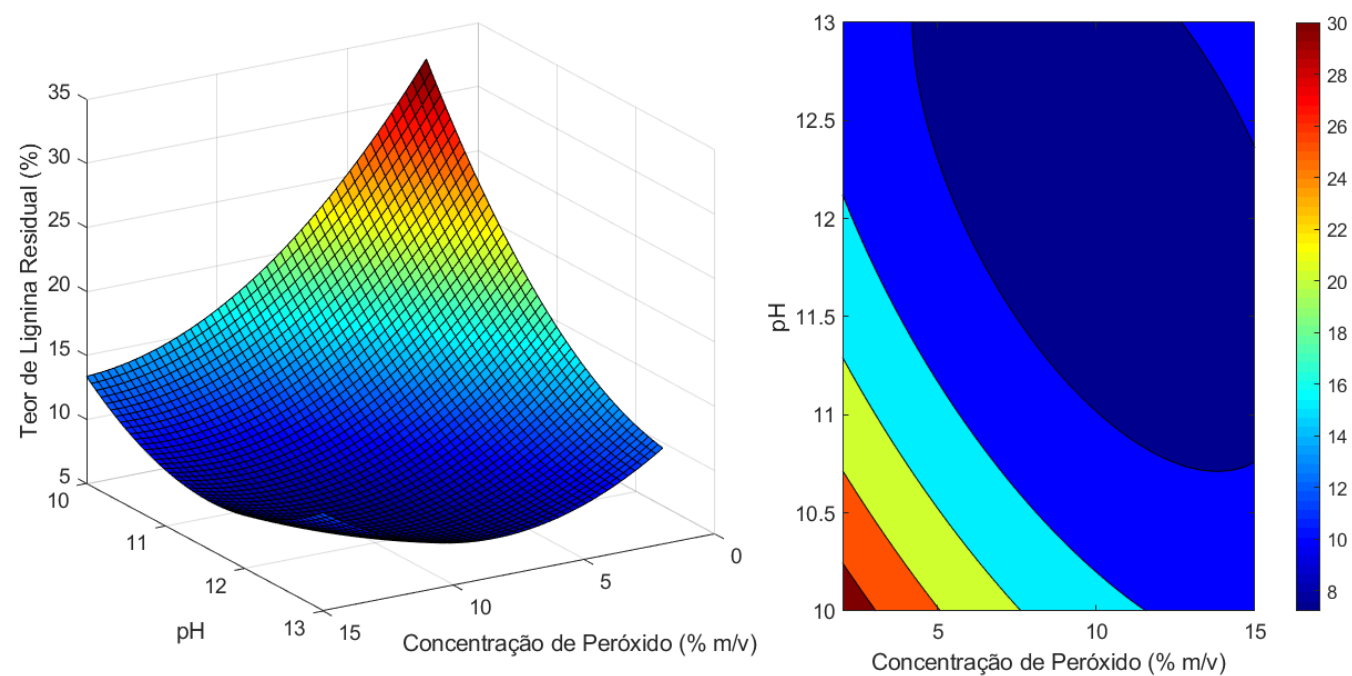

Figura 5.9: Superfície de resposta e curva de contorno da interação entre as variáveis concentração de $\mathrm{H}_{2} \mathrm{O}_{2} \mathrm{e} \mathrm{pH}$ para o modelo de predição por GA do teor de lignina residual após pré-tratamento com $\mathrm{H}_{2} \mathrm{O}_{2}$. 
Em [87], a modelagem com GA foi utilizada em conjunto com MMQ para estimação dos parâmetros cinéticos de dois modelos distintos de pírolise. Resíduos agrícolas foram submetidos à análises de termogravimetria com diferentes condições de aquecimento e as curvas obtidas nas análises foram utilizadas como referência para adequação dos modelos desenvolvidos. Ao contrário da proposta ao uso dos métodos apresentados até agora neste trabalho, o autor utilizou os parâmetros encontrados por GA como palpite inicial na utilização de MMQ, a fim de se obter um modelo de predição melhor ajustado. Como resultado, os parâmetros preditos pelos modelos desenvolvidos se mostraram em concordância com os valores encontrados na literatura.

Em [52], utilizou-se as técnicas de modelagem a partir de MMQ e GA na otimização dos parâmetros do processo de fermentação do melaço da cana-deaçúcar para produção de etanol. As variáveis estudadas foram temperatura, pH, concentração total de açúcares redutores e tempo de fermentação. O planejamento experimental desenvolvido resultou em uma modelagem por Mínimos Quadrados, cujos parâmetros estimados foram utilizados como palpite inicial na busca dos parâmetros do modelo otimizado por GA. A técnica de otimização previu um rendimento máximo de 59,6 g/L de etanol à condição experimental de $31^{\circ} \mathrm{C}, \mathrm{pH}$ de 5,13, $216 \mathrm{~g} / \mathrm{L}$ de açúcares redutores e $44 \mathrm{~h}$ de processo. A validação experimental do resultado apresentou rendimento de $58,4 \mathrm{~g} / \mathrm{L}$ de etanol na fermentação, indicando que o modelo é satisfatório para a predição das condições ótimas dos parâmetros.

Neste trabalho, a utilização de GA se mostrou equivalente à utilização de MMQ, já que os dois modelos apresentam o mesmo valor para o $F_{\text {calculado }}$ e valores muito próximos de coeficiente de correlação. Este fato indica que o modelo polinomial desenvolvido já se encontra otimizado, não sendo capaz de realizar predições mais próximas por limitação dos métodos. Ao que tudo indica, a modelagem com o polinômio quadrático não é capaz de explorar as interações mais complexas entre as variáveis de estudo.

\subsubsection{3}

\section{Predição do teor de lignina residual por Redes Neurais Artificiais}

Redes Neurais Artificiais também foram utilizadas como ferramenta no desenvolvimento de um modelo capaz de predizer o teor de lignina residual no processo de pré-tratamento com $\mathrm{H}_{2} \mathrm{O}_{2}$.

A base de dados utilizada para treinamento e teste é proveniente das análises por método Klason. Foram calculadas médias entre as quadruplicatas analisadas, a fim de se obter mais vetores para melhor utilização das ANNs. Dessa forma, foram utilizados 187 conjuntos de entrada, sendo 130 para 
treinamento e 57 para teste, o que caracteriza uma proporção aproximada de $70 \%$ e $30 \%$, respectivamente.

Inicialmente, um modelo neural formado por apenas 1 camada intermediária foi implementado. Os 3 neurônios presentes na camada de entrada são referentes às variáveis independentes do processo: temperatura, concentração de $\mathrm{H}_{2} \mathrm{O}_{2}$ e pH, enquanto a camada de saída é constituída de 1 neurônio, referente à variável dependente a ser predita: o teor de lignina residual.

A Tabela 5.9 apresenta algumas topologias testadas para o modelo de predição do teor de lignina residual no processo de pré-tratamento com $\mathrm{H}_{2} \mathrm{O}_{2}$. Para cada topologia proposta, pode-se observar seus valores correspondentes de $\mathrm{R}^{2}$, índices de erro e número de parâmetros da rede.

Tabela 5.9: Topologias testadas para o ajuste do modelo ANN com 1 camada intermediária para predição do teor de lignina residual no processo de pré-tratamento com $\mathrm{H}_{2} \mathrm{O}_{2}$.

\begin{tabular}{|c|c|c|c|c|c|c|c|}
\hline $\begin{array}{c}\text { Neurônios } \\
\text { (camada } \\
\text { intermediária) }\end{array}$ & $\begin{array}{c}\text { Função de } \\
\text { ativação }\end{array}$ & $\begin{array}{c}\text { Algoritmo de } \\
\text { treinamento }\end{array}$ & $\mathrm{R}^{2}$ & SSE & MSE & RMSE & $\begin{array}{l}\text { Número de } \\
\text { parâmetros }\end{array}$ \\
\hline 4 & logsig & trainlm & 98,76 & 0,496 & 0,003815 & 0,061769 & 21 \\
\hline 10 & logsig & trainlm & 98,76 & 0,510 & 0,003923 & 0,062634 & 51 \\
\hline 20 & tansig & trainlm & 98,65 & 0,437 & 0,003362 & 0,057979 & 101 \\
\hline 4 & tansig & traingdx & 93,20 & 1,140 & 0,008769 & 0,093644 & 21 \\
\hline 4 & logsig & traingdx & 92,76 & 1,340 & 0,010308 & 0,101527 & 21 \\
\hline 10 & logsig & traingdx & 79,43 & 2,490 & 0,019154 & 0,138397 & 51 \\
\hline 4 & tansig & traincgb & 95,26 & 0,646 & 0,004969 & 0,070493 & 21 \\
\hline 4 & logsig & traincgb & 95,31 & 0,796 & 0,006123 & 0,078250 & 21 \\
\hline 4 & logsig & trainbr & 98,78 & 0,532 & 0,004092 & 0,063971 & 21 \\
\hline 6 & logsig & trainbr & 98,78 & 0,527 & 0,004054 & 0,063670 & 31 \\
\hline 14 & tansig & trainbr & 98,80 & 0,530 & 0,004077 & 0,063851 & 71 \\
\hline 4 & tansig & trainbr & 98,71 & 0,479 & 0,003685 & 0,060701 & 21 \\
\hline
\end{tabular}

De acordo com as simulações apresentadas, é possível observar que aumentar o número de neurônios na camada intermediária não levou à melhora significativa em nenhum modelo. Em alguns casos, essa estratégia proporcionou uma pequena diminuição nos valores de índices de erro. No entanto, o número de parâmetros da rede aumentou de tal forma que seu uso não é justificável.

Deste modo, a topologia mais adequada apresenta 4 neurônios na camada intermediária, função de treinamento tansig e algoritmo de treinamento trainbr. O modelo neural 3-4-1 (tansig-purelin / trainbr) desenvolvido é capaz de explicar $98,71 \%$ da variabilidade das variáveis estudadas no processo, apresentando índices de erro SSE, MSE e RMSE com valores de 0,479, 0,003685 
e 0,060701, respectivamente. A Tabela 5.10 apresenta os pesos e os bias que descrevem este modelo.

Tabela 5.10: Tabela com os pesos e os bias que descrevem o modelo neural 3-4-1 (tansig-purelin / trainbr).

\begin{tabular}{lrrrrrrr} 
& \multicolumn{3}{c}{ Camada intermediária } & & \multicolumn{2}{c}{ Camada de saída } \\
\cline { 2 - 4 } & $\mathbf{w}_{j 1}(i=1)$ & $\mathbf{w}_{j 2}(i=2)$ & $\mathbf{w}_{j 3}(i=3)$ & $\theta_{j}$ & & $\mathbf{w}_{j 1}(k=1)$ & $\theta_{k}$ \\
\hline $\mathrm{j}=1$ & 0,5708 & 1,0768 & 2,6064 & 0,9555 & & $-1,3732$ & $-0,21324$ \\
$\mathrm{j}=2$ & $-1,0346$ & $-0,3738$ & $-0,7282$ & $-0,3030$ & & 0,6525 & \\
$\mathrm{j}=3$ & $-0,2569$ & 0,4227 & 0,8953 & 0,5287 & & 0,4392 & \\
$\mathrm{j}=4$ & 1,0217 & 0,2034 & 1,4678 & 0,7994 & & 1,1819 & \\
\hline
\end{tabular}

A Figura 5.10 apresenta a janela de simulação do software, na qual se vê, na parte superior, a estrutura do modelo neural. Na parte inferior, está indicado o SSE, usado no cálculo dos outros índices de erro. Para este caso, onde se utilizou o algoritmo de treinamento que implementa o método Backpropagation com Regularização Bayesiana, é possível também observar o número de parâmetros efetivos. O uso de 4 neurônios na camada intermediária limitou a capacidade da ANN à 21 parâmetros modificáveis. No entanto, para este caso, apenas 14,4 parâmetros foram efetivamente utilizados para os cálculos realizados.
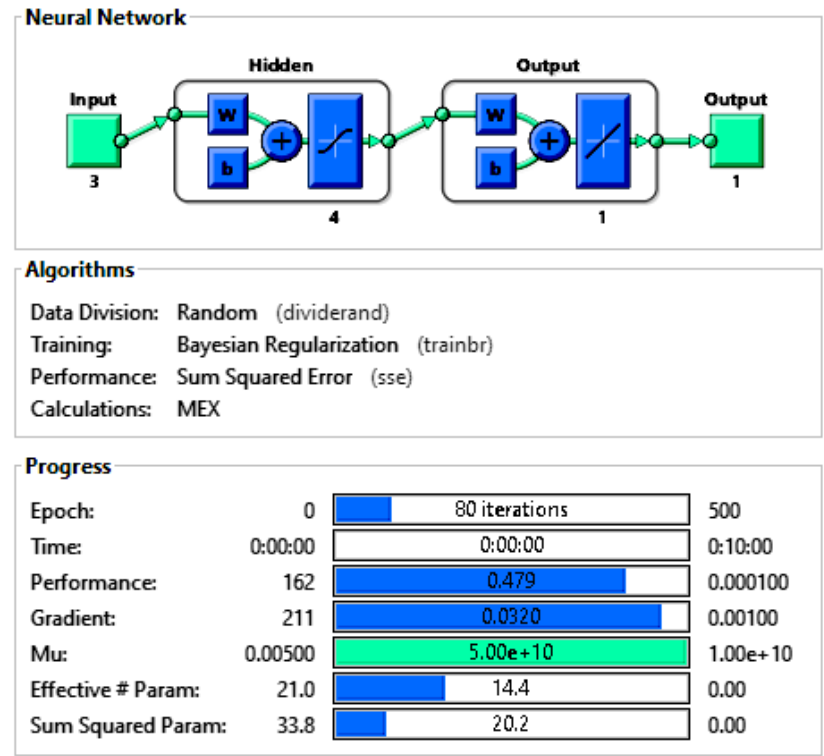

Figura 5.10: Janela do software Matlab R2018a indicando os parâmetros de simulação do modelo neural 3-4-1 (tansig-purelin / trainbr) para predição do teor de lignina residual após pré-tratamento com $\mathrm{H}_{2} \mathrm{O}_{2}$.

A Figura 5.11(a) mostra a correlação entre os teores de lignina residual experimentais e preditos pelo modelo neural. O valor de $\mathrm{R}^{2}$ igual a $98,71 \%$ 
indica que o modelo foi bem ajustado. Por sua vez, a Figura 5.11(b) mostra o comportamento das respostas experimentais e preditas do processo. Notase que os dados preditos pelo modelo se encontram próximos aos dados obtidos experimentalmente, o que explica os baixos valores dos índices de erro apresentados.

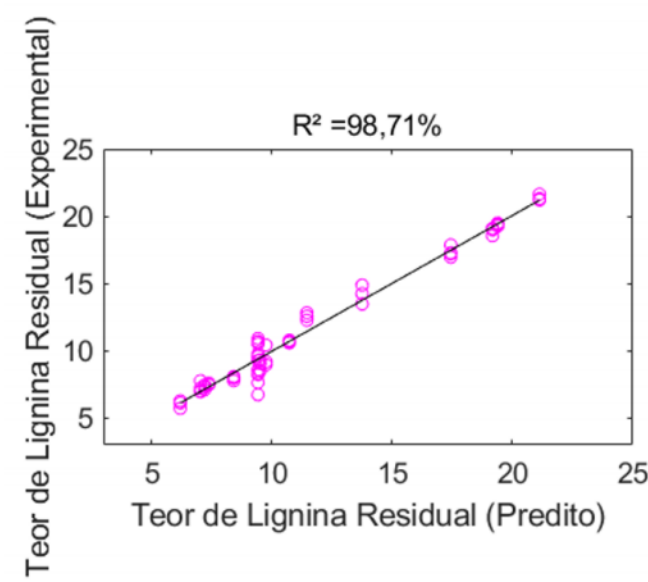

(a)

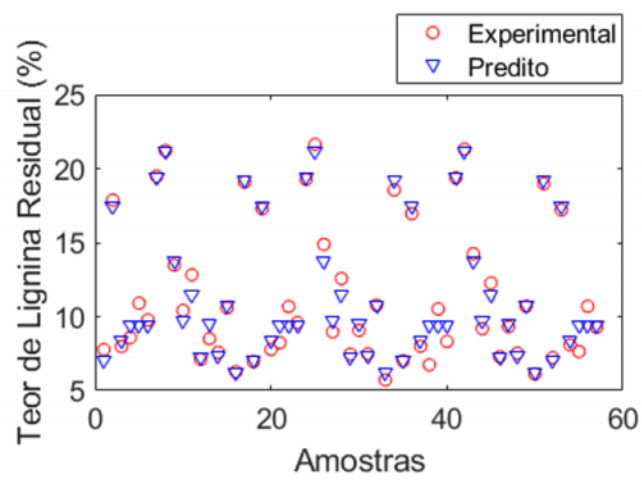

(b)

Figura 5.11: Gráficos da simulação do modelo neural 3-4-1 (tansig-purelin / trainbr) para predição do teor de lignina residual após pré-tratamento com $\mathrm{H}_{2} \mathrm{O}_{2}$.

As superfícies de respostas e curvas de contorno para o modelo neural 3-4-1 (tansig-purelin / trainbr) estão apresentadas nas Figuras 5.12, 5.13 e 5.14 .
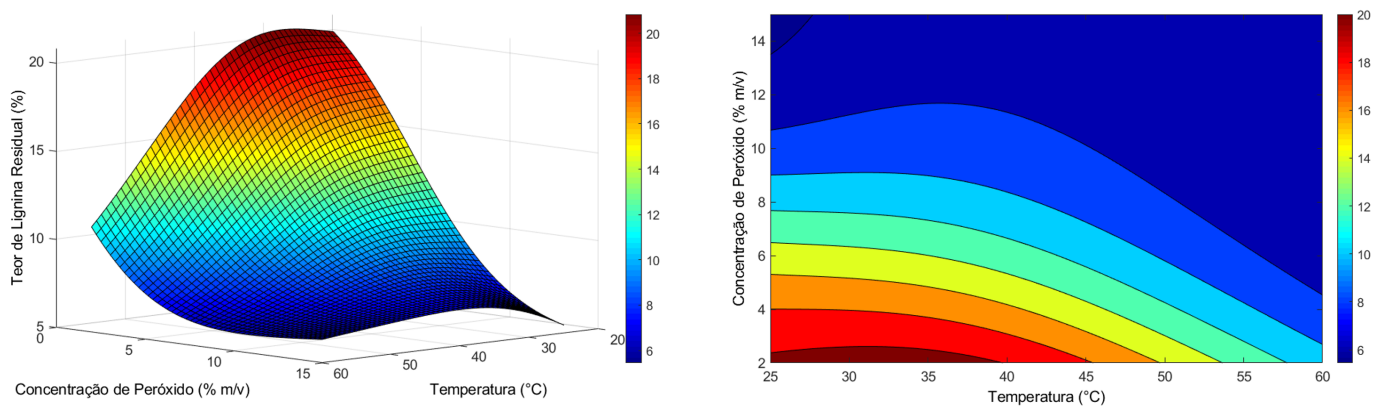

Figura 5.12: Superfície de resposta e curva de contorno da interação entre as variáveis temperatura e concentração de peróxido para o modelo neural 3-4-1 (tansig-purelin / trainbr).

Da Figura 5.12, é possível observar que a diminuição do valor da concentração de $\mathrm{H}_{2} \mathrm{O}_{2}$ no experimento leva ao maior teor de lignina residual na biomassa. No entanto, para temperaturas acima de $55^{\circ} \mathrm{C}$, a utilização de $4 \%$ de $\mathrm{H}_{2} \mathrm{O}_{2}$ começa a se mostrar satisfatória para diminuição do teor de lignina residual na biomassa. Para temperaturas em torno de $25^{\circ} \mathrm{C}$, a utilização de $14 \%$ 
de $\mathrm{H}_{2} \mathrm{O}_{2}$ também se mostra uma alternativa satisfatória para minimização do teor de lignina residual no processo. Contudo, como relatado anteriormente, a utilização de valores mais elevados para concentração de $\mathrm{H}_{2} \mathrm{O}_{2}$ pode levar à degradação dos açúcares presentes na biomassa, o que não é desejado.

A Figura 5.13, por sua vez, apresenta a interação entre as variáveis temperatura e $\mathrm{pH}$.
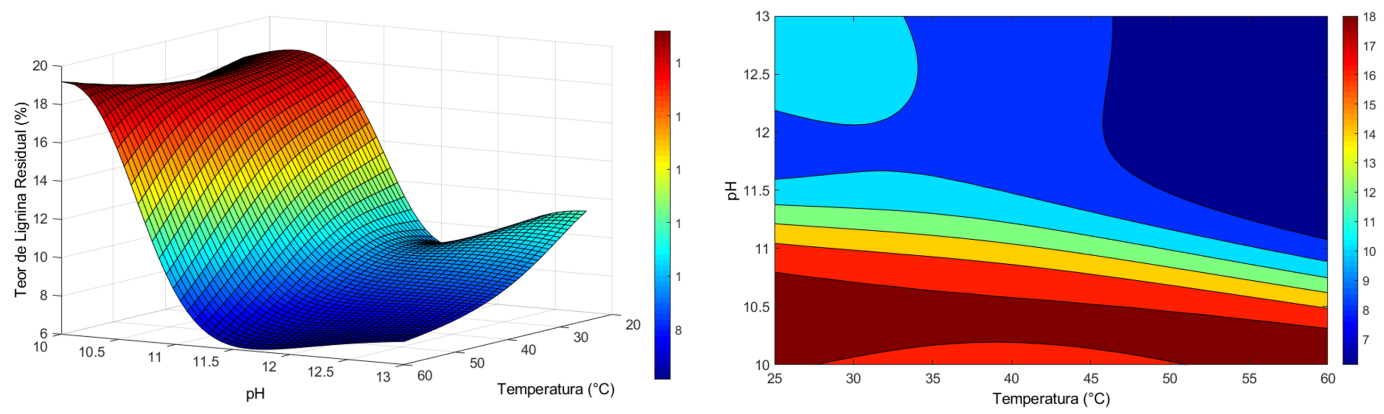

Figura 5.13: Superfície de resposta e curva de contorno da interação entre as variáveis temperatura e pH para o modelo neural 3-4-1 (tansig-purelin / trainbr).

De acordo com a superfície, para o valor de $\mathrm{pH}$ em 11,5, experimentos com valores de temperatura em aproximadamente $50^{\circ} \mathrm{C}$, levam à diminuição do teor de lignina residual.

A Figura 5.14 mostra a interação entre as variáveis concentração de $\mathrm{H}_{2} \mathrm{O}_{2}$ e $\mathrm{pH}$.
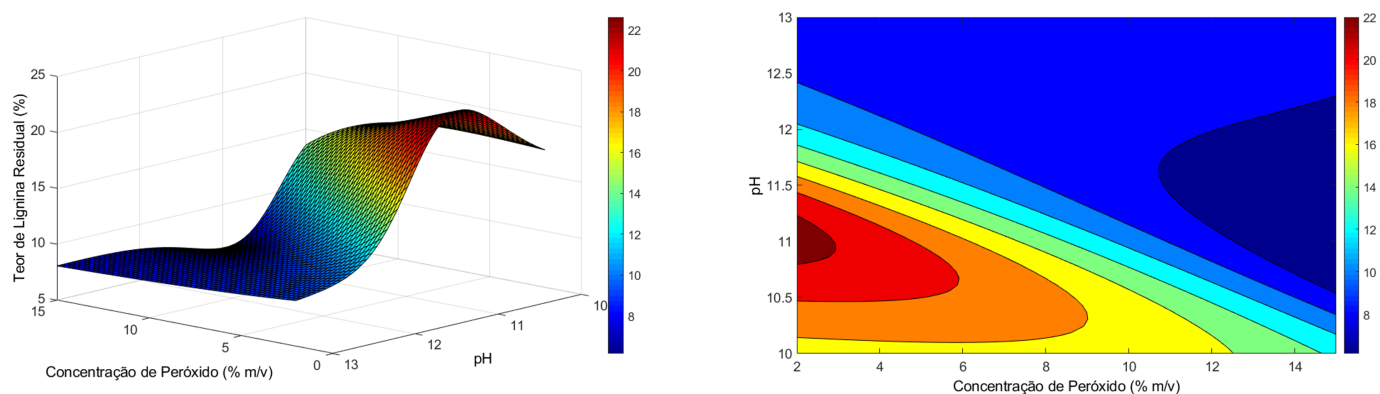

Figura 5.14: Superfície de resposta e curva de contorno da interação entre as variáveis concentração de peróxido e $\mathrm{pH}$ para o modelo neural 3-4-1 (tansig-purelin (trainbr).

Neste caso, é possível observar que a utilização dos menores valores de concentração combinados aos menores valores de $\mathrm{pH}$ não são recomendados para o processo. Considerando o $\mathrm{pH}$ de 11,5 como valor ótimo, recomenda-se o uso de aproximadamente $11 \%$ de $\mathrm{H}_{2} \mathrm{O}_{2}$ para se atingir a minimização do teor de lignina residual. 
Definidos os valores ótimos de concentração e pH pelo modelo neural, a Figura 5.12 é novamente analisada, de onde se conclui que, para concentração de $\mathrm{H}_{2} \mathrm{O}_{2}$ em $11 \%$, o teor de lignina residual no processo é minimizado por qualquer valor da faixa de temperatura investigada nesse trabalho, podendo o ótimo ser fixado em $25^{\circ} \mathrm{C}$, assim como determinado em [5].

Continuando a investigação acerca do modelo neural, foi estudada a influência da inserção de uma segunda camada intermediária para predição da resposta do processo. A camada de entrada continua sendo composta pelas 3 variáveis independentes do processo e a camada de saída, pela variável dependente do processo.

A Tabela 5.11 apresenta algumas topologias testadas para o modelo neural com 2 camadas intermediárias para predição do teor de lignina residual no processo de pré-tratamento com $\mathrm{H}_{2} \mathrm{O}_{2}$. Para cada topologia proposta, podese observar seus valores correspondentes de $\mathrm{R}^{2}$, índices de erro e número de parâmetros da rede.

Tabela 5.11: Topologias testadas para o ajuste do modelo ANN com 2 camadas intermediárias para predição do teor de lignina residual no processo de pré-tratamento com $\mathrm{H}_{2} \mathrm{O}_{2}$.

\begin{tabular}{cccccccccc}
\hline $\begin{array}{c}\text { Neurônios } \\
\text { (camada } \\
\text { intermediária)(1) }\end{array}$ & $\begin{array}{c}\text { Função de } \\
\text { ativação }\end{array}$ & $\begin{array}{c}\text { Neurônios } \\
\text { (camada } \\
\text { intermediária)(2) }\end{array}$ & $\begin{array}{c}\text { Função de } \\
\text { ativação }\end{array}$ & $\begin{array}{c}\text { Algoritmo } \\
\text { de } \\
\text { treinamento }\end{array}$ & $\mathbf{R}^{\mathbf{2}}$ & SSE & MSE & RMSE & $\begin{array}{c}\text { Número de } \\
\text { parâmetros }\end{array}$ \\
\hline 8 & logsig & 6 & tansig & trainbr & 98,59 & 0,448 & 0,003446 & 0,058704 & 93 \\
4 & logsig & 3 & logsig & trainbr & 98,86 & 0,559 & 0,004300 & 0,065574 & 35 \\
4 & tansig & 3 & tansig & trainbr & 98,81 & 0,548 & 0,004215 & 0,064926 & 35 \\
4 & tansig & 3 & logsig & trainlm & 98,49 & 0,348 & 0,002677 & 0,051739 & 35 \\
4 & tansig & 6 & logsig & trainlm & 98,73 & 0,522 & 0,004015 & 0,063367 & 53 \\
3 & tansig & 4 & logsig & trainlm & 96,76 & 0,640 & 0,004923 & 0,070165 & 33 \\
4 & tansig & 3 & logsig & trainoss & 95,88 & 0,655 & 0,005038 & 0,070982 & 35 \\
4 & logsig & 3 & logsig & trainoss & 95,59 & 0,612 & 0,004708 & 0,068613 & 35 \\
4 & logsig & 3 & tansig & trainoss & 36,89 & 5,000 & 0,038462 & 0,196116 & 35 \\
4 & tansg & 6 & logsig & traingdx & 92,39 & 0,756 & 0,005815 & 0,076259 & 53 \\
4 & tansig & 3 & logsig & traincgb & 97,51 & 0,605 & 0,004654 & 0,068219 & 35 \\
\hline
\end{tabular}

Da Tabela 5.11, é possível inferir que a inserção de uma segunda camada intermediária não serviu para melhorar o poder de predição do modelo neural apresentado anteriormente. Os índices de erro não diminuíram e o valor do coeficiente de correlação não aumentou satisfatoriamente, de modo que se justificasse o aumento do número de parâmetros da rede.

Segundo [88], o fato do modelo neural apresentar melhor ajuste é atribuído à capacidade de maior generalização dos dados, se comparado com o MMQ. Essa maior precisão pode estar relacionada à sua habilidade de melhor considerar as não linearidades presentes no sistema, enquanto o modelo proposto nas metodologias de MMQ e GA foi um polinômio de $2^{\circ}$ ordem. O modelo neural 3-4-1 (tansig-purelin / trainbr) se mostrou superior aos modelos 
polinomiais utilizados para predição do teor de lignina residual, apresentando maior coeficiente de correlação.

\subsubsection{4}

\section{Predição do teor de lignina residual por Neuro-Fuzzy}

Um modelo ANFIS também foi desenvolvido para predição do teor de lignina residual no processo de pré-tratamento do bagaço da cana-deaçúcar com $\mathrm{H}_{2} \mathrm{O}_{2}$. As variáveis de entrada do sistema, assim como nos outros modelos, são temperatura, concentração de $\mathrm{H}_{2} \mathrm{O}_{2}$ e pH. Todos os dados foram normalizados entre 0 e 1 . A Figura 5.15 apresenta a estrutura da topologia do modelo ANFIS desenvolvido.

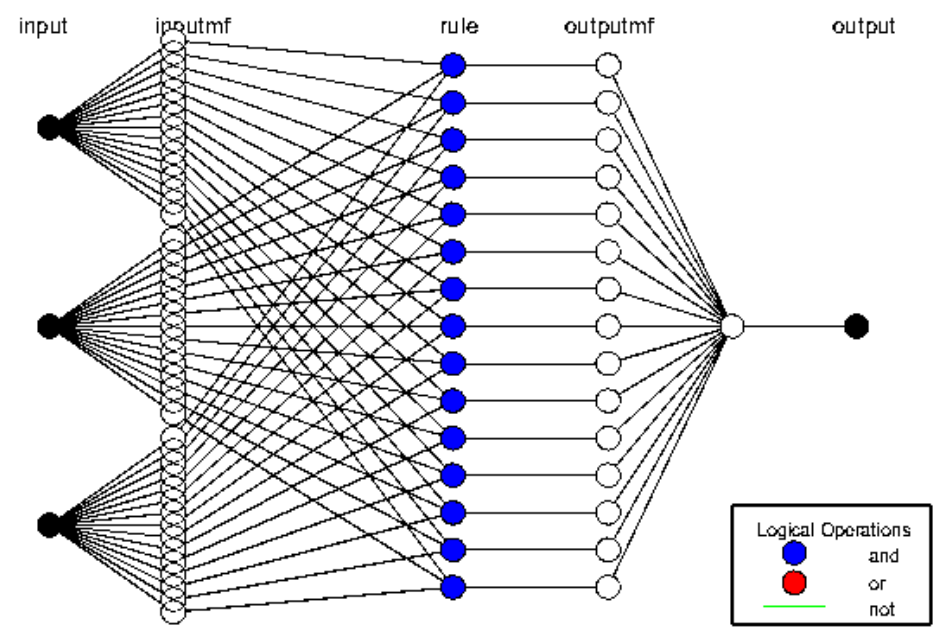

Figura 5.15: Topologia do modelo ANFIS desenvolvido para predição do teor de lignina residual no processo de pré-tratamento com $\mathrm{H}_{2} \mathrm{O}_{2}$.

A função de pertinência obtida foi do tipo Gaussiana, gerando 15 regras. O modelo ANFIS apresentou $\mathrm{R}^{2}$ de $98,89 \%$ e índices de erro SSE, MSE e RMSE de 0,2019, 0,001553 e 0,039416, respectivamente.

No entanto, este modelo utilizou 150 parâmetros modificáveis na realização dos cálculos, quantidade maior que o número de vetores de entrada para treinamento da rede. Tal fato caracteriza overfitting e, por isso, este modelo não é recomendável para predição da resposta do processo.

\section{5 .2}

No processo de pré-tratamento com $\mathrm{ScCO}_{2}$ 


\subsubsection{1}

\section{Predição do teor de lignina residual por Redes Neurais Artificiais}

Foram desenvolvidos também modelos neurais para predição do teor de lignina residual no processo de pré-tratamento com $\mathrm{ScCO}_{2}$. A base de dados utilizada para treinamento e teste é proveniente das análises por Método Klason das amostras desse processo. Para aumentar a quantidade de conjuntos disponíveis na base de dados, foram calculadas médias entre as duplicatas dos experimentos. Dessa forma, foram utilizados 33 vetores, sendo 22 para treinamento e 11 para teste, o que caracteriza uma proporção aproximada de $67 \%$ e $33 \%$, respectivamente.

Inicialmente, um modelo neural formado por apenas 1 camada intermediária foi implementado. Os 3 neurônios presentes na camada de entrada são referentes às variáveis estudadas no processo: temperatura, pressão e teor de etanol na mistura do co-solvente, enquanto a camada de saída é constituída de 1 neurônio, referente à resposta a ser predita: o teor de lignina residual.

Para este caso, o número de neurônios na camada intermediária é fixado em 4. A utilização de mais neurônios faz com que o número de parâmetros da rede seja maior que o número de vetores utilizados para treinamento, ocasionando overfitting.

A Tabela 5.12 apresenta algumas topologias testadas para o modelo de predição do teor de lignina residual no processo de pré-tratamento com $\mathrm{ScCO}_{2}$ com 1 camada intermediária. Para cada topologia proposta, pode-se observar seus valores correspondentes de $\mathrm{R}^{2}$, índices de erro e número de parâmetros da rede.

Tabela 5.12: Topologias testadas para o ajuste do modelo ANN com 1 camada intermediária para predição do teor de lignina residual no processo de pré-tratamento com $\mathrm{ScCO}_{2}$.

\begin{tabular}{cccccccc}
\hline $\begin{array}{c}\text { Neurônios } \\
\text { (camada } \\
\text { intermediária) }\end{array}$ & $\begin{array}{c}\text { Função de } \\
\text { ativação }\end{array}$ & $\begin{array}{c}\text { Algoritmo de } \\
\text { treinamento }\end{array}$ & $\mathbf{R}^{\mathbf{2}}$ & SSE & MSE & RMSE & $\begin{array}{c}\text { Número de } \\
\text { parâmetros }\end{array}$ \\
\hline 4 & tansig & trainbr & 41,44 & 1,130 & 0,008692 & 0,093233 & 21 \\
4 & logsig & trainbr & 41,50 & 0,907 & 0,006977 & 0,083528 & 21 \\
4 & tansig & trainlm & 78,10 & 0,388 & 0,002985 & 0,054632 & 21 \\
4 & logsig & trainlm & 35,10 & 0,032 & 0,000242 & 0,015566 & 21 \\
4 & tansig & trainoss & 55,64 & 0,395 & 0,003038 & 0,055122 & 21 \\
4 & logsig & trainoss & $-43,47$ & 0,690 & 0,005308 & 0,072854 & 21 \\
4 & tansig & traingdx & 34,31 & 0,606 & 0,004662 & 0,068275 & 21 \\
4 & logsig & traingdx & $-27,03$ & 0,561 & 0,004315 & 0,065692 & 21 \\
& tansig & traincgb & 88,09 & 0,153 & 0,001177 & 0,034306 & 21 \\
\end{tabular}

A topologia que melhor modela o processo de pré-tratamento com 
$\mathrm{ScCO}_{2}$ apresenta função de treinamento tansig e algoritmo de treinamento traincgb. O modelo neural 3-4-1 (tansig-purelin / traincgb) desenvolvido é capaz de explicar 88,09\% da variabilidade das variáveis estudadas no processo, apresentando índices de erro SSE, MSE e RMSE com valores de 0,153, 0,001177 e 0,034306, respectivamente. A Tabela 5.13 apresenta os pesos e os bias que descrevem este modelo.

Tabela 5.13: Tabela com os pesos e os bias que descrevem o modelo neural 3-4-1 (tansig-purelin / traincgb).

\begin{tabular}{lrrrrrrr} 
& \multicolumn{3}{c}{ Camada intermediária } & & \multicolumn{2}{c}{ Camada de saída } \\
\cline { 2 - 4 } & $\mathbf{w}_{j 1}(i=1)$ & $\mathbf{w}_{j 2}(i=2)$ & $\mathbf{w}_{j 3}(i=3)$ & $\theta_{j}$ & & $\mathbf{w}_{j 1}(k=1)$ & $\theta_{k}$ \\
\hline $\mathrm{j}=1$ & 1,6453 & 1,1559 & 1,5114 & $-1,4648$ & & $-0,9098$ & $-0,5452$ \\
$\mathrm{j}=2$ & 2,0631 & $-0,9330$ & $-0,9022$ & $-0,1616$ & & $-0,2139$ & \\
$\mathrm{j}=3$ & 2,0689 & 0,4836 & 0,5696 & 0,8660 & & 0,4264 & \\
$\mathrm{j}=4$ & $-0,2877$ & 1,2235 & 1,8956 & $-2,1450$ & & 0,1803 & \\
\hline
\end{tabular}

Apesar de apresentar baixos valores para os índices de erro, o modelo não apresenta boa capacidade de predição do teor de lignina residual. A Figura 5.16(a) mostra a correlação entre os teores de lignina residual experimentais e preditos pelo modelo neural. Por sua vez, a Figura 5.16(b) ilustra o comportamento das respostas experimentais e preditas do processo. Nota-se que alguns dados preditos pelo modelo se encontram distantes dos dados obtidos experimentalmente, o que confirma o baixo valor encontrado para o coeficiente de correlação.

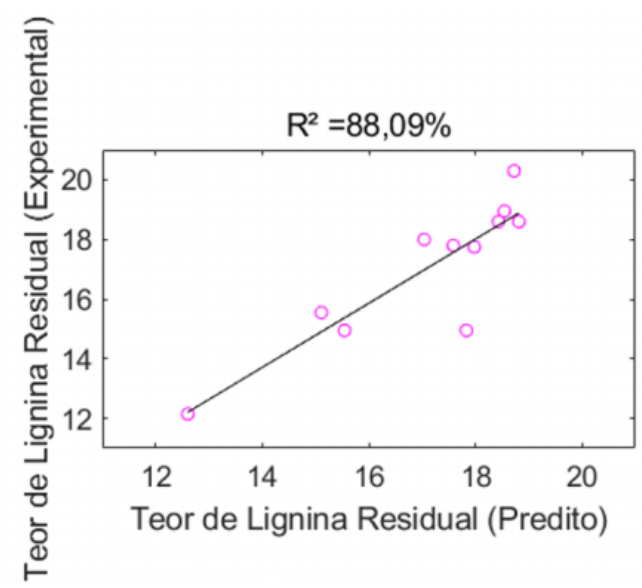

(a)

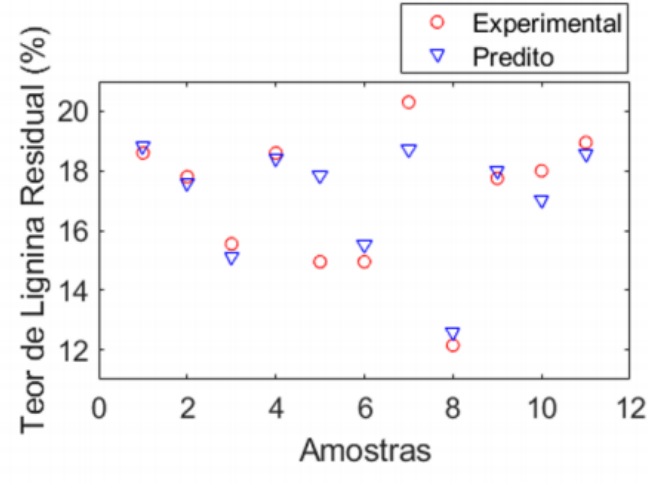

(b)

Figura 5.16: Gráficos da simulação do modelo neural com 1 camada intermediária 3-4-1 (tansig-purelin / traincgb) para predição do teor de lignina residual após pré-tratamento com $\mathrm{ScCO}_{2}$. 
Visando a melhora do modelo neural obtido, topologias com 2 camadas intermediárias também poderiam ser investigadas. No entanto, a utilização de 3 neurônios em cada camada intermediária, já implica em 28 parâmetros modificáveis na rede, maior que a quantidade de vetores de entrada disponível. Dessa forma, para este caso, não é possível desenvolver um modelo neural com 2 camadas intermediárias que descreva corretamente o processo de prétratamento com $\mathrm{ScCO}_{2}$ sem que haja ocorrência de overfitting.

As superfícies de respostas e curvas de contorno para o modelo neural 34-1 (tansig-purelin / traincgb) com 1 camada intermediária estão apresentadas nas Figuras 5.17, 5.18 e 5.19 .
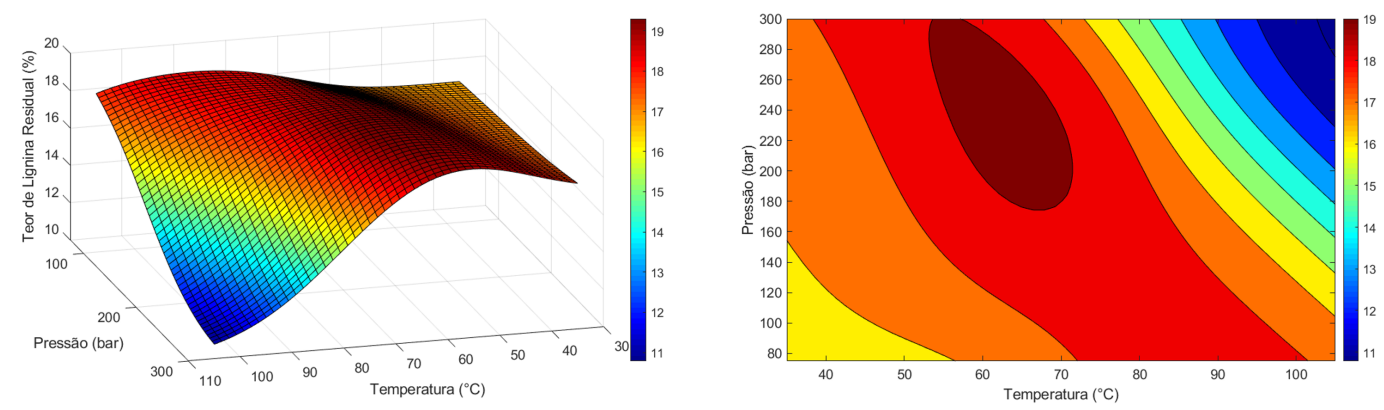

Figura 5.17: Superfície de resposta e curva de contorno da interação entre as variáveis temperatura e pressão para o modelo neural 3-4-1 (tansig-purelin / traincgb).

Da Figura 5.17, é possível observar a presença de um pico bem definido, onde os experimentos realizados nas faixas entre 60 e $70^{\circ} \mathrm{C}$ e entre 180 e 300 bar atingem o maior teor de lignina residual, o que indica a ineficiência do processo de pré-tratamento com $\mathrm{ScCO}_{2}$. Com relação à essas variáveis, a eficiência do processo começa a ser satisfatória ao se empregar temperaturas maiores que $90^{\circ} \mathrm{C}$ e pressões maiores que 220 bar.

A Figura 5.18, por sua vez, apresenta a interação entre as variáveis temperatura e teor de etanol na mistura de co-solvente. 

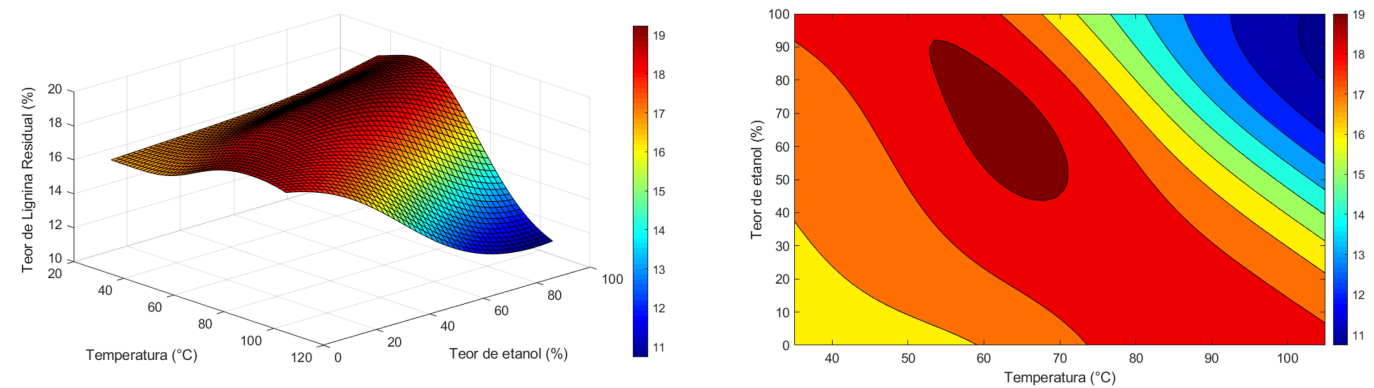

Figura 5.18: Superfície de resposta e curva de contorno da interação entre as variáveis temperatura e teor de etanol para o modelo neural 3-4-1 (tansig-purelin / traincgb).

Mais uma vez o ponto máximo para o teor de lignina residual é observado para valores intermediários de temperatura e valores intermediários do teor de etanol. A minimização da resposta do processo começa a ser notada ao se utilizar nos experimentos temperatura acima de $90^{\circ} \mathrm{C}$ e teor de etanol acima de $60 \%$.

A Figura 5.19 apresenta a interação entre as variáveis pressão e teor de etanol na mistura de co-solvente.
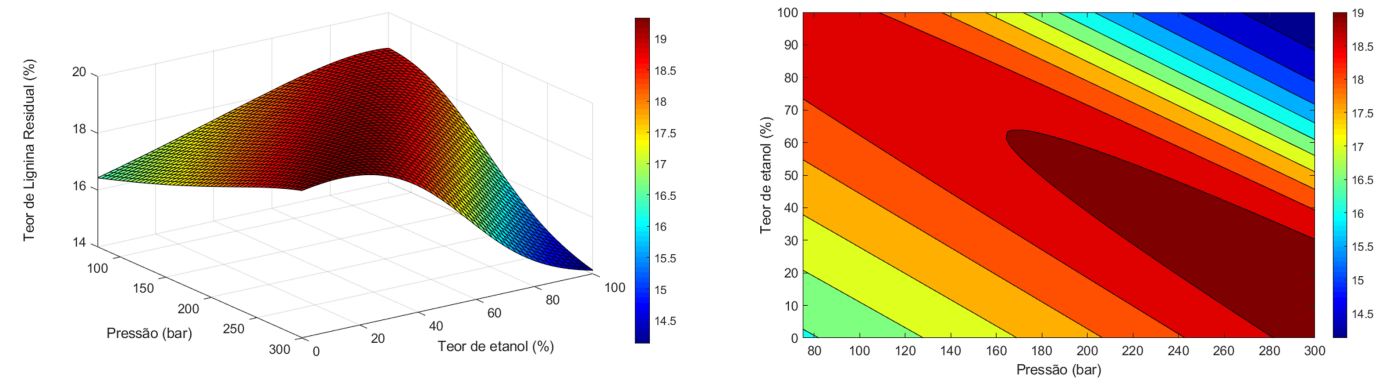

Figura 5.19: Superfície de resposta e curva de contorno da interação entre as variáveis pressão e teor de etanol para o modelo neural 3-4-1 (tansig-purelin / traincgb).

De acordo com o que é mostrado, a utilização de maiores valores de pressão e de teor de etanol levam à minimização do teor de lignina residual no processo de pré-tratamento com $\mathrm{ScCO}_{2}$.

É relevante observar que as variáveis temperatura e pressão são importantes fatores a serem considerados no processo. Porém, a escolha do co-solvente é de suma importância para que o objetivo de se atingir a maior remoção de lignina na biomassa seja alcançado. Da Figura 5.19, nota-se que a utilização de menores valores de pressão também podem levar à minimização da resposta do processo. O mesmo se observa para menores valores de temperatura na Figura 5.13 . 
Segundo [46], a utilização de maiores valores de pressão no processo ocasiona aumento na densidade do gás, o que eleva sua capacidade solvente. Entretanto, com a utilização do co-solvente adequado, talvez seja possível a utilização das variáveis pressão e temperatura em patamares mais amenos. Ainda segundo o autor, os valores otimizados das variáveis temperatura e pressão para o processo, considerando o teor de etanol entre 50 e 100\%, são $190^{\circ} \mathrm{C}$ e 160 bar, respectivamente. Esse resultado é divergente com o apresentado pelo modelo neural, que aponta o surgimento do início de um ponto de máximo para o teor de lignina residual, se considerada pressão de 160 bar e, aproximadamente, $60 \%$ de etanol na mistura do co-solvente.

O modelo neural desenvolvido para predição do teor de lignina residual no processo de pré-tratamento com $\mathrm{ScCO}_{2}$ não apresenta um mínimo global bem definido. Dessa forma, é recomendável a realização de mais experimentos com ampliação das faixas de estudo das variáveis temperatura e pressão.

\subsubsection{2}

\section{Predição do teor de lignina residual por Neuro-Fuzzy}

Um modelo ANFIS também foi desenvolvido para predição do teor de lignina residual no processo de pré-tratamento do bagaço da cana-de-açúcar com $\mathrm{ScCO}_{2}$. As variáveis de entrada do sistema, assim como no modelo neural, são temperatura, pressão e teor de etanol na mistura de co-solvente. Todos os dados foram normalizados entre 0 e 1. A Figura 5.20 apresenta a estrutura da topologia do modelo ANFIS desenvolvido.

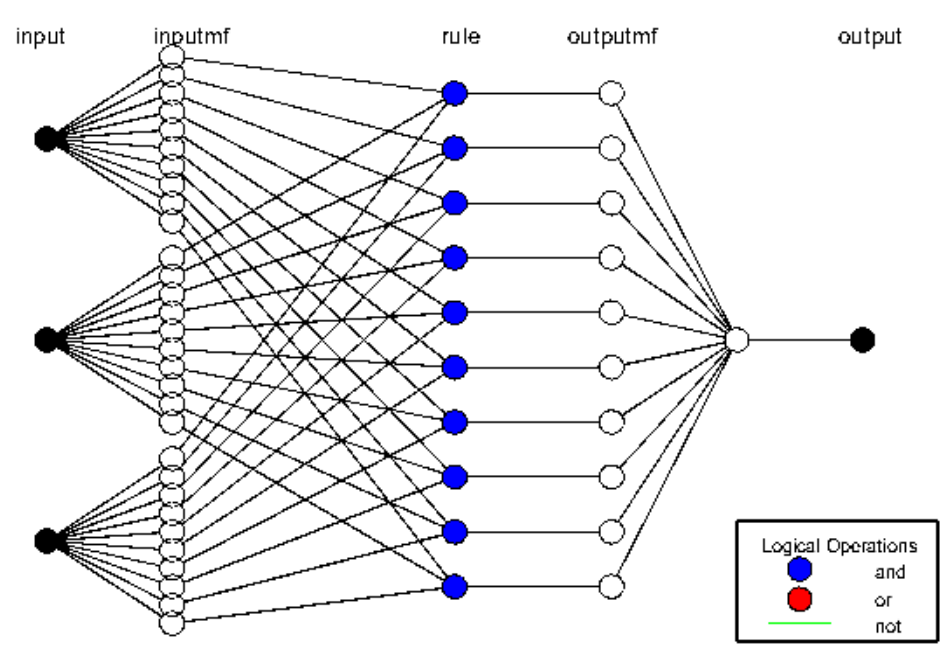

Figura 5.20: Topologia do modelo ANFIS desenvolvido para predição do teor de lignina residual no processo de pré-tratamento com $\mathrm{ScCO}_{2}$.

A função de pertinência obtida foi do tipo Gaussiana, gerando 10 regras. O modelo ANFIS apresentou $\mathrm{R}^{2}$ de $100 \%$ e índices de erro SSE, MSE e RMSE 
de $8,20 \times 10^{-11}, 3,72 \times 10^{-12}$ e $1,93 \times 10^{-6}$, respectivamente.

No entanto, assim como no modelo ANFIS discutido anteriormente, este modelo utilizou 100 parâmetros modificáveis na realização dos cálculos, quantidade muito maior que o número de vetores de entrada para treinamento da rede. Tal fato caracteriza overfitting e justifica a ótima predição e os baixos índices de erro encontrados. Este modelo ANFIS também não é recomendável para predição da resposta do processo. 


\section{Conclusão}

Neste trabalho, foram avaliadas estratégias de modelagem e otimização de dois processos de pré-tratamento do bagaço da cana-de-açúcar: o primeiro utilizando $\mathrm{H}_{2} \mathrm{O}_{2}$ e o segundo, $\mathrm{ScCO}_{2}$.

Os experimentos para o processo de pré-tratamento com $\mathrm{H}_{2} \mathrm{O}_{2}$ foram realizados a partir de um planejamento experimental desenvolvido, onde foram investigadas as variáveis temperatura $\left({ }^{\circ} \mathrm{C}\right)$, concentração de $\mathrm{H}_{2} \mathrm{O}_{2}(\% \mathrm{~m} / \mathrm{v})$ e pH. Para o processo de pré-tratamento com $\mathrm{ScCO}_{2}$, por sua vez, não foi possível a execução dos experimentos a partir de planejamento experimental, devido à dificuldades operacionais no equipamento. Neste caso, as variáveis estudadas foram temperatura $\left({ }^{\circ} \mathrm{C}\right)$, pressão (bar) e teor de etanol na solução aquosa de co-solvente (\%). Nos dois processos, as interações entre as variáveis foram avaliadas após análises por método Klason para quantificação de lignina residual e FT-IR para estimação do teor de lignina oxidada.

Para o processo de pré-tratamento com $\mathrm{H}_{2} \mathrm{O}_{2}$, observou-se que para uma mesma temperatura, o teor de lignina residual na biomassa diminui se o experimento for executado utilizando-se maiores valores de concentração de $\mathrm{H}_{2} \mathrm{O}_{2}$ ou de $\mathrm{pH}$. O menor valor experimental para o teor de lignina residual obtido foi de $6,13 \%$, proveniente do ensaio realizado à $60^{\circ} \mathrm{C}, 8,5 \%$ de $\mathrm{H}_{2} \mathrm{O}_{2}$ e 11,5 de $\mathrm{pH}$.

O processo de pré-tratamento com $\mathrm{ScCO}_{2}$, nas condições estudadas, não se mostrou eficiente para remoção da lignina na biomassa. O menor teor de lignina residual observado foi de $12,17 \%$, resposta do ensaio realizado à $100^{\circ} \mathrm{C}$, 300 bar e $100 \%$ de etanol na solução de co-solvente.

As análises para estimativa do teor de lignina oxidada nos dois processos de pré-tratamento não apresentaram sentido físico e, portanto, não foram utilizadas nas modelagens.

Os modelos desenvolvidos para predição do teor de lignina residual no processo de pré-tratamento com $\mathrm{H}_{2} \mathrm{O}_{2}$ foram os modelos polinomiais, a partir de MMQ e GA e os modelos neurais, a partir de ANN e ANFIS. Os modelos polinomiais se mostraram bem ajustados, com $\mathrm{R}^{2}$ de aproximadamente $93 \%$. A partir das superfícies de respostas construídas, os valores apontados como ótimos das variáveis investigadas para minimização do teor de lignina residual 
foram $60^{\circ} \mathrm{C}, 8 \%$ de $\mathrm{H}_{2} \mathrm{O}_{2}$ e 11,5 de $\mathrm{pH}$. O modelo ANFIS obtido não foi recomendado para predição do teor de lignina residual no processo devido à ocorrência de overfitting. O modelo neural 3-4-1 (tansig-purelin / trainbr) apresentou coeficiente de correlação de $98,71 \%$ e índices de erro SSE, MSE e RMSE de 0,479, 0,003685 e 0,060701, respectivamente. Esses resultados indicam que o modelo neural foi capaz de modelar as não linearidades do sistema mais satisfatoriamente do que os modelos polinomiais propostos. De acordo com as superfícies de respostas e curvas de contorno para este modelo, a minimização do teor de lignina residual começa a ocorrer à $50^{\circ} \mathrm{C}, 10 \%$ de $\mathrm{H}_{2} \mathrm{O}_{2}$ e pH 11,5 .

Para predição do teor de lignina residual no processo de pré-tratamento com $\mathrm{ScCO}_{2}$, foram desenvolvidos modelos neurais a partir de ANN e ANFIS. O modelo ANFIS, assim como descrito para o processo anterior, não teve sua utilização recomendada devido ao overfitting observado. O modelo neural 3-41 (tansig-purelin / traincgb), por sua vez, apresentou $\mathrm{R}^{2}$ de aproximadamente $88 \%$, não se mostrando satisfatório para predição da variável dependente do processo. No entanto, sua utilização é capaz de promover uma estimativa quanto à resposta do processo, indicando as faixas a serem estudadas para as variáveis envolvidas. Os índices de erro SSE, MSE e RMSE para este modelo foram 0,153, 0,001177 e 0,034306, respectivamente. A partir das superfícies de respostas e curvas de contorno construídas, foi possível estimar que a minimização do teor de lignina residual se dá com a utilização de temperatura maior que $100^{\circ} \mathrm{C}$, pressão em torno de 300 bar e mais de $50 \%$ de etanol na solução co-solvente.

Para os dois processos de pré-tratamento estudados, foi indicada a necessidade da realização de uma nova investigação com valores mais altos de temperatura para melhor observação do ponto de mínimo da resposta dos modelos.

Por fim, os dois processos de pré-tratamento se mostraram promissores como alternativas sustentáveis para retirada de lignina do bagaço da canade-açúcar. Os modelos desenvolvidos, com destaque para os modelos neurais, foram satisfatórios para o direcionamento das variáveis investigadas em cada caso para o ótimo dos processos. 


\section{Sugestão para Trabalhos Futuros}

Para trabalhos futuros, sugere-se o desenvolvimento e aprofundamento do aprendizado desenvolvido nessa Dissertação de Mestrado, como explicitado a seguir:

1. Fazer as análises de FT-IR para as amostras de biomassa após o prétratamento pelo método da leitura de pastilhas com KBr.

2. Desenvolver os modelos para predição do teor de lignina oxidada nos processos.

3. Realizar análises de HPLC para determinação dos teores de açúcares disponíveis para posterior hidrólise e fermentação da biomassa.

4. Para o processo de pré-tratamento com $\mathrm{ScCO}_{2}$, estudar a influência de diversos co-solventes diferentes.

5. Realizar estudos com diferentes tamanhos de partículas de bagaço da cana-de-açúcar nos processos de pré-tratamento.

6. Desenvolver novos planejamentos experimentais para os processos de prétratamento, ampliando as faixas de busca para o mínimo global das respostas do processo.

7. Desenvolver um sistema de aquisição de dados durante a realização dos experimentos, visando aumentar a quantidade de dados disponíveis para treinamento e teste dos modelos neurais. 


\section{8 \\ Referências bibliográficas}

[1] GROSSI, C. D.. Modelagem com redes neurais para predição do crescimento microbiano em reator batelada. Master's thesis, Pontifícia Universidade Católica do Rio de Janeiro, 2017.

[2] DA SILVA, V. F. N.. Estudos de pré-tratamento e sacarificação enzimática de resíduos agroindustriais como etapas no processo de obtenção de etanol celulósico Estudos de pré-tratamento e sacarificação enzimática de resíduos agroindustriais como etapas no processo de obtenção. PhD thesis, Universidade de São Paulo, 2009.

[3] CONAB. Acompanhamento da safra brasileira: cana-de-açúcar. Technical Report 61, 2018.

[4] APARECIDO LOPES SILVA, D.; DELAI, I.; LAURA DELGADO MONTES, M. ; OMETTO ROBERTO, A.. Life cycle assessment of the sugarcane bagasse electricity generation in Brazil. Renewable and Sustainable Energy Reviews, 32:532-547, 2014.

[5] RABELO, S. C.. Avaliação de Desempenho de Pré-Tratamento com Peróxido de Hidrogênio Alcalino para a Hidrólise Enzimática de Bagaço de Cana-de-Açúcar. Master's thesis, 2007.

[6] RABELO, S. C.. Avaliação E Otimização De Pré-Tratamentos E Hidrólise Enzimática Do Bagaço De Cana-De-Açúcar Para a Produção De Etanol De Segunda Geração. PhD thesis, 2010.

[7] M RUBIN, E.. Rubin em. genomics of cellulosic biofuels. nature 454(7206). Nature, 454:841-5, 092008.

[8] ZHU, W.. Equilibrium of Lignin Precipitation. PhD thesis, Chalmers University of Technology, 2013.

[9] FERREIRA, V.F; ROCHA, D.. Potencialidades e oportunidades na química da sacarose e outros açúcares. Química Nova, 32(3):623638, 2009. 
[10] MILÉO, P. C.. Aplicações da celulose de palha de cana-de-açúcar: obtenção de derivados partindo de celulose branqueada e de biocompósitos com poliuretana obtida a partir de óleo de mamona (Ricinus communis L.). Master's thesis, 2011.

[11] SANTOS, F. A.; QUEIROZ, J. H. D.; COLODETTE, J. L.; MANFREDI, M.; QUEIROZ, M. E. L. R.; CELSO, S. ; SOARES, F. E. F.. Otimização do pré-tratamento hidrotérmico da palha de cana-de-açúcar visando à produção de etanol celulósico. Química Nova, 37(1):56-62, 2014.

[12] REGO, A. S. D. C.. Otimização dos parâmetros da desliginização do bagaço de cana-de-açúcar com peróxido de hidrogênio alcalino através de modelo neural. Master's thesis, Pontifícia Universidade Católica do Rio de Janeiro, 2017.

[13] SILVA, O. G.. Produção De Etanol Com a Utilização Do Bagaço De Cana-De-Açúcar. Master's thesis, 2010.

[14] FENGEL, D.; WEGENER, G.. Wood: Chemistry, Ultrastructure, Reactions. Kessel, Norbert, Dr., 2003.

[15] BRIENZO, M.. Extração da hemicelulose do bagaço de cana-deaçúcar para produção de. PhD thesis, Universidade de São Paulo, 2010.

[16] LABAT, G.A.A; GONÇALVES, A.. Oxidation in Acidic Medium of Lignins from Agricultural Residues Oxidation in Acidic Medium of Lignins from Agricultural Residues. Applied Biochemistry and Biotechnology, 148:151-161, 2008.

[17] HU, T. Q.. Chemical Modification, Properties and Usage of Lignin. Springer Science, 2002.

[18] HAMELINCK, C. N.; VAN HOOIJDONK, G. ; FAAIJ, A. P.. Ethanol from lignocellulosic biomass: techno-economic performance in short-, middle- and long-term. Biomass and Bioenergy, 28(4):384 - 410, 2005.

[19] WYMAN, C.. Handbook on Bioethanol: Production and Utilization. CRC Press, 2018.

[20] DE OLIVEIRA, C. C. D. S.. Otimização do pré-tratamento com peróxido de hidrogênio alcalino a alta concentração de sólidos para a hidrólise enzimática de bagaço de cana-de-açúcar. Master's thesis, Universidade Estadual de Campinas, 2012. 
[21] SARI, F.; BUDIYONO, B.. Enhanced biogas production from rice straw with various pretreatment : a review. Waste Technology, 2, 032014.

[22] MOSIER, N.; WYMAN, C.; DALE, B.; ELANDER, R.; LEE, Y.; HOLTZAPPLE, M. ; LADISCH, M.. Features of promising technologies for pretreatment of lignocellulosic biomass. Bioresource Technology, 96(6):673 - 686, 2005.

[23] SUN, Y.; CHENG, J.. Hydrolysis of lignocellulosic materials for ethanol production: a review. Bioresource Technology, 83(1):1 - 11, 2002. Reviews Issue.

[24] KOULLAS, D. P.; CHRISTAKOPOULOS, P.; KEKOS, D.; MACRIS, B. J. ; KOUKIOS, E. G.. Correlating the Effect of Pretreatment. Biotechnology and Bioengineering, 39:113-116, 1992.

[25] AZUMA, J.-I.; HIGASHINO, J.; ISAKA, M. ; KOSHIJIMA, T.. Microwave irradiation of lignocellulosic materials : Iv. enhancement of enzymatic susceptibility of microwave-irradiated softwoods. Wood Research, 71, 011985.

[26] RAMOS, L.; NAZHAD, M. ; SADDLER, J.. Effect of enzymatic hydrolysis on the morphology and fine structure of pretreated cellulosic residues. Enzyme and Microbial Technology, 15(10):821 - 831, 1993.

[27] FARID, M. A.; SHAKER, H. M. ; EI-DIWANY, A. I.. Effect of peracetic acid, sodium hydroxide and phosphoric acid on cellulosic materials as a pretreatment for enzymatic hydrolysis. Enzyme and microbial technology, 5:421-424, 1983.

[28] BES, R.; GAS, G.; MOLINIER, J.; VIDAL, P.; MATHIEU, J. ; MORA, J.. Enhancement of poplar cellulose susceptibility to cellulase enzyme hydrolysis by ozonation. Ozone: Science \& Engineering, 11(2):217-226, 1989.

[29] SZCZODRAK, J.; LLCZUK, Z.; ROGALSKI, J. ; LEONOWICZ, A.. Intensification of oak sawdust enzymatic hydrolysis by chemical or hydrothermal pretreatment. Biotechnology and bioengineering, 28:50410, 041986.

[30] ROLZ, C.; DE LEON, R.; ARRIOLA, M. ; DE CABRERA, S.. Biodelignification of lemon grass and citronella bagasse by white-rot fungi. Applied and environmental microbiology, 52:607-11, 111986. 
[31] MES-HARTREE, M.; YU, E. K. C.; REID, I. D. ; SADDLER, J. N.. Suitability of aspenwood biologically delignified with pheblia tremellosus for fermentation to ethanol or butanediol. Applied Microbiology and Biotechnology, 26(2):120-125, May 1987.

[32] PURI, V.; R PEARCE, G.. Alkali-explosion pretreatment of straw and bagasse for enzymic hydrolysis. Biotechnology and bioengineering, 28:480-5, 041986.

[33] ALVIRA, P.; TOMÁS-PEJÓ, E.; BALLESTEROS, M. ; NEGRO, M. J.. Pretreatment technologies for an efficient bioethanol production process based on enzymatic hydrolysis: A review. Bioresource technology, 101 13:4851-61, 2010.

[34] MICHAEL GOULD, J.. Studies on the mechanism of alkaline peroxide delignification of agriculture residues. Biotechnology and bioengineering, 27:225-31, 031985.

[35] MICHAEL GOULD, J.. Alkaline peroxide delignification of agricultural residues to enhance enzymatic saccharification. [trichoderma reesei]. Biotechnology and bioengineering, 26:46-52, 011984.

[36] SUN, R. C.; FANG, J. ; TOMKINSON, J.. Delignification of rye straw using hydrogen peroxide. Industrial Crops and Products, 12(2):71 - 83, 2000.

[37] CHANDRA, R.; BURA, R.; MABEE, W.; BERLIN, A.; PAN, X. ; SADDLER, J.. Substrate pretreatment: the key to effective enzyme hydrolysis of lignocellulosics? Adv. Biochem. Eng. Biotechnol., 108:69-93, 01 2007.

[38] NGUYEN, Q.; DICKOW, J.; DUFF, B.; FARMER, J.; GLASSNER, D.; IBSEN, K.; RUTH, M.; SCHELL, D.; THOMPSON, I. ; TUCKER, M.. Nrel/doe ethanol pilot-plant: Current status and capabilities. Bioresource Technology, 58(2):189 - 196, 1996. IEA Network-Biotechnology for the Conversion of Lignocellulosics.

[39] KUMAR, P.; BARRETT, D. M.; DELWICHE, M. J. ; STROEVE, P.. Methods for pretreatment of lignocellulosic biomass for efficient hydrolysis and biofuel production. Industrial \& Engineering Chemistry Research, 48(8):3713-3729, 2009. 
[40] SUN, Y.. Supercritical Fluid Technology in Materials Science and Engineering: Syntheses: Properties, and Applications. Taylor \& Francis, 2002.

[41] SIHVONEN, M.; JÄRVENPÄÄ, E.; HIETANIEMI, V. ; HUOPALAHTI, R.. Advances in supercritical carbon dioxide technologies. Trends in Food Science Technology, 10(6):217 - 222, 1999.

[42] PIMENTA, M. T. B.. Utilização de fluídos no estado sub/supercrítico na polpação de Eucalptus E Pinus taeda. PhD thesis, 2005.

[43] DALMOLIN, I.; MAZUTTI, M. A.; BATISTA, E. A.; MEIRELES, M. A. A. ; OLIVEIRA, J. V.. Chemical characterization and phase behaviour of grape seed oil in compressed carbon dioxide and ethanol as co-solvent. The Journal of Chemical Thermodynamics, 42(6):797 - 801, 2010.

[44] PASQUINI, D.; PIMENTA, M. T.; FERREIRA, L. H. ; CURVElO, A. A.. Sugar cane bagasse pulping using supercritical CO2associated with co-solvent 1-butanol/water. Journal of Supercritical Fluids, 34(2 SPEC. ISS.):125-131, 2005.

[45] MEIRELES, M. A.. Extracting Bioactive Compounds for Food Products: Theory and Applications. CRC Press, 2008.

[46] PASQUiNI, D.; PIMENTA, M. T. B.; FERREIRA, L. H. ; CURVElO, A. A. D. S.. Extraction of lignin from sugar cane bagasse and Pinus taeda wood chips using ethanol-water mixtures and carbon dioxide at high pressures. Journal of Supercritical Fluids, 36(1):31-39, 2005.

[47] RODRIGUES, M. I.; IEMMA, A. F.. Planejamento de Experimentos e Otimização de Processos. CRC Press, 2005.

[48] RABElO, S. C.; ANDRADE, R. R.; MACIEL FILHO, R. ; COSTA, A. C.. Alkaline hydrogen peroxide pretreatment, enzymatic hydrolysis and fermentation of sugarcane bagasse to ethanol. Fuel, 136:349357, 2014.

[49] LINDEN, R.. Algoritmos genéticos: uma importante ferramenta da inteligência computacional. Brasport, 2006. 
[50] PAPPU, S. M. J.; GUMMADI, S. N.. Artificial neural network and regression coupled genetic algorithm to optimize parameters for enhanced xylitol production by Debaryomyces nepalensis in bioreactor. Biochemical Engineering Journal, 120:136-145, 2017.

[51] RIVERA, E. C.; COSTA, A. C.; ATALA, D. I. P.; MAUGERI, F.; MACIEL, M. R. W. ; FILHO, R. M.. Evaluation of optimization techniques for parameter estimation: Application to ethanol fermentation considering the effect of temperature. Process Biochemistry, 41(7):16821687, 2006.

[52] MAITI, B.; RATHORE, A.; SRIVASTAVA, S.; SHEKHAWAT, M. ; SRIVASTAVA, P.. Optimization of process parameters for ethanol production from sugar cane molasses by Zymomonas mobilis using response surface methodology and genetic algorithm. Applied Microbiology and Biotechnology, 90(1):385-395, 2011.

[53] How the genetic algorithm works. https://www.mathworks.com/ help/gads/how-the-genetic-algorithm-works.html. Acessado em: 10-07-2018.

[54] EIBEN, A.; SMITH, J.. Introduction to Evolutionary Computing. Natural Computing Series. Springer Berlin Heidelberg, 2007.

[55] LOWEN, R.; VERSCHOREN, A.. Foundations of Generic Optimization: Volume 2: Applications of Fuzzy Control, Genetic Algorithms and Neural Networks. Mathematical Modelling: Theory and Applications. Springer Netherlands, 2007.

[56] KAYRI, M.. Predictive Abilities of Bayesian Regularization and Levenberg-Marquardt Algorithms in Artificial Neural Networks: A Comparative Empirical Study on Social Data. Mathematical and Computational Applications, 21(2):20, 2016.

[57] DE PÁDUA BRAGA, A.. Redes neurais artificiais: teoria e aplicações. LTC Editora, 2007.

[58] AlBUQUERQUE, C. D. D. C.. Processo de produção de bioemulsificante por Candida lipolytica: otimização, ampliação de escala e desenvolvimento de softsensor baseado em redes neurais artificiais. PhD thesis, Universidade Estadual de Campinas, 2006.

[59] VATS, S.; NEGI, S.. Use of artificial neural network (ANN) for the development of bioprocess using Pinus roxburghii fallen foliages 
for the release of polyphenols and reducing sugars. Bioresource Technology, 140:392-398, 2013.

[60] NAIR, V. V.; DHAR, H.; KUMAR, S.; THALLA, A. K.; MUKHERJEE, S. ; WONG, J. W.. Artificial neural network based modeling to evaluate methane yield from biogas in a laboratory-scale anaerobic bioreactor. Bioresource Technology, 217:90-99, 2016.

[61] VALIM, I. C.; FIDALGO, J. L.; REGO, A. S.; VILANI, C.; MARTINS, A. R. F. ; SANTOS, B. F.. Neural network modeling to support an experimental study of the delignification process of sugarcane bagasse after alkaline hydrogen peroxide pre-treatment. Bioresource Technology, 243:760-770, 2017.

[62] SANCHEZ, E. C. M.. Controle por Aprendizado Acelerado e Neuro-Fuzzy de Sistemas Servo - Hidráulicos de Alta Frequência Controle por Aprendizado Acelerado e Neuro-Fuzzy de Sistemas Servo - Hidráulicos de Alta Frequência. Master's thesis, Pontifícia Universidade Católica do Rio de Janeiro, 2009.

[63] traingdx. https://www.mathworks.com/help/nnet/ref/traingdx. html. Acessado em: 15-08-2018.

[64] Neural Networks and Fuzzy Systems: A Dynamical Systems Approach to Machine Intelligence/Book and Disk. Neural Networks and Fuzzy Systems: A Dynamical Systems Approach to Machine Intelligence. Prentice-Hall International, 1992.

[65] Neural network architectures. https://www.mathworks.com/help/ nnet/ug/neural-network-architectures.html. Acessado em: 12-072018.

[66] QUINTERO, E. C. Z. G. J. D. V. H. R. A. S.. Sistemas adaptativos de inferencia neurodifusa con errores heterocedásticos para el modelado de series financieras. Cuadernos De Administración, (37):311334.

[67] LUCCHESI, S.; ROVEDA, S. R. M. M.. SISTEMAS NEURO-FUZZY. (1):1-5, 2004.

[68] AKKAYA, E.. ANFIS based prediction model for biomass heating value using proximate analysis components. Fuel, 180:687-693, 2016. 
[69] LERKKASEMSAN, N.. Fuzzy logic-based predictive model for biomass pyrolysis. Applied Energy, 2016.

[70] ERDIRENCELEBI, D.; YALPIR, S.. Adaptive network fuzzy inference system modeling for the input selection and prediction of anaerobic digestion effluent quality. Applied Mathematical Modelling, 35(8):3821-3832, 2011.

[71] TAKAGI, T.; SUGENO, M.. Fuzzy Identification of Systems and Its Applications to Modeling and Control. IEEE, (1):116-132, 1985.

[72] ABDULSHAHED, A. M.; LONGSTAFF, A. P.; FLETCHER, S. ; MYERS, A.. Thermal error modelling of machine tools based on ANFIS with fuzzy c-means clustering using a thermal imaging camera. Applied Mathematical Modelling, 39(7):1837-1852, 2014.

[73] SILARBI, S.; ABDERRAhMANE, B. ; BENYETTOU, A.. Adaptive Network Based Fuzzy Inference System for Speech Recognition Through Subtractive. International Journal of Artificial Intelligence Applications, 5(6):43-52, 2014.

[74] Membership function gallery. https://www.mathworks.com/help/ fuzzy/examples/membership-function-gallery.html. Acessado em: 15-07-2018.

[75] Genfis. https://www.mathworks.com/help/fuzzy/genfis.html. Acessado em: 15-07-2018.

[76] SLUITER, A.; HAMES, B.; RUIZ, R.; SCARLATA, C.; SLUITER, J.; TEMPLETON, D. ; CROCKER, D.. NREL/TP-510-42618 analytical procedure - Determination of structural carbohydrates and lignin in Biomass. Laboratory Analytical Procedure (LAP), (April 2008):17, 2012.

[77] SRINIVAS, K.; DE CARVALHO OLIVEIRA, F.; TELLER, P. J.; GONALVES, A. R.; HELMS, G. L. ; AHRING, B. K.. Oxidative degradation of biorefinery lignin obtained after pretreatment of forest residues of Douglas Fir. Bioresource Technology, 221:394-404, 2016.

[78] DE FRANÇA, J.; FRANÇA, M.; HITOMI KOYAMA, M. ; SILVA, T.. Uma implementação do algoritmo levenberg-marquardt dividido para aplicações em visão computacional. In: SEMINA: ClêNCIAS EXATAS E TECNOLóGICAS, volumen 30, 032009. 
[79] trainlm. https://www.mathworks.com/help/nnet/ref/trainlm. html. Acessado em: 15-08-2018.

[80] trainbr. https://www.mathworks. com/help/nnet/ref/trainbr.html. Acessado em: 15-08-2018.

[81] traincgb. https://www.mathworks.com/help/nnet/ref/traincgb. html. Acessado em: 15-08-2018.

[82] trainoss. https://www.mathworks.com/help/nnet/ref/trainoss. html. Acessado em: 15-08-2018.

[83] GREEN, D.W; PERRY, R.H. Perry's Chemical Engineers' Handbook. 8th edition, 2008.

[84] AZZAM, A.. Pretreatment of cane bagasse with alkaline hydrogen peroxide for enzymatic hydrolysis of cellulose and ethanol fermentation. Journal of Environmental Science and Health, Part B, 24(4):421-433, 1989.

[85] GARCIA, D. D. R.. Determinação de Dados Cinéticos do PréTratamento de Bagaço de Cana-de-Açúcar com Peróxido de Hidrogênio Alcalino e da Hidrólise Enzimática Posterior. Master's thesis, 2009.

[86] FAN, L. T.; LEE, Y.-H. ; GHARPURAY, M. M.. The nature of lignocellulosics and their pretreatments for enzymatic hydrolysis. In: MICROBIAL REACTIONS, p. 157-187, Berlin, Heidelberg, 1982. Springer Berlin Heidelberg.

[87] FERREIRO, A. I.; RABAÇAL, M. ; COSTA, M.. A combined genetic algorithm and least squares fitting procedure for the estimation of the kinetic parameters of the pyrolysis of agricultural residues. Energy Conversion and Management, 125:290-300, 2016.

[88] NAZERIAN, M.; KAMYABB, M.; SHAMSIANB, M.; DAHMARDEHB, M. ; KOOSHAA, M.. Comparison of response surface methodology (RSM) and artificial neural networks (ANN) towards efficient optimization of flexural properties of gypsum-bonded fiberboards. CERNE, 24:35 - 47, 032018. 


\section{Anexos}

\section{1}

\section{Código para desenvolvimento dos modelos ANN}

close all; :fecha todas as janelas abertas

clear all; olimpa as informaçoes de todas as variáveis salvas

clc; \%apaga os dados da janela de comando

ócarregamento e Normalização da Planilha de dados

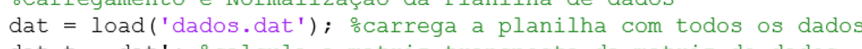

dat_t = dat'; \%calcula a matriz transposta da matriz de dados

in $\operatorname{tr}=$ dat $t(1: 3,1: 130)$; odefine os dados de entrada do treinamento

out_tr = dat_t $(4,1: 130)$; odefine os dados de saída do treinamento

[in_tr_norm, ft_in_tr_norm] = mapminmax (in_tr, 0, 1); onormalização dos dados de entrada do treinamento

[out_tr_norm, ft_out_tr_norm] = mapminmax (out_tr, 0, 1); onormalização dos dados de saida do treinamento

\%Carregamento e Normalização dos dados do teste

in teste $=$ dat $t(1: 3,131: 187)$; odefine os dados de entrada do teste

out_teste $=$ dat_t $(4,131: 187)$; o define os dados de saída do teste

[in_teste_norm] = mapminmax ('apply', in_teste, ft_in_tr_norm); onormalização dos dados de entrada do teste usando os mesmos parâmetros do treinamento

[out teste norm] = mapminmax ('apply', out teste, ft out tr norm); onnormalização dos dados de saida do téste usando os mesmos parâmetros do treinamento 
\% Simulação da rede com os dados de treinamento

out_calc_tr_norm $=\operatorname{sim}(r e d e$, in_tr_norm $(:,:))$; $\%$ simula a rede com os dados de entrada do treinamento e devolve a saída calculada e normalizada

out_calc_tr_desnorm = mapminmax ('reverse', out_calc_tr_norm, ft_out_tr_norm); odesnormaliza a saída calculadà dō treinamento

ㅇsimulação da rede com os dados do teste

out calc teste norm $=$ sim(rede, in teste norm $(:,:))$; \%simula a rede com os dados de entrada do teste out calc teste desnorm = mapminmax ('reverse', out calc teste norm, ft out tr norm); \%desnormaliza saída cā̄culadā do teste

\%Gráficos do Treinamento

。Criação da reta de ajuste linear para o treinamento

[coef_curve1, error1] = polyfit(out_calc_tr_desnorm, out_tr,1); o define os coeficientes da reta de ajuste 1

Y_curve1 = polyval (coef_curve1, out_calc_tr_desnorm, error1); oodefine a variável y da reta de ajuste X_curve1 = out_calc_tr_desnorm; oofefine à variável $\mathrm{x}$ da reta de ajuste

:Criação da reta modelo

$\mathrm{x}=0: 1 ;$

$\mathrm{y}=\mathrm{x}$;

ㅇráficos do Teste

\%Criação da reta de ajuste linear para o teste

[coef_curve2, error2] = polyfit(out_calc_teste_desnorm, out_teste,1); odefine os coeficientes da reta de ajuste 1

Y curve2 = polyval (coef curve2, out calc teste desnorm); odefine a variável y da reta

X_curve2 = out_calc_teste_desnorm; ơdefiñe a variável $\mathrm{x}$ da reta

oCálculo do R2 e dos coeficientes de erro da reta 2

r2_curve2 = calc_r2 (out_calc_teste_desnorm, out_teste);

sse_curve2 = sse (rede, out_teste, out_calc_teste_desnorm);

mse curve2 = immse (out teste, out calc teste desnorm);

rmse_curve2 = sqrt (mse_curve2);

subplot $(1,2,1)$; oplota $\circ$ terceiro conjunto de curvas no terceiro quadrante da figura 1

plot (out_calc_teste_desnorm, out_teste, 'og ${ }^{\prime}$ );

hold on opermite que mais de uma curva seja plotada no mesmo gr?fico

plot (X_curve2, Y curve2, '-k'); 을 lota a reta de melhor ajuste dos pontos

plot $\left(\mathrm{x}, \mathrm{y},{ }^{\prime}--\mathrm{b}^{\prime}\right)$

title2 = strcat ('R ${ }^{2}=$ ', num2str(r2_curve2)); oartificio para plotar texto e valores no t?tulo

title(title2, 'FontSize',11);

xlabel('Teor de Lignina Residual (Predito)','FontSize',9); o.legenda do eixo x

ylabel('Teor de Lignina Residual (Experimental) ',9); olegenda do eixo y

hold off

subplot $(2,2,4)$; oplota o quarto conjunto de curvas no quarto quadrante da figura 1

plot(out_teste, '-k'); \%saída real do teste

hold on

plot (out calc teste desnorm, 'vb'); \%saída calculada pela rede - om para aparecer pontos

xlabel ('Ámostras', 'FontSize', 9)'

ylabel ('Teor de Lignina Residual (\%) ', 'FontSize', 9);

legend ('Experimental', 'Predito');

hold off

colordef white; oncor de fundo dos gráficos

을

weight_c1 = rede.IW $\{1\}$; \%sempre, na camada de entrada, usa-se IW.

bias_c $\overline{1}=$ rede.b $\{1\}$;

weight_c2 = rede.LW $\{2,1\}$; $\frac{\circ}{L} \mathrm{~W}$ é usado nas camadas seguinte; 2 e 1 significam que a informação vem da camada 1 , é processada, e sai pela camada 2.

bias_c2 $=$ rede.b $\{2\}$

savefig ('Rede53'); osalva o gráfico como arquivo editável do matlab

save 'Rede53'; \%salva a rede, com todos os parametros e variáveis do teste que foi rodado 


\section{2}

\section{Código para desenvolvimento dos modelos GA}

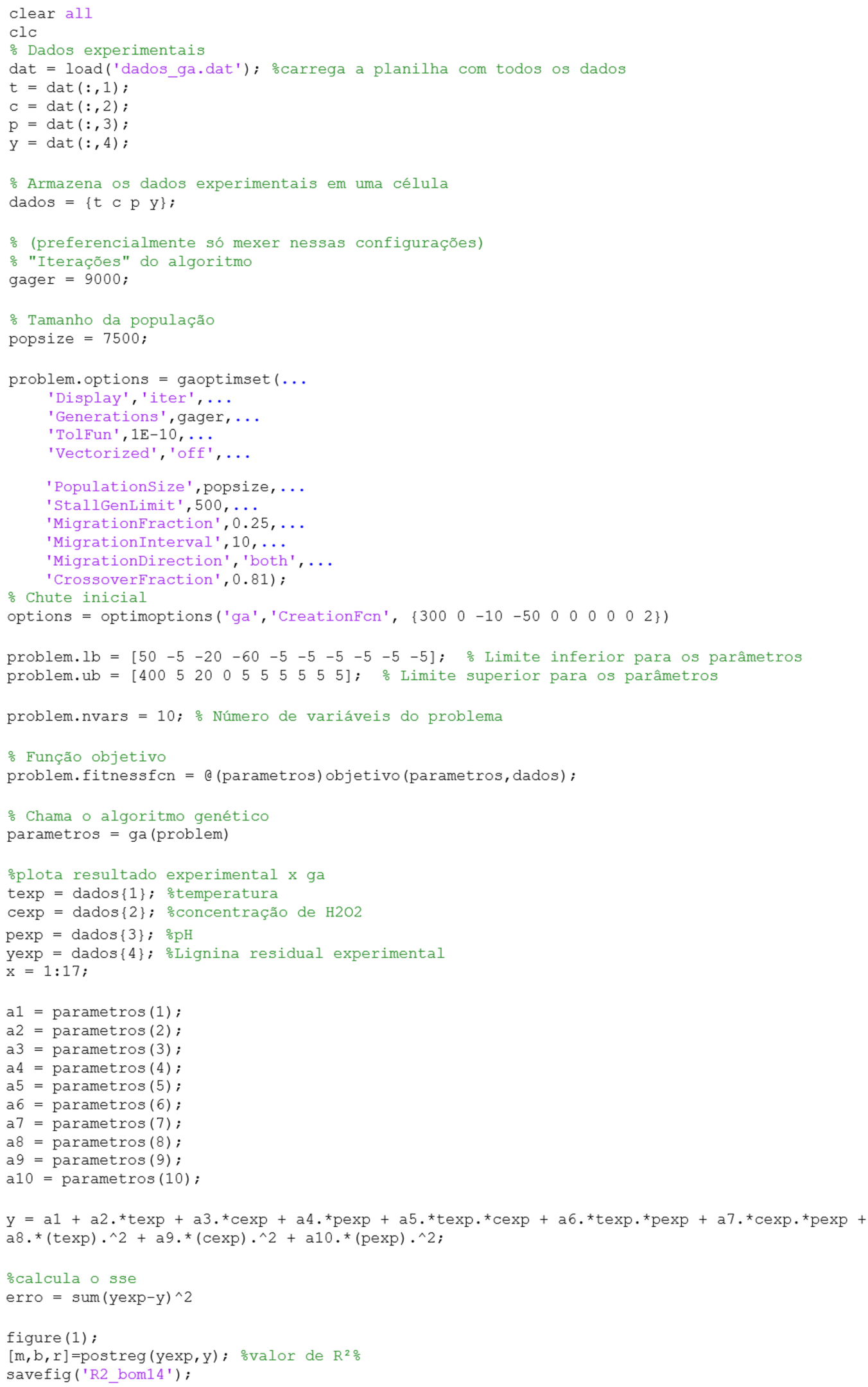


figure (2)

plot $\left(x, y e x p, ' b: \circ^{\prime}, x, y,{ }^{\prime} r v^{\prime}\right)$;

xlabel ('Amostras');

ylabel('Teor de Lignina Residual (응) ');

legend('Experimental', 'GA')'

save ('ga_bom34');

savefig ('ga_bom34');

function fobj = objetivo(parametros, dados)

: Parâmetros

a1 = parametros (1);

a2 = parametros (2);

a 3 = parametros (3);

a 4 = parametros (4)

a5 = parametros (5);

a 6 parametros (6);

a7 = parametros (7);

a8 = parametros $(8)$

a 9 = parametros (9);

a10 = parametros $(10)$

\% Dados experimentais

texp $=\operatorname{dados}\{1\} ;$ \%temperatura

cexp $=$ dados $\{2\} ;$ \% concentração de H2O2

$\operatorname{pexp}=\operatorname{dados}\{3\} ; \circ \mathrm{pH}$

yexp $=\operatorname{dados}\{4\} ;$ oLignina residual experimental

\% Calcula a função com os parâmetros atuais

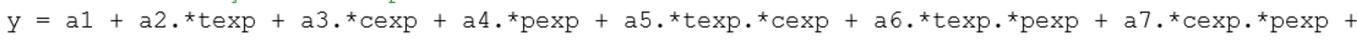
$\mathrm{a} 8 \cdot{ }^{\star}(\operatorname{texp}) \cdot{ }^{\wedge} 2+\mathrm{a} 9 \cdot{ }^{\star}(\operatorname{cexp}) \cdot{ }^{\wedge} 2+\mathrm{a} 10 \cdot{ }^{\star}($ pexp $) \cdot{ }^{\wedge} 2 ;$

\% Mínimos quadrados

fobj $=\operatorname{sum}\left((y-y e x p) \cdot{ }^{\wedge} 2\right)$

end 


\section{3}

\section{Código para geração das superfícies de respostas e curvas de contorno dos modelos polinomiais}

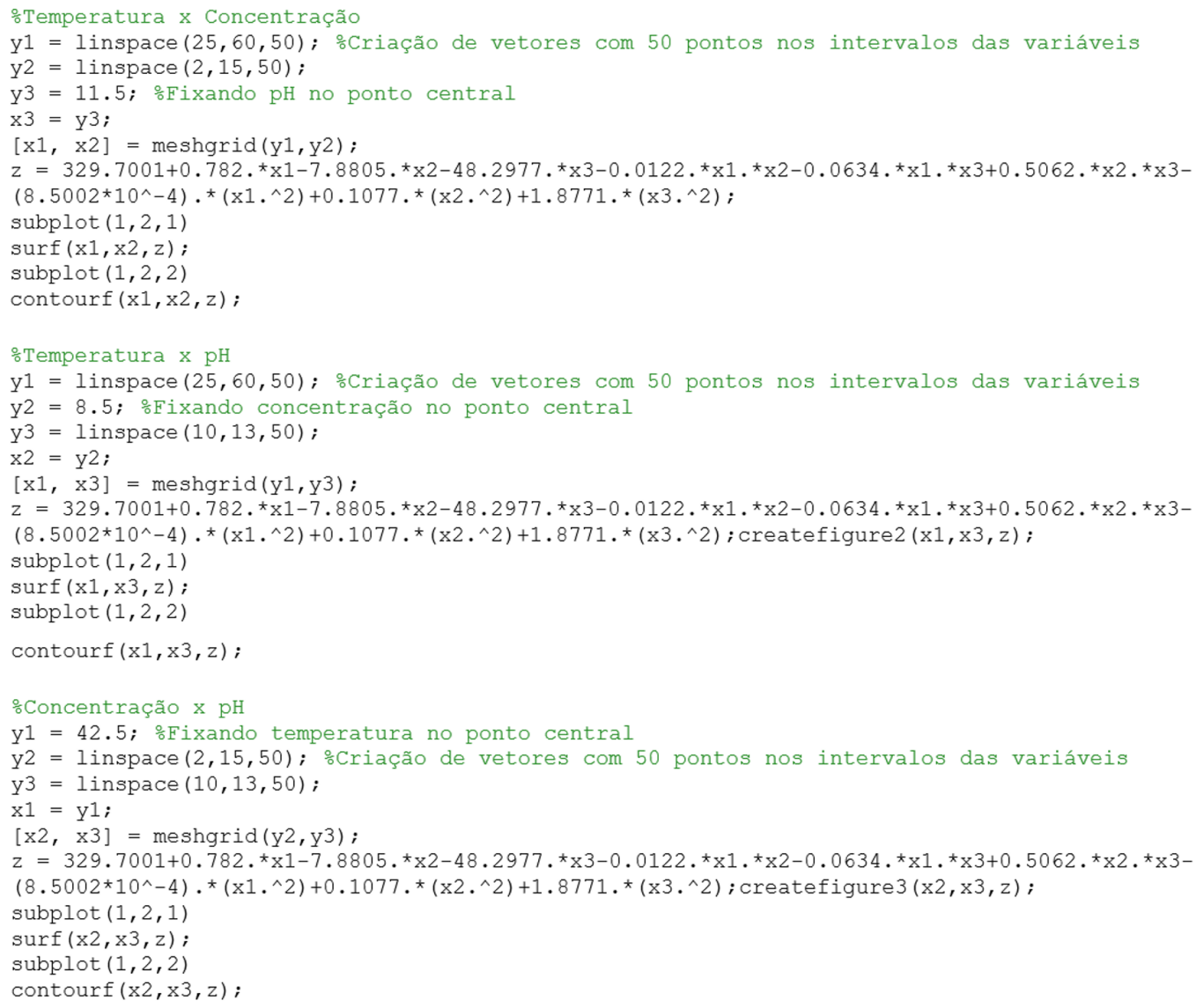




\section{4}

\section{Código para geração das superfícies de respostas e curvas de contorno dos modelos neurais}

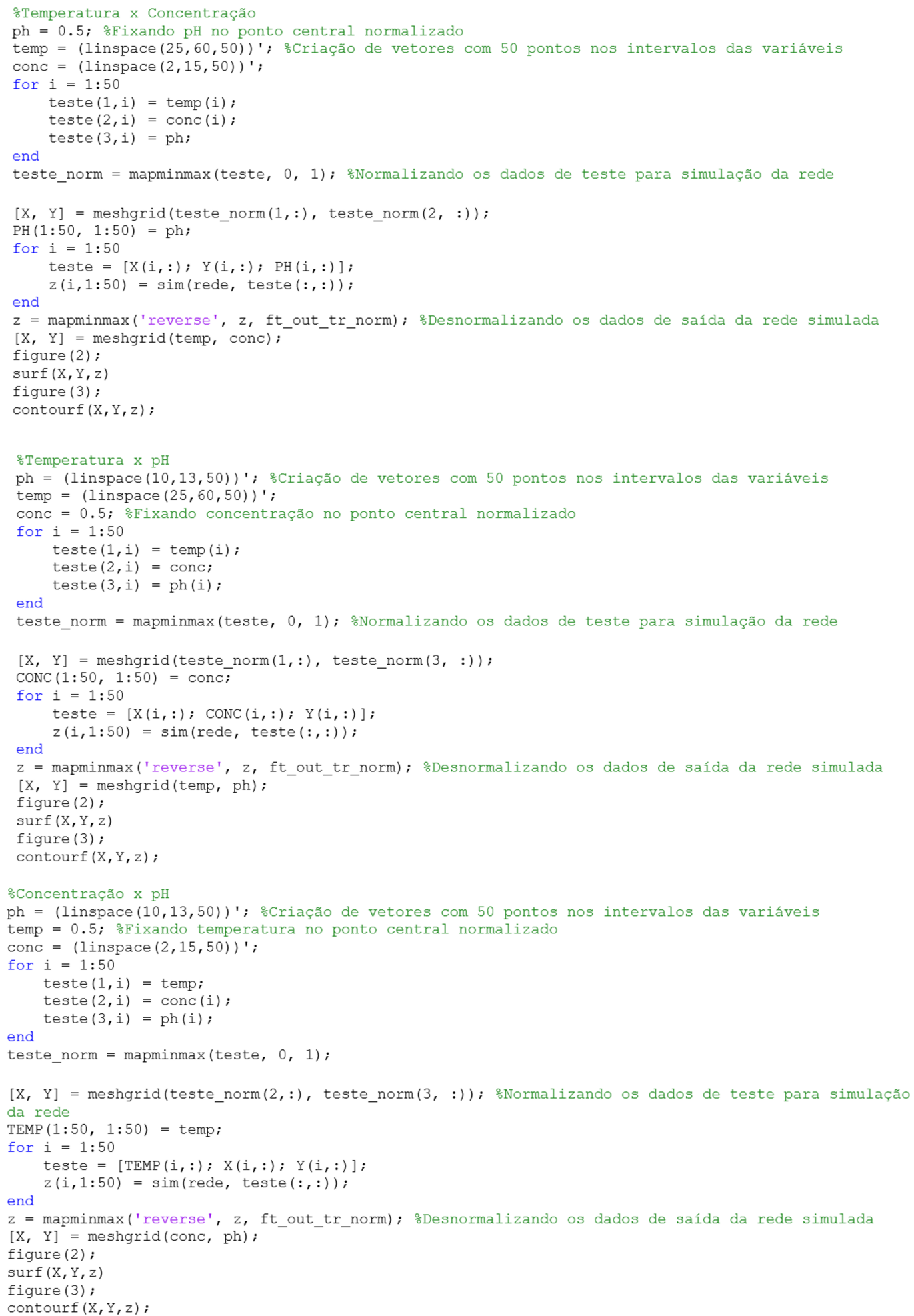




\section{5}

\section{Manual para utilização da Toolbox para geração de modelos ANFIS}

1. Na janela de simulação, escolher o modelo de inferência do tipo Sugeno.

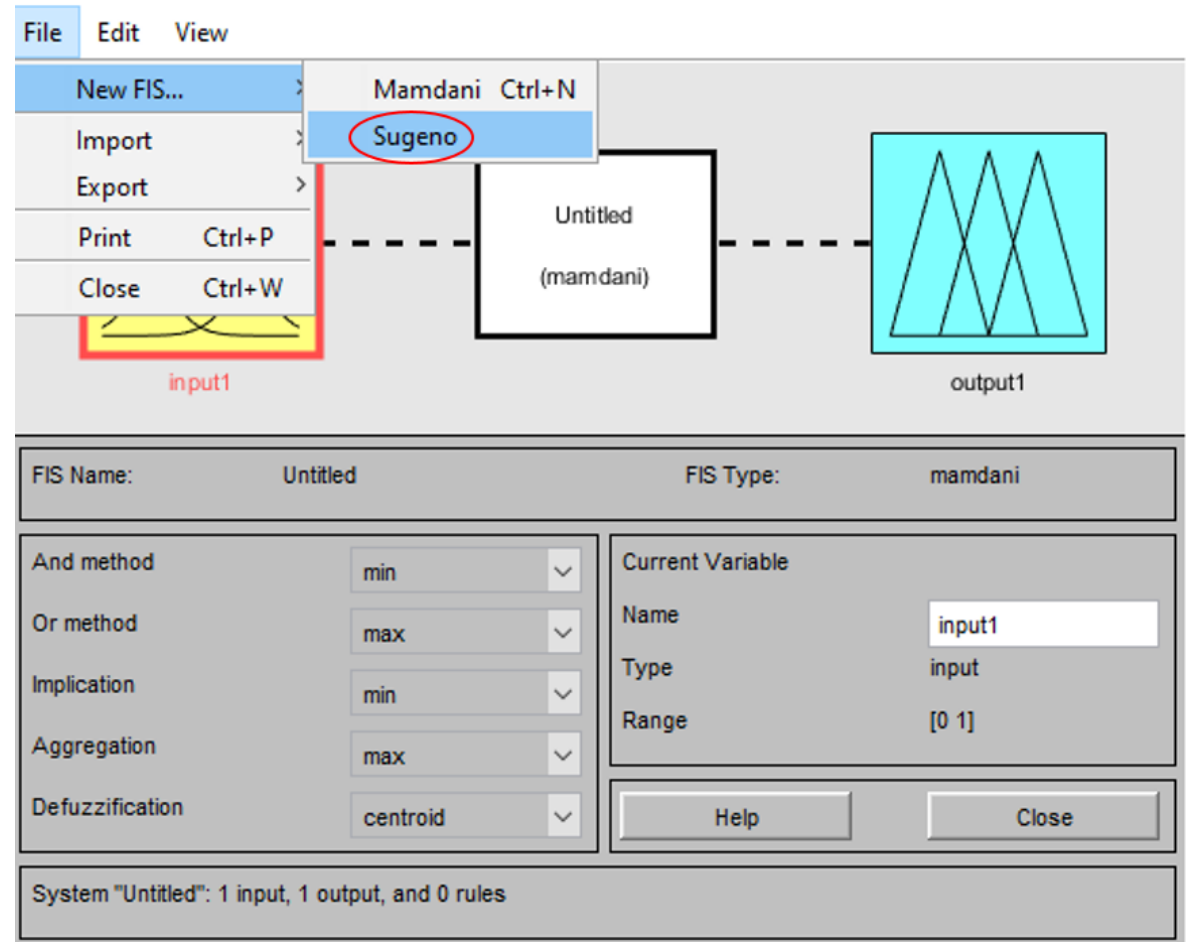

2. Incluir a quantidade exata de variáveis de entrada para o modelo.

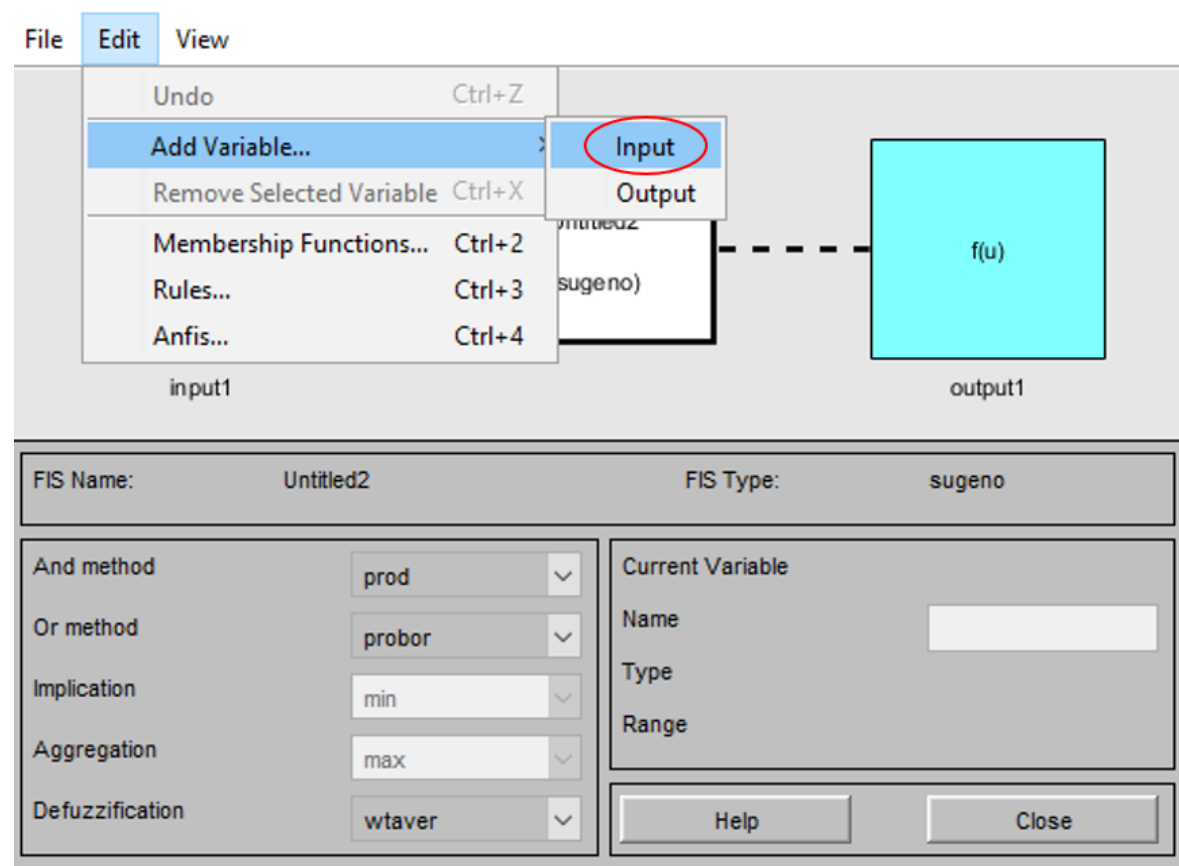


3. Abrir a interface para treinamento e teste do modelo ANFIS.

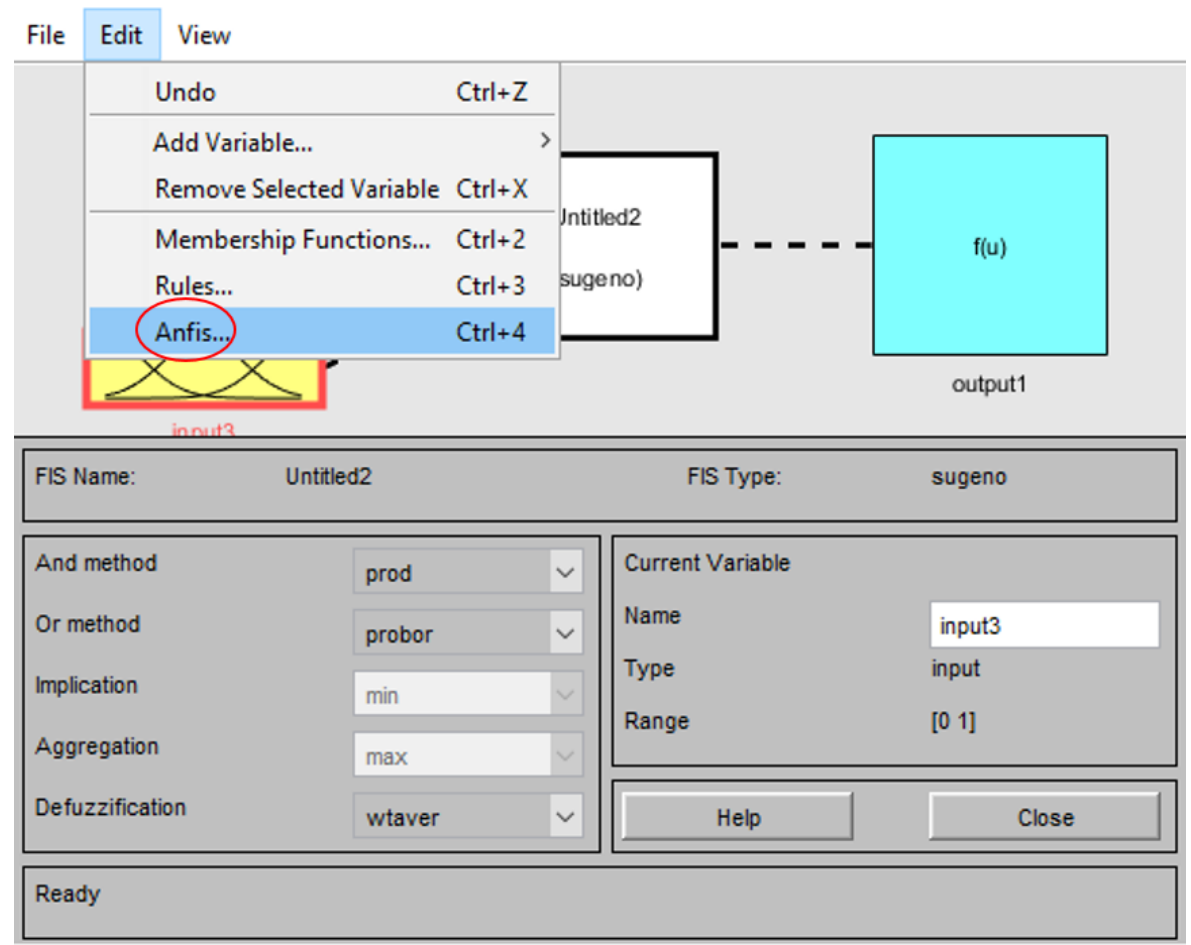

4. Carregar o arquivo com extensão ".dat"dos dados de treinamento previamente normalizados.

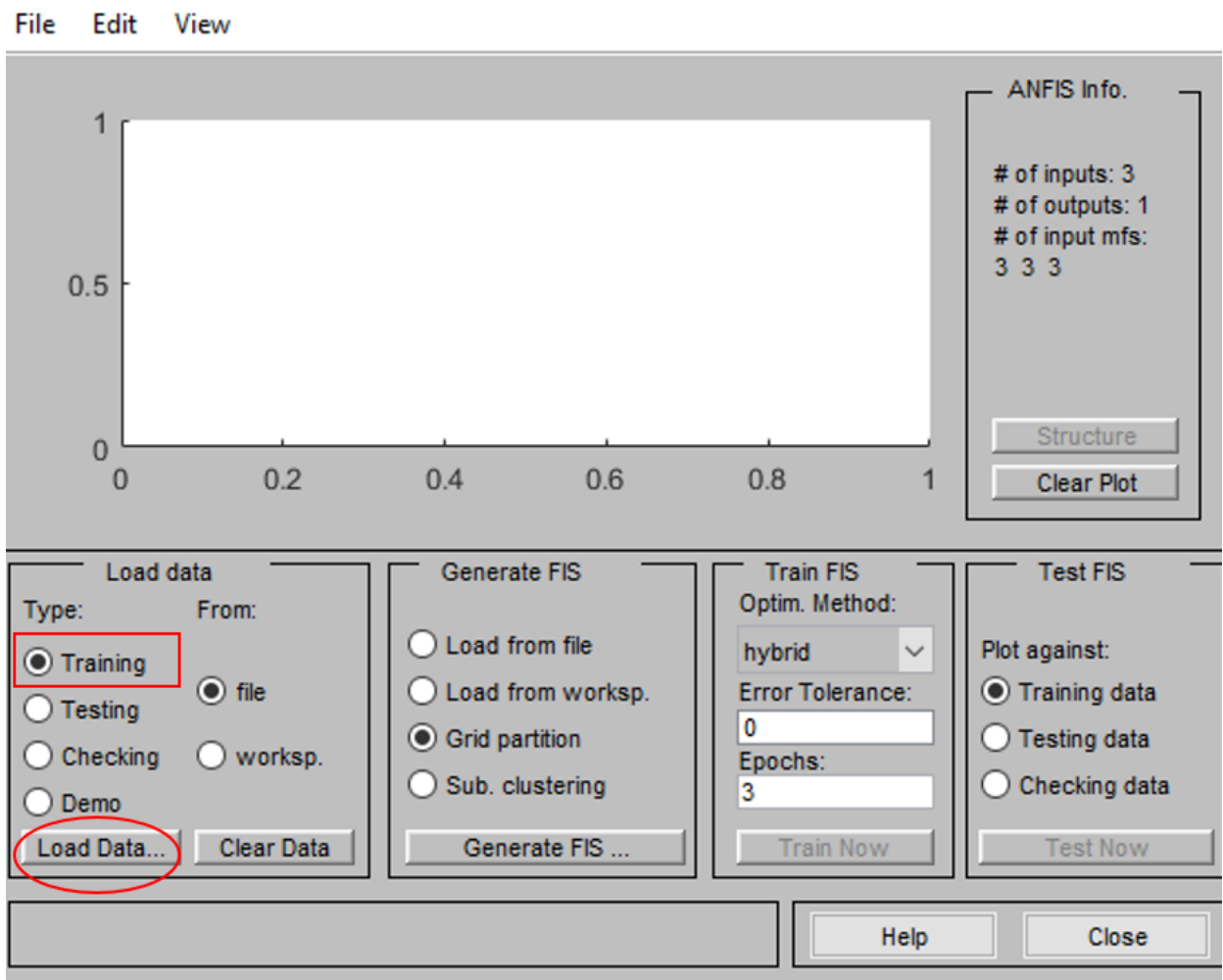


5. Selecionar o método de grupamento desejado. Neste caso, foi utilizado o Método de Subtractive Clustering.

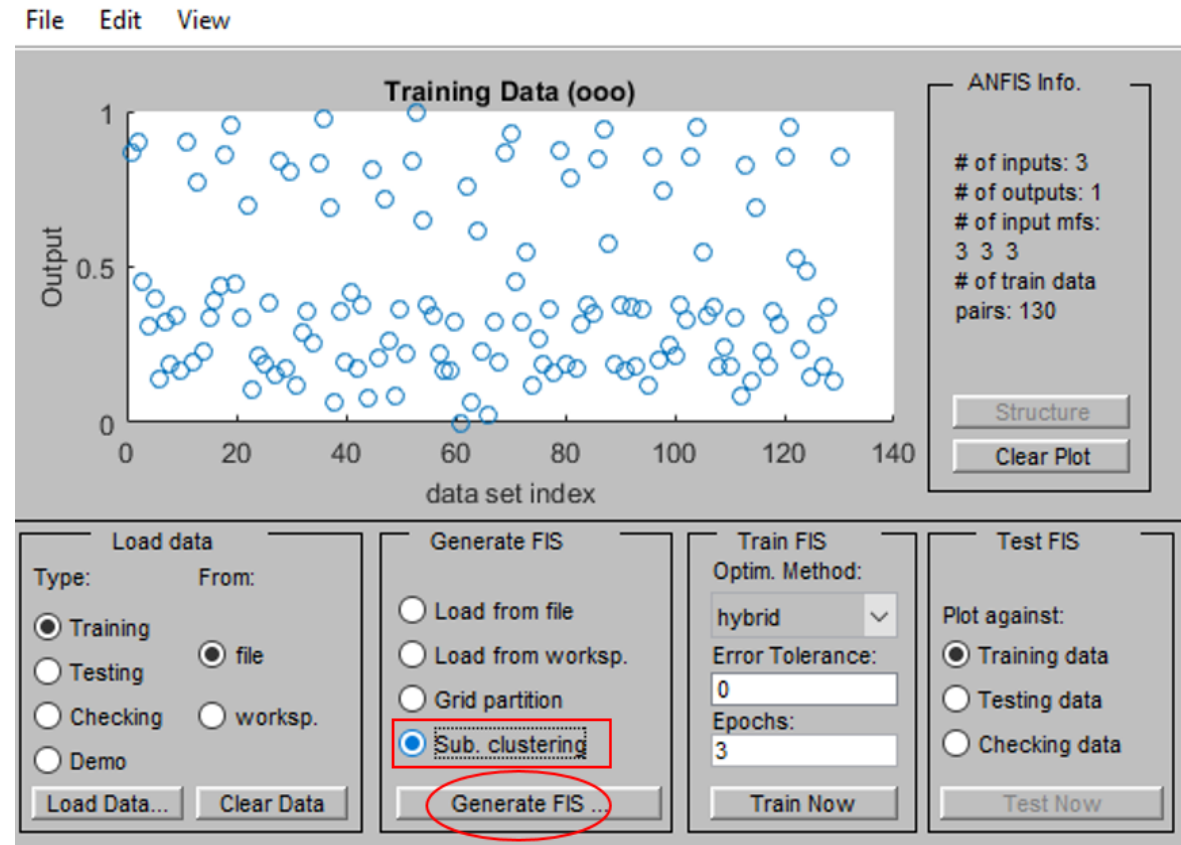

\begin{tabular}{|l|l|l|}
\hline train data loaded & Help & Close \\
\hline
\end{tabular}

6. Os parâmetros do Método de Subtractive Clustering utilizados neste trabalho foram os valores default.

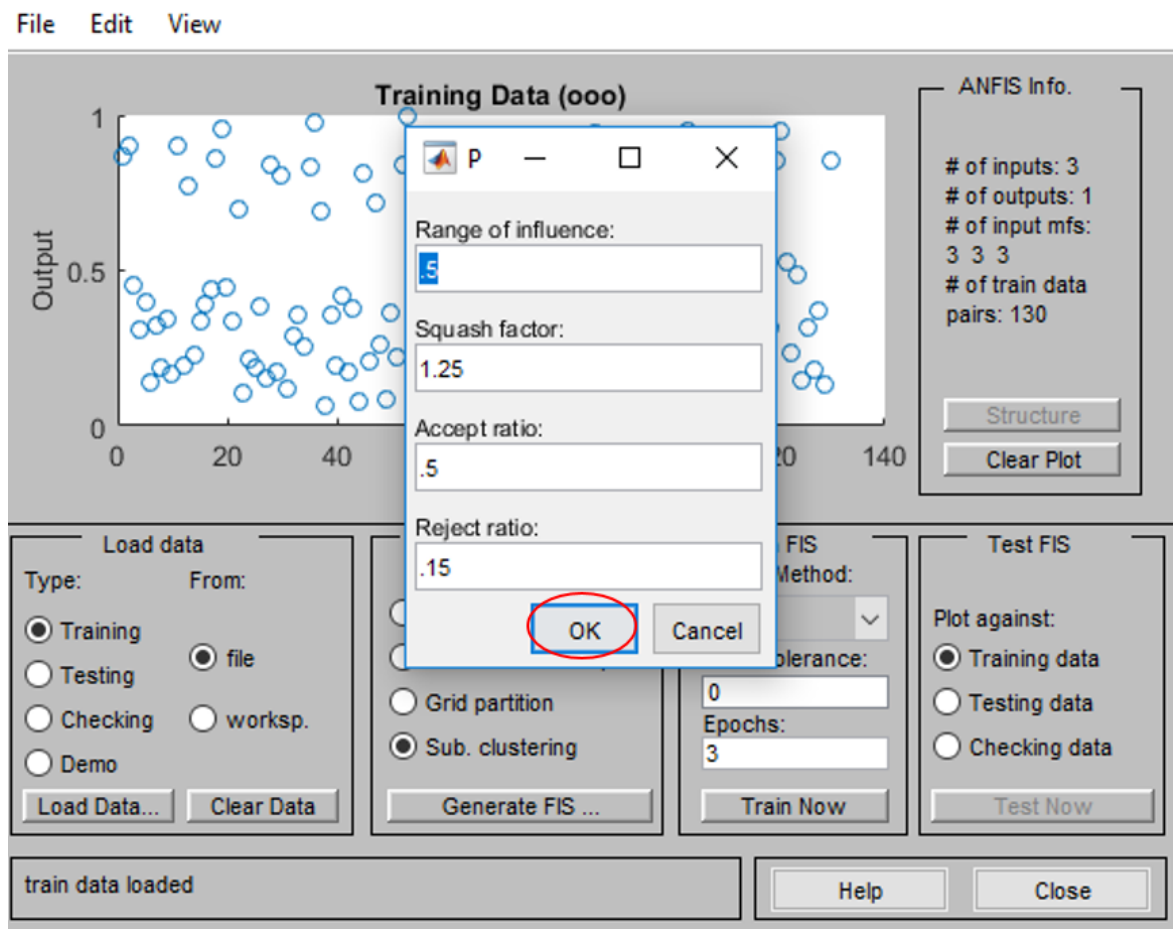


7. A tolerância e a quantidade de iterações para treinamento devem ser estipulados pelo operador.

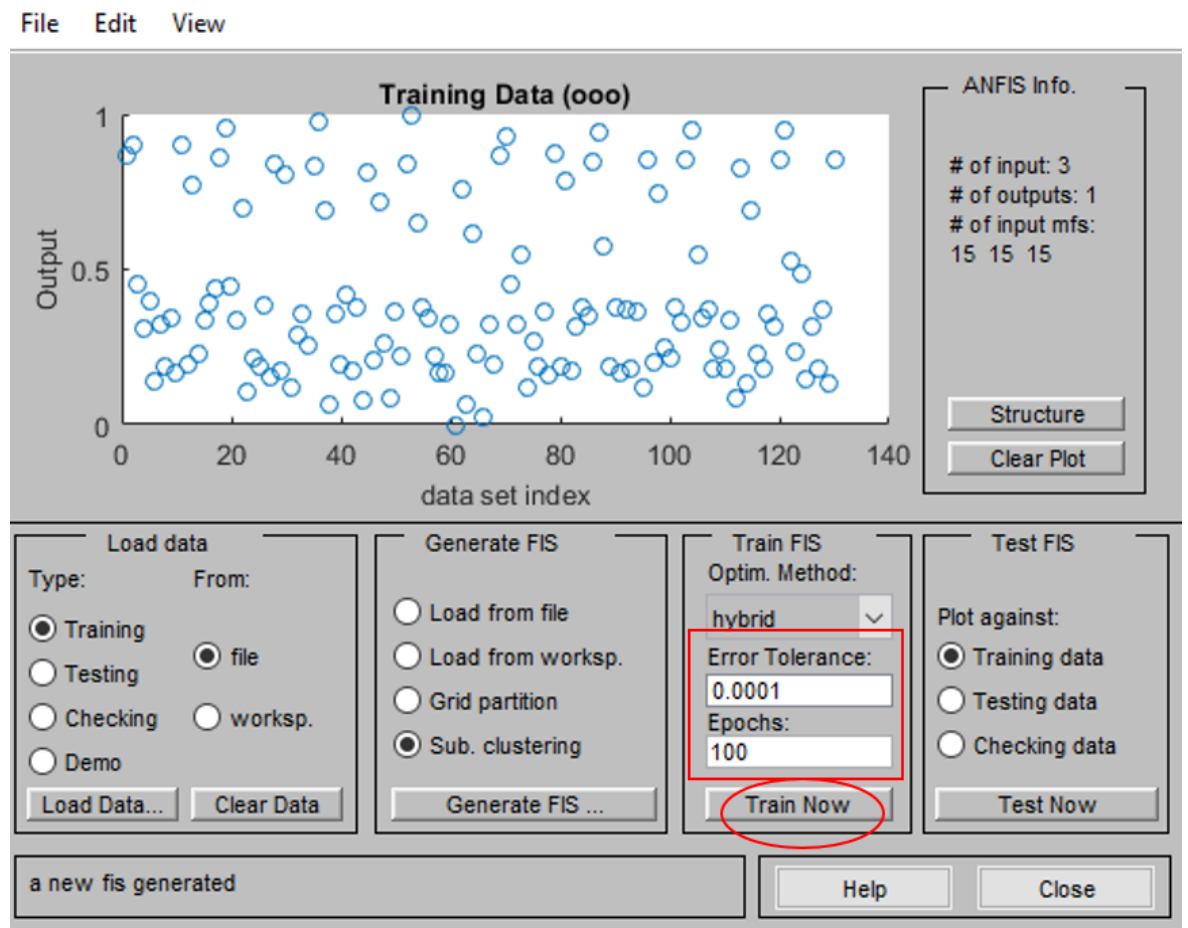

8. A curva de minimização do RMSE é apresentada após a etapa de treinamento.

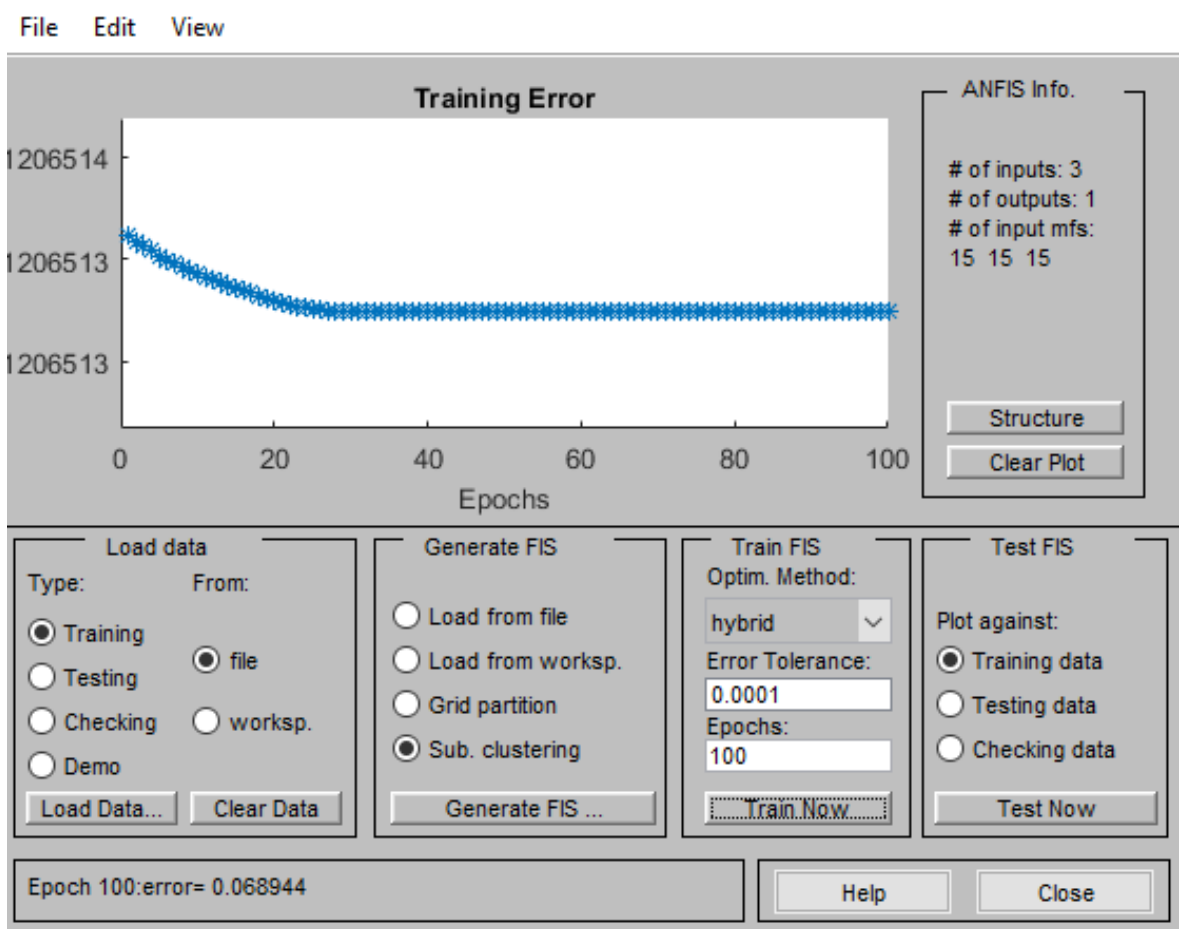


9. Carregar o arquivo com extensão ".dat"dos dados de teste previamente normalizados.

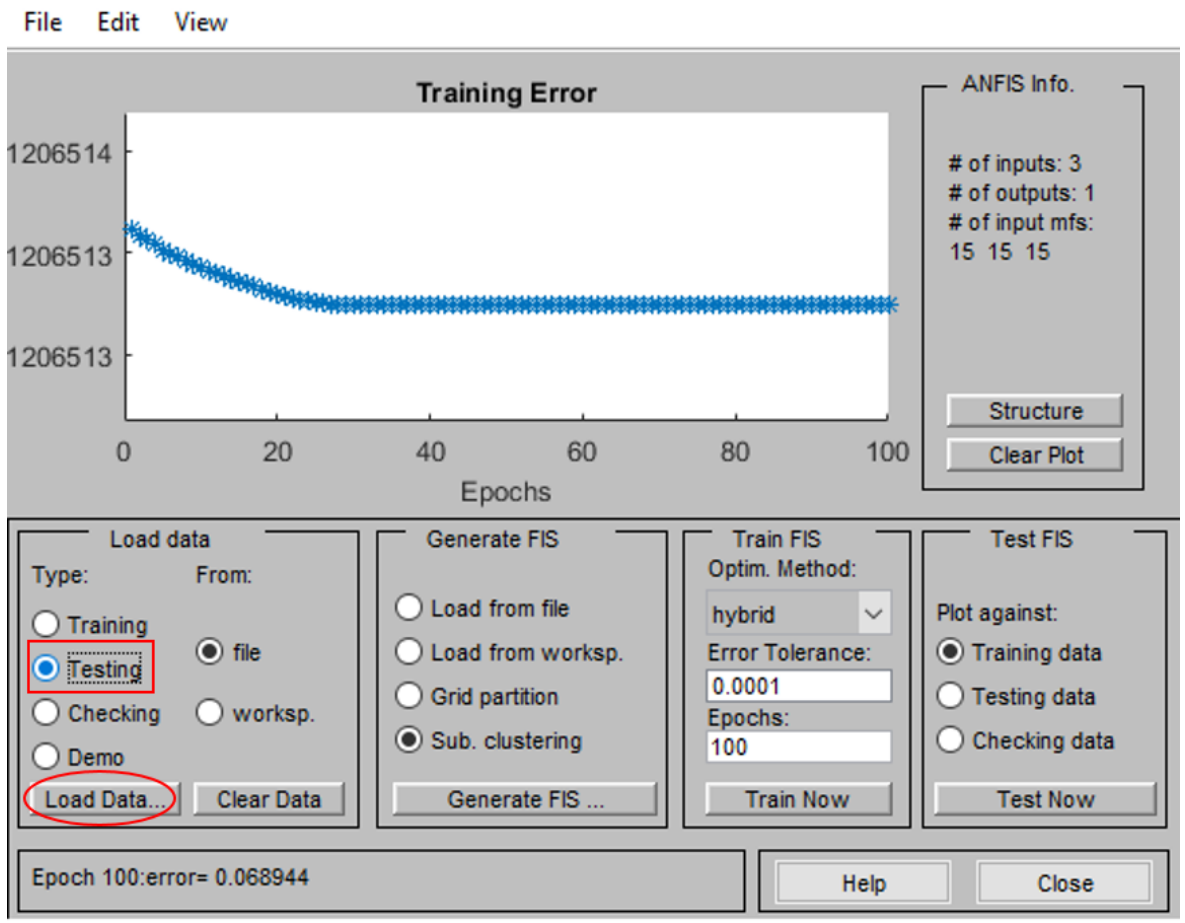

10. Efetuar a etapa de teste do modelo.

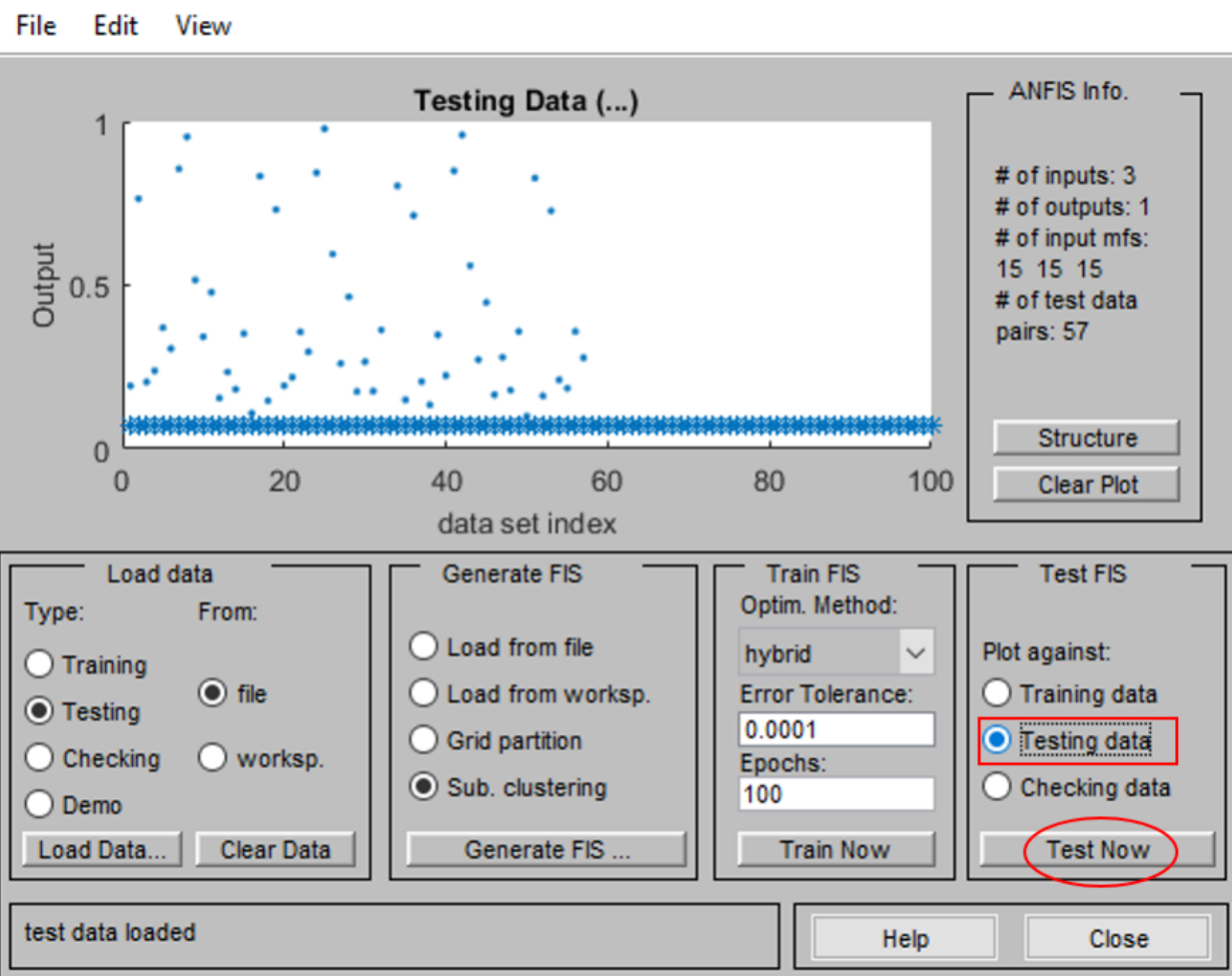


11. A correlação entre os dados experimentais e os dados preditos pelo modelo é apresentada após a etapa de teste.

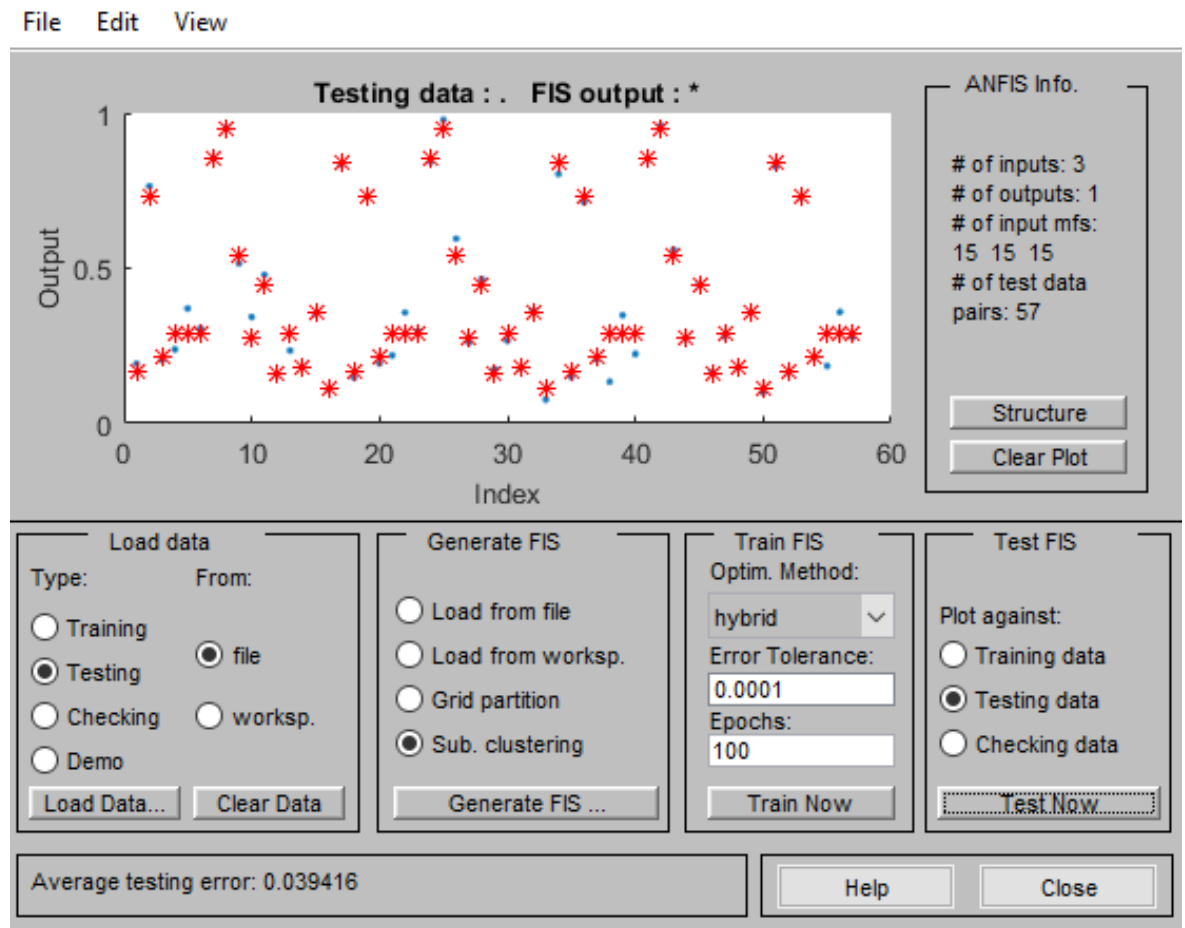

